\title{
THE “OTHER” MEXICANS: TRANSNATIONAL CITIZENSHIP AND MEXICAN MIDDLE CLASS MIGRATION IN TORONTO, CANADA
}

by

\author{
Omar Lujan \\ B.A. (Hons), University of Toronto, 2005 \\ B.Ed. (Cum Laude), University of Ottawa, 2007 \\ M.A., Queen's University, 2009 \\ A dissertation \\ presented to Ryerson University \\ in partial fulfillment of the \\ requirements for the degree of \\ Doctor of Philosophy \\ in the program of \\ Policy Studies
}

Toronto, Ontario, Canada, 2017

(C) Omar Lujan 2017 


\section{Author's Declaration}

I hereby declare that I am the sole author of this dissertation. This is a true copy of the dissertation, including any required final revisions, as accepted by my examiners.

I authorize Ryerson University to lend this dissertation to other institutions or individuals for the purpose of scholarly research.

I further authorize Ryerson University to reproduce this dissertation by photocopying or by other means, in total or in part, at the request of other institutions or individuals for the purpose of scholarly research.

I understand that my dissertation may be made electronically available to the public.

\section{Omar Lujan}




\title{
The "Other" Mexicans: Transnational Citizenship And Mexican Middle Class Migration In Toronto, Canada
}

\author{
Doctor of Philosophy, 2017 \\ Omar Lujan \\ Policy Studies \\ Ryerson University
}

\begin{abstract}
Mexico has one of the highest numbers of emigrants in the world (Martin, 2009) and Canada is one of the states with the highest per capita immigration rates globally (Léonard, 2011). Mexico and Canada are typical examples of immigrant and emigrant countries and both countries have developed policies and strategies that aim to foster civic participation among their immigrant and emigrant population respectively (Martin, 2009; Goldring, 2002; Barry, 2002; Li, 2002; Reitz, 2005; Bauder, 2011). In Canada, academic research on immigration has centred on the effect immigration policies and practices have on including and excluding immigrants from exercising citizenship rights but it has tended to ignore the effect emigration policies have in the development of transnational citizenship practices, such as civic engagement, political participation, social activism, and acts of solidarity that transcend the frontiers of the nation-state. This has left important questions unanswered on how transnational citizenship is developed and exercised in a migration context including: 1) which policies and practices immigrants use to exercise transnational citizenship; 2) what is the impact of transnational citizenship practices in terms of the expansion and contraction of
\end{abstract}


citizenship rights in the context of migration; 3 ) who is included and excluded by emigration policies promoting transnational citizen engagement; and 4) how do internal community issues, conflicts, cooperation, and solidarity affect the process of transnational enacting of citizenship? I attempt to fill this research gap by studying the effects Mexican emigration policies have on promoting transnational citizenship practices among middle class Mexican immigrants in Toronto and other cities in Ontario and by showing the avenues these immigrants use in order to participate civically with Mexico and with the Mexican diaspora in Canada. 


\section{Acknowledgement}

I would like to express my immense gratitude to my mentors at Ryerson University and to the research participants, for without their support this study would not have been possible. I can only hope that this dissertation makes some justice to the guidance and patience I received from my professors, and also to the great generosity and the vote of confidence of those who shared their stories of migration with me. To you my gratitude will always be indebted. Gracias, Danke, Teşekkür Ederim, Kiitos. 


\section{Preface}

The study of middle class Mexican immigration to Canada has been both a privilege and a challenge. It led me to explore the effects of Mexico and Canada's complex social, economic, and political realities on immigrants who have chosen to leave their country for greener and safer pastures. Also, it took me into an investigation about the lives of courageous people who chose to invest their savings and their efforts in the pursuit of better career prospects, higher education, or just a peaceful place to live and raise a family. The study of middle class Mexican immigration to Canada is an exploration into the stories of migration of businesspeople, artists, entrepreneurs, scientists, scholars, single mothers, manual labourers, and former refugees, which has provided me with a glance at Mexico's hardworking, creative, and persevering people. The potential of Mexican immigrants for making significant contributions to both Canada and Mexico motivated me to study the development of their civic lives in the context of migration. Now, after the completion of my dissertation, I am reassured that the Mexican presence in Canada adds new and valuable civic elements to the country at large. There are many areas for further investigation about the citizenship practices of members of the Mexican diaspora in Canadian cities and I am confident that future studies on Mexican immigration will add new insight into the process of community formation, transnational civic engagement, and cultural contributions of Mexican-Canadians. For my part, I am forever grateful for having been given the opportunity to learn about inspiring stories of migration and for having a glance at what I believe is a new and important chapter in the evolving story of the Mexican Diaspora across North America. 


\section{Table of Contents}

Author's Declaration ..................................................................................................... ii

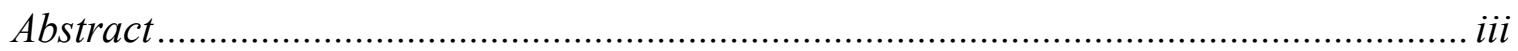

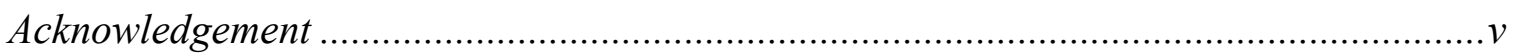

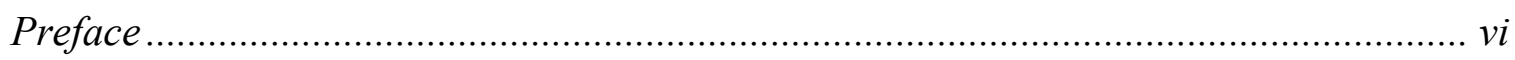

Chapter I: Introduction ................................................................................................. 1

Empirical Context and Statement of Research Problem............................................. 5

Research Approach .................................................................................... 10

Contribution to Policy Studies and Immigration Research: Transnationalism and

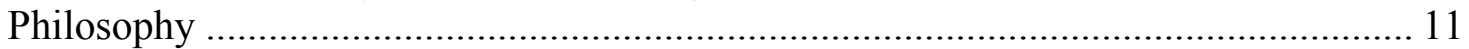

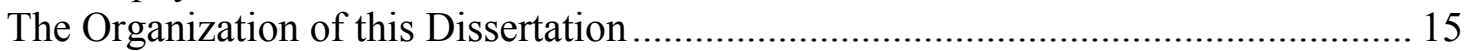

Chapter II: Literature Review............................................................................... 18

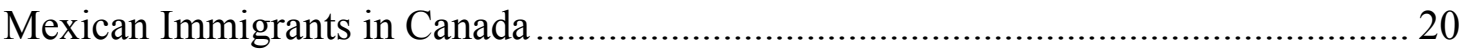

Globalization, Transnationalism and Policy Studies ............................................... 22

Citizenship Engagement of the Mexican Diaspora in the United States ..................... 44

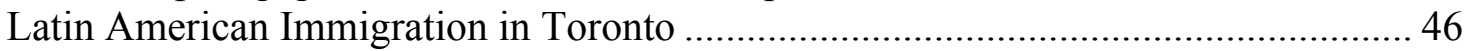

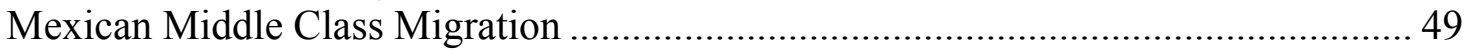

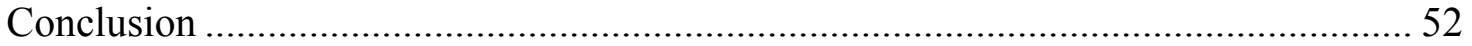

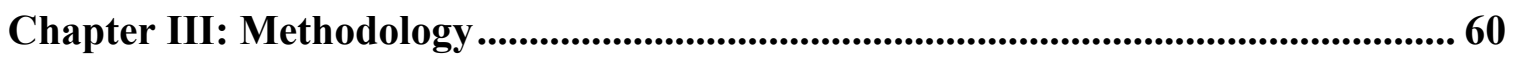

Ontology and Epistemology: Adapting Jose Ortega y Gasset's Philosophy to the

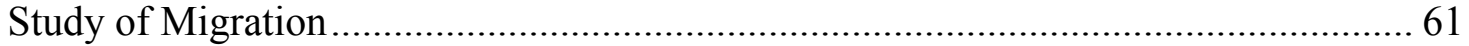

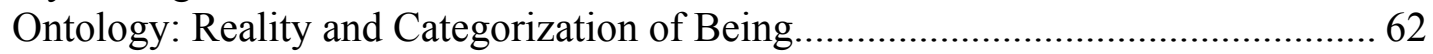

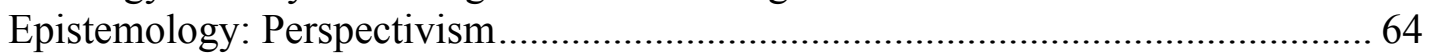

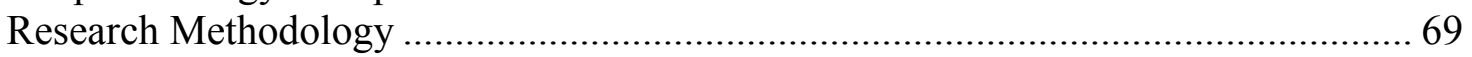

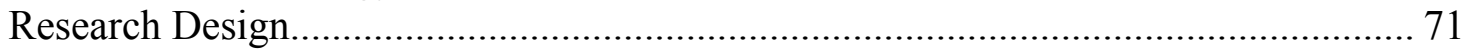

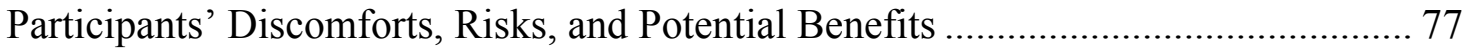

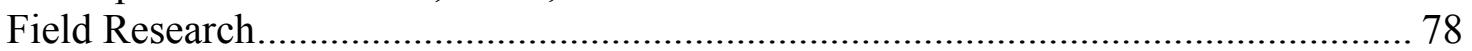

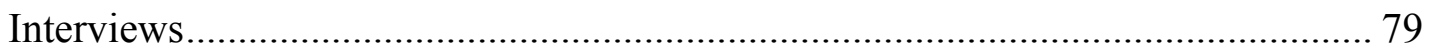

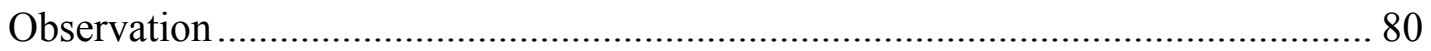

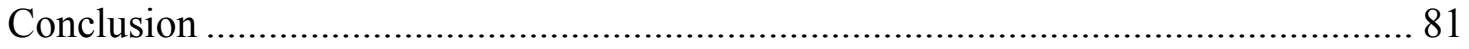




\section{Chapter IV: Transnational Citizenship and Middle Class Mexican Immigration in Toronto.}

An Overview of Middle Class Mexican Immigrants in Toronto: Social Capital, Place of Origin, and Reasons for Migration 85

Mexican Middle Class Families: Fleeing Violence, Overcoming Challenges and

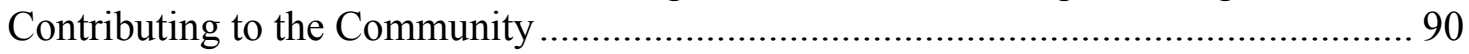

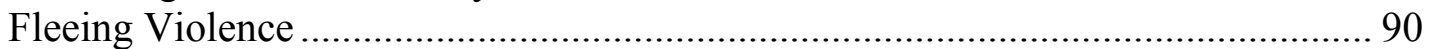

Overcoming Challenges and Contributing to the Community ................................ 94

Types of Transnational Citizenship in the Context of Mexican Middle Class

Migration.

Latin American Citizenship Practices and Identity ............................................. 108

Mexican-Canadian Citizenship Practices and Identity ........................................... 113

Pluri-cultural Transnational Citizenship Practices and Identity ............................. 119

Conclusion

\section{Chapter V: Policies and Practices: Building Relations with Emigrant} Communities

Introduction to Mexican Emigration Policies

Utilizing IME and CCIME in Canada: The Experiences of Jonathan, Mercedes, and

Mary.....

CCIME as a Policy of Differentiation: Mexicans in Canada as a Middle Class

Community

CCIME and Political Engagement.

Conclusion: Intersecting IME and CCIME with Ideas of the Common Good and the

Community of Value.

Chapter VI: Policies and Practices: Building Relations with Highly Skilled Emigrants

The Mexican Global Network (RGMX) Toronto Chapter.

Roger: RGMX's Institutional and Work Agenda

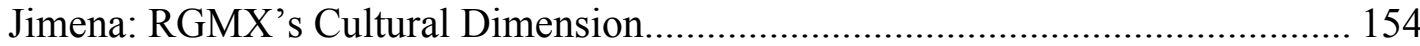

Lázaro: The Question of Location .................................................................. 155

Luciana: The Question of Social Relations ........................................................ 157

CONACYD: Mexican Policies and The Movement of Highly Skilled People from

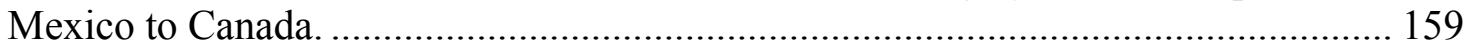

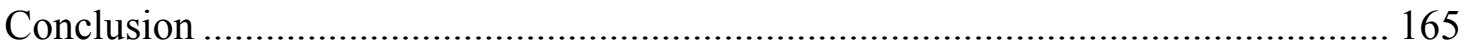




\section{Chapter VII: Policies and Practices: Citizen-State Relations with Businesspeople and the Enjoyment of Business Class Citizenship Rights.................. 169}

Business Class Citizenship ............................................................................... 170

ProMexico and the Trade Office: Access to Public Services to Advance Foreign Trade, and Access to Public Funding to Facilitate Imports and Exports ............................. 172 Economic Policies, Transnational Politics, and International Business Opportunities:

Operationalizing the Right to Benefit from Changes in Economic Policies ............. 176 Spaces for Socialization and Policy Knowledge: The Social Dimension of Business Class Citizenship Rights ....

Lack of utilization of Mexican Policies and Programs: Alternative to Business Class

Citizenship Rights

Conclusion: Business Class Citizenship and the Transnational Affirmation of

Citizenship.

Chapter VIII: Conclusion

Summary: Emigration Policies

The Civic Character of Mexican Middle Class Immigrants: Transnational Citizenship

as Modus Vivendi

Recommendations: The Role of Culture and the Arts for Social Inclusion ............... 203

Final Remarks

Appendices.............................................................................................................................. 208

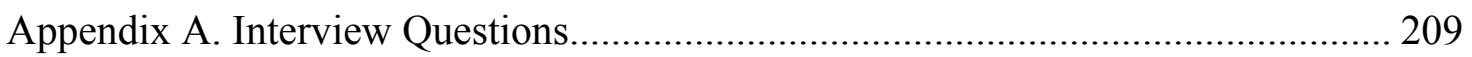

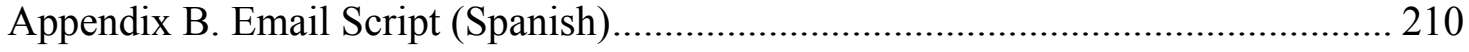

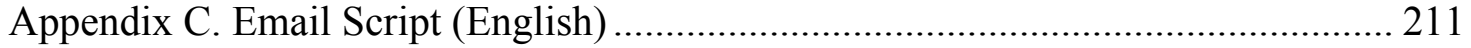

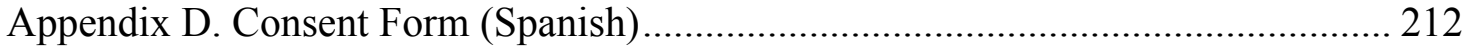

Appendix E. Consent Form (English) ............................................................ 215

Appendix F. Ethics Approval ................................................................... 218

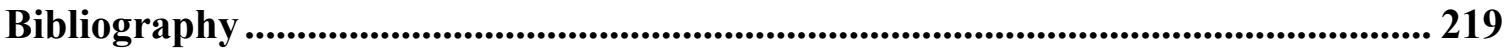




\section{Chapter I}

\section{Introduction}

Feathers and Maple Leafs

"As the years go by, the circle of the Ojibway gets bigger and bigger. Canadians of all colours and religions are entering the circle. You might feel that you have roots somewhere else, but in reality, you are right here with us".

Grand Chief John Kelly, as quoted in Belonging: The Paradox of Citizenship by Adrienne Clarkson.

Aztec warriors dance to the beat of the drums dressed in full regalia. Canadian Indigenous dancers sing and dance with them, and together they pay tribute to their ancestors. Every year, hundreds of Torontonians watch the spectacle of Mexican immigrants and Canadian Indigenous people celebrating together the Day of Dead at Artscape Wychwood Barns, a community cultural space in midtown Toronto. Through the enjoyment of traditional Mexican food, dance, and music people of this city are exposed to Indigenous understandings of life and death, which tell us that the spirit of those who have passed away are still here with us. In 2014, celebrations of the Day of the Dead were not only commemoratory but also political. Pictures of forty-three university students who disappeared in the Mexican State of Guerrero a few weeks earlier hanged on the walls of Wychwood Barns and in the midst of songs and dances people could heard cries saying aloud: “¡Vivos los Llevaron, Vivos los Queremos!” Alive they were taken! Alive we want them back!

The Mexican presence in Toronto is relatively new and rather small. According to the 2011 National Household Survey (NHS), in 2011 there were 69,695 immigrants who 
reported Mexico as their place of birth and according to the same survey only 9,200 immigrants residing in the Census Metropolitan Area of Toronto reported to have been borne in Mexico. Moreover, the connection between Mexicans and the land we now call Canada is ancestral, and the potential for Mexican immigrants' civic and cultural contributions to this country are enormous. Mexican art, music, and culinary traditions are expressions of hundreds of years of fusion between European and Indigenous cultures, which contrasts to Canada's historical alienation of Indigenous cultural elements from the dominant culture and society. The expansion of Mexican culture in Canada provides an opportunity to further develop Canadian multiculturalism by including Indigenous traditions and values along with those of European settlers and their descendants.

Despite Mexico's cultural achievements, as suggested by the chants of protesters against the disappearance of Mexican university students, contemporary Mexico is far from being a peaceful and inclusive society. Drug related violence, internal displacement, economic underperformance, and corruption have led to a significant rise in the number of Mexicans looking for opportunities outside their country, and Canada has been one of the destinations of choice. In 2008, at the peak of violence in the war against drug cartels, 9400 Mexican nationals submitted refugee claims in Canada. The following year, Citizenship and Immigration Canada indicated that the number of Mexican refugee claimants had almost tripled since 2005, and accounted for 25 percent of all refugee claims in the country (CIC Official News Release, July 13 2009). Canadian Government's responses however, have not been very considerate of the humanitarian crisis occurring in Mexico. 
The Balanced Refugee Reform Act, Bill C-11, introduced a new asylum system reducing the time to process refugee claims and only allowing failed applicants to file an appeal depending of their country of origin (CIC Background on Bill C-11, June 29, 2010). In 2008, just 11 percent Mexican refugee claims were accepted (CIC Official News Release, July 13 2009), and since Mexico was considered a safe country by the Government of Canada, failed refugee applicants from Mexico were not allowed to appeal for refugee status on humanitarian and compassionate grounds under the new asylum law. In addition, in 2009 the Canadian government passed a law requiring Mexican citizens to apply for a visa to enter Canadian territory. According to the official news release by CIC the visa requirement was a response to the increasing number of Mexican citizens claiming asylum in Canada (CIC News Release, July 13, 2009).

Draconian immigration policy responses to the humanitarian crisis occurring in Mexico contrasted with the amicable commercial relations between the two North American Free Trade Agreement (NAFTA) partners ${ }^{1}$. Also, Canada receives twenty-two thousand Mexican agricultural workers through initiatives such as the Seasonal Agricultural Workers Programs (SAWP), which has become vital to the agricultural sector in provinces like Ontario (Salter, 2011). Barriers enacted against Mexican refugees, the requirement of a visa for Mexicans, and the increasing reliance on seasonal agricultural workers from Mexico meant that Canada was prepared to welcome Mexicans

\footnotetext{
1 Since the signing of NAFTA in 1994, Canada has become Mexico's second largest trade partner and Mexico is the fourth most important market for Canadian goods in the world (Parks, 2011). Canadian exports to Mexico have gone from \$2 billion per year in 1994 to almost \$17 billion in 2009, and Canadian direct foreign investment (FDI) in Mexico had risen from \$500 million in 1993 to \$5 billion in 2009 (Zabludovsky and Barquera, 2011), the year the visa requirement for Mexicans was introduced.
} 
as temporary labourers but not as potential citizens, even in light of the highly profitable commercial relations enjoyed between the two countries.

The reason why Mexicans were increasingly excluded from entering to and living permanently in Canada despite of the importance of the movement of goods, services, and people between the two countries puzzled me. I increasingly felt that unwelcome measures against Mexican immigration reflected a lack of knowledge about the potential of Mexican immigrants in Canada and the benefit they already provide to this country. The desire to fill this lack of knowledge among Canadian policy makers led me into pursuing a multidisciplinary $\mathrm{PhD}$ in Policy Studies at Ryerson University where I dedicated myself to investigate the citizenship practices of Mexican immigrants in the city of Toronto and to a lesser extent in the cities of Ottawa, London, and Waterloo.

Citizenship has been described as the obvious vehicle for binding individuals to the state and to each other in bonds of civic solidarity (Cairns, 2009, p209). Traditionally, the study of citizenship has been confined to a national territory. Immigrants' citizenship practices however, tend to transcend national barriers, adding a transnational dimension to the investigation of immigrants' engagement with the body polity. Accordingly, my dissertation adopted a transnational policy and citizenship perspective, suitable to investigating the mutually constitutive process of emigration and immigration. After all, an immigrant in Canada is an emigrant in Mexico.

The study of Mexican immigration to Canada from a transnational policy and citizenship perspective has taken me into a long path of philosophical enquiry, ethnographical research, and policy analysis, which has taught me important lessons about civic practices and citizen-state relations in the context of migration. The purpose 
of this introduction is twofold. First, it is to explicate the relevance of conducting a doctoral dissertation on Mexican immigration to Toronto focused on emigration and diaspora policies as well as on the transnational expansion of citizenship in the context of migration. Second, it is to provide a map of the major themes covered in my thesis and to present the organization of my doctoral dissertation.

\section{Empirical Context and Statement of Research Problem}

Since the late $19^{\text {th }}$ century, Mexico and Canada have become typical examples of emigrant and immigrant countries and they both have developed policies and strategies that aim to foster civic participation among their emigrant and immigrant population respectively (Goldring, 2002; Barry, 2002; Li, 2002; Reitz, 2005; Bauder, 2011). In Canada, academic research on immigration has centred on the effect immigration policies and practices have on including and excluding immigrants from exercising citizenship rights but it has tended to ignore the effect emigration policies have in the development of transnational citizenship practices, such as civic engagement, political participation, social activism, and acts of solidarity that transcend the frontiers of the nation-state. This has left important questions unanswered on how transnational citizenship is developed and exercised in a migration context, including:

1. Which policies and practices do immigrants use to exercise citizenship rights in a transnational context?

2. What is the impact of transnational citizenship practices in terms of the expansion and contraction of citizenship rights in the context of migration?

3. Who is included and excluded by emigration policies promoting transnational citizen engagement? 
4. How do internal community issues, problems, conflicts, cooperation, and solidarity affect the process of immigrant citizen engagement?

The purpose of my doctoral dissertation is to answer these research questions by studying the effects Mexican emigration policies have on promoting transnational citizenship. Specifically, my research aims to shed light at the avenues and practices by which middle class Mexican immigrants in Toronto, and to a lesser extend in other cities in Ontario, exercised transnational citizenship rights and contribute civically to Mexico and to the Mexican diaspora in Canada, paying special attention to their utilization of Mexican emigration policies and programs. Access to citizenship rights has been historically influenced by gender, race, and social class. In this regard, by focusing on the transnational enjoyment of citizenship rights of relatively privileged Mexican migrants and by studying their ability to contribute to issues of public concern, my doctoral dissertation aims to provide a comprehensive picture of the development of transnational citizenship in the context of middle class Mexican immigration to Canada.

The decision to highlight the middle class as a central component of my dissertation is based on the empirical findings of my field research with Mexican immigrants in Toronto. As my field research progressed it became evident that the overwhelming majority of the participants, ninety five percent, were university-educated professionals and enjoyed significant social capital. The participants' citizenship practices and utilization of emigration policies were influenced by their level of education and areas of professional expertise, suggesting a social class dimension to the transnational expansion of citizenship practices in the context of migration. The title of my dissertation, The “Other” Mexicans: Transnational Citizenship and Mexican Middle 
Class Migration in Toronto, Canada, reflects this significant development in the focus of my dissertation, a nuance that provided my investigation with gratifying but also challenging complexities.

Historically in the United States, immigration policies and anti-immigrant political discourses have been utilized to portray Mexican immigrants as "the other", the quintessential illegal alien whose social and cultural characteristics are incompatible with the social values of an imagined Anglo-Saxon protestant America (Carrigan and Webb, 2013; Gutiérrez, 1995; Rivera-Batiz, 1999; Sánchez, 1993; De Genova, 2005). In Canada, Mexican immigration is much more recent than in the United States but studies reveal that Mexican undocumented migrants and temporal agricultural workers experience significant levels of social exclusion, marginality, and vulnerability as a result of exclusive immigration policies and practices (Basok, 2003; Binford, 2005; Villegas, 2014). The title, The "Other" Mexicans, refers to the participants' relatively privileged socio-economic status, which allows them to: 1) benefit from Canadian immigration policies and programs favouring the migration movement of people with significant social and human capital; and 2) access Mexican emigration policies and programs tailored to the interests of business people, intellectuals, and those interested in building a middle class Mexican emigrant community that differentiates from other Mexican immigrants living in precarious and vulnerable circumstances such as the case of Mexican temporal agricultural workers and undocumented migrants in the United States and Canada. I explore the intricate social class dimension of Mexican immigration in Toronto in the research findings section of this dissertation. 
Moreover, I chose to focus my dissertation on Mexican immigrants in Toronto because of a number of practical considerations, among them Mexican immigrants' cultural and ethnic diversity as well as their significant differences in migratory category and status in Canada. In addition, Toronto is the city with the largest number of Mexican immigrants in Canada (NHS, 2011) and thus it is an ideal empirical context to conduct research on the current migratory movement of Mexican citizens in the country. Also, the Mexican community in Toronto has an official representation in the government of Mexico via the Consejo Consultivo del IME (CCIME), the consulting body that represents the interests of Mexican communities abroad to the Mexican government. This official representation matters because it allows communities to have active communication with the government of Mexico, to participate in official activities with other Mexican communities living abroad, and to voice their concerns and interests to the Mexican government (Gutiérrez, 2006). Lastly, the social and ethno-cultural differences among Mexican immigrants in Toronto provide a unique opportunity to study immigrant citizenship practices from different vantage points and to explore how questions of race and social class factor in the utilization of emigration and immigration policies by transnational actors. In order to complement the experiences of Mexican immigrants in Toronto my study includes a small number of participants (5) from the cities of Ottawa, Waterloo, and London, Ontario.

Furthermore, my dissertation aims at filling a significant research gap in the study of Mexican immigration. Academic research on Mexican citizenship practices in the context of migration has focused either on migrants' citizen engagement with Mexico or with the United States, looking at these processes independently from one another. A 
study of citizen engagement of Mexican immigrants in Canada looking conjointly at both emigrant and immigrant citizen engagement can fill an important gap in the area of Mexican diaspora and could contribute to the further understanding of: 1) the problematic surrounding the systemic reproduction of social, civic and economic inequalities of Mexican immigrants living outside the United States; and 2) the relationship between the migrants' experience in citizenship engagement as both emigrant and immigrant. Equally important, there is no empirical evidence that middle class Mexican immigrants are increasingly moving to the United States (Ochoa, 2008). Studies on Mexican American middle class look at 1.5 and second generation Mexican Americans (Vallejo, 2012, 2015) but there is a significant lack of knowledge about the immigration experiences of first generation middle class Mexican emigrants. My dissertation contributes to fill this research gab by showing the motivations as well as the avenues by which middle class Mexicans immigrate to Canada.

Lastly, studying transnational citizenship practices of Mexican immigrants living in Canada has allowed me to shed light on Mexican policies and practices conducive to and deterring of the enjoyment of citizenship rights and fulfillment of citizenship responsibilities among Mexican immigrants within a larger North American context. Along this line, the theoretical and policy lessons gained from my dissertation research can be utilized to inform policy recommendations for promoting citizenship participation and reducing disparities in the transnational exercise of citizenship rights. 


\section{Research Approach}

My basic research approach is to examine emigrant and immigrant citizenship practices as potentially interconnected. The rationale behind this approach is to study Mexican immigrants as transnational actors whose civic engagement could potentially be informed by their experiences with both the "Mexican" and "Canadian" polity. Taking into consideration both emigrant and immigrant citizenship practices allows for the investigation of the relationships between: 1) the mutually constitutive process of emigration and immigration; and 2) the distinct national policies that regulate such movements of people and assert different ideas of the nation-state. Also, by taking a migrant-centric rather than a nation-centric approach my research aimed to minimize the nation-state centrism imperative in the study of citizenship and immigration both as policies and social phenomena ${ }^{2}$.

Moreover, the qualitative investigation of immigrants' citizenship practices and civic contributions is an exploration of commitments made by people whose civic life is indicative of an emerging transnational reality. The development, implementation, and evaluation of emigration, immigration, and citizenship policies are conducted however by bureaucracies focus on national economic and political imperatives. A migrant-centric research approach prioritizes immigrants' collective and individual expectations, motivations, and experiences over the imperatives of national bureaucracies and national policy objectives. In this regard, my research approach is in line with a Lasswellian conceptualization of policy studies. Harold Lasswell and Abraham Kaplan argued for the

\footnotetext{
2 In Political Sciences, nation-state centrism or methodological nationalism is understood as the general tendency to see domestic political systems as the paramount playing field on which political actors pursue their goals (Cerny, 2001 p397).
} 
purpose of policy studies to provide the "intelligence pertinent to the integration of values realized by and embodied in interpersonal relations, which prizes not the glory of a depersonalized state [and] the efficiency of social mechanisms, but [rather on] human dignity and the realization of human capabilities" (Lasswell and Kaplan, 1950, p xii, xxiv as quoted in De Leon, 2006, p41).

Also as a researcher, I subscribe to the fundamental idea of critical policy analysis in which the policy expert is viewed as a facilitator of democracy and a protector of human dignity. Critical policy analysis has further advanced the study of public policies in Canada by increasingly including citizen engagement in the policy process (Laforest and Phillips, 2007), the role of globalization in policy analysis (Mahon, Andrew, and Johnson, 2007), and the role of Indigenous knowledge in development of public policies (Abele, 2007). I situate my dissertation research as part of the ongoing effort of critical policy analysis to include people's voices and experiences with complex transnational policy processes and to understand people's civic contributions in relation to larger social, cultural and historical processes of exclusion. Lastly, I recognize Canada as a country built on Indigenous land and I approach the study of immigration and citizenship in Canada by taking into consideration how they relate to the problématique surrounding Indigenous Peoples.

\section{Contribution to Policy Studies and Immigration Research: Transnationalism and Philosophy}

In its learning from the past, in its concern with the world of ideas, and in its commitment to foster understanding about social needs, Policy Studies is historical, philosophical, and sociological. Also, Policy Studies is geographical and the analysis of 
public policies is largely bound to the political geography of the nation state, a traditional but also increasingly contested practice in the social sciences. Accordingly, this dissertation adopts a transnational and interdisciplinary policy perspective, relying heavily on history and philosophy. This is only fitting, since the greater significances of public policies are revealed in light of larger sociological, philosophical, cultural and historical dimensions.

The study of the governability of citizen-state relations in the context of migration pushes the traditional boundaries of Policy Studies to include transnational processes of policy development and implementation. My investigation of the transnational citizenship practices of Mexican emigrants in Canada sheds light on the processes by which national policies are implemented in a transnational context. In this regard, my dissertation attempts to make a contribution to the increasing attempts to capture the spatial dimension of policy analysis in the era of globalization and transnationalism (e.g., Mahou, Andrew, and Johnson, 2007). My thesis demonstrates how an immigrant-sending country like Mexico has developed the legal and institutional framework to operationalize complex transnational relationships with its diasporic people in Canada and in doing so my research contributes to further understanding the transnational dimension of public policies.

In addition, my dissertation intends to further advance the theoretical basis of studies looking at migrant transnational citizenship. My theoretical approach is grounded on the life experiences and perspectives of the research participants, adopting a bottomup methodology in which theory is informed by the research findings. Specifically, I have assumed an ontological and epistemological position building on the thought of twenty 
century Spanish philosopher Jose Ortega y Gasset in order to shed light on the live experiences and perspectives of the research participants and also to address questions of agency and structure influencing their civic lives. Rather than starting from a set of theoretical premises, my ontological and epistemological positions informed by Ortega were developed a postereori and grounded on my empirical research with Mexican immigrants.

The theoretical foundations of my thesis rest on what is commonly known in the social sciences as grounded theory (Glaser and Strauss, 1967). Grounded theory is a methodology that generates theories or interpretations that include the perspective and voices of research participants. By developing theories from the data collected in social scientific investigations, a "grounded theory fits empirical situations [allowing] to close the gab between theory and empirical research" (ibid p.vii, and p.1). As a qualitative methodology, grounded theory centres on the voices of research participants in an attempt to capture and theorize on that which people see as central to their lived realities. In my thesis, the same idea is manifested in my application of Ortega's (1914 and 1938) work to the study of migration.

My dissertation relies on Ortega's emphasis on perspectivism and radio-vitalism to present an ontology and epistemology that furthers the understanding of citizenship practices in the context of migration based on immigrants' own life-experiences and points of view. Radio-vitalism looks at methaphysics as the quest for a ultimate reality found in the life of an individual in a given society and at a given time in history (Ortega, 1914) and perspectivism assumes knowledge and reality are always interpreted through different perspectives and therefore an individual's perceptions of his or her own reality 
are ontologically and epistemologically valid (Ortega, 1938). My dissertation therefore relies on ontology and epistemology, rather than on specific schools of thought, as the driving force of my data analysis. The utilization of specific theoretical perspectives in my dissertation serves to provide context to the analysis of the research participants' own perspectives and not to ground their life experiences in such a theories. The specific theories used in my dissertation include: political economic critiques of neoliberalism, globalization, and transnationalism, and transnational citizenship, each of which will be defined and operationalized as they are introduced in the literature review chapter.

The application of an immigrant-centric epistemology and ontology that are inclusive of various theories, offers an original multidisciplinary approach to the study of citizenship practices and the utilization of emigration policies in the context of the transnational lives of Mexican middle class migrants. In this way, my dissertation takes the first steps toward developing a new approach that relies on grounding theoretical developments on the perspectives and life experiences of research participants (Glaser and Strauss, 1967), as expressed in Ortega's (1914 and 1938) philosophy. The application of Ortega's philosophy to further ground the study of migration in immigrants' own perspective and circumstances will be further explained in Chapter III.

In short, my dissertation aims to make theoretical and empirical contributions to the study of emigration policy, immigration, and citizenship. Also, by exploring the citizenship practices and citizen-state relations of Mexican immigrants in Canada, I aim to tell a valuable part in the story of Mexican immigration to this country and thus contribute to the study of Mexican diaspora in Canada. Lastly, my research findings 
reveal the unique contributions Mexican immigrants bring to Mexico and Canada, and contribute to further understanding the human dimension of the policies and practices underneath the movement of people between Canada and Mexico.

\section{The Organization of this Dissertation}

My dissertation is divided into eight chapters, Chapter I being this introduction. Chapter II consists of a literature review, which covers academic literature of Mexican immigration to Canada, the United States, Latin American immigration to Toronto, the study of transnationalism, the Mexican middle class, and Policy Studies. The main purpose of the literature review is to present the reader an overall map of the academic works pertinent to the study of Mexican presence in Toronto from a policy and citizenship perspective and also laying the ground to the exploration of middle class Mexican immigration to Canada.

Chapter III contains the methodology section of the dissertation in which I present my epistemology, ontology, and the methods I utilized in in my field research. In this chapter, I explicate the research design, the methods I used for conducting data gathering and analysis, as well as my overall experience with Mojado ethnography. Also, in this chapter I provide a detailed explanation of the epistemology and ontology of my dissertation, which I have developed in light of the thought of Jose Ortega y Gasset, Applying Ortega's philosophy to the study of migration has helped me balance questions of structure and agency in the study of Mexican immigrants' citizenship practices and citizenship identities in Canada and it has been one of the most rewarding aspects of my dissertation journey. 
The next chapters of my dissertation contain my research findings. Chapter IV is divided in three sections. First, it introduces the research participants as part of a middle class migration, then elaborates on the context of Mexican middle class immigrant families, and finally presents the different types of transnational citizenship identities and practices developed by research participants. In this chapter, I explore the civic lives of research participants by taking into consideration: 1) the epistemic validity of the participants' own civic thoughts and civic actions; and 2) the overall socio-economic circumstances in which their citizenship identities and practices have developed.

Chapter V looks at Mexican emigration policies and programs aiming at developing citizen-state relations with Mexican emigrant communities. Specifically, this chapter examines the utilization of the Institute of Mexican Abroad (IME) and Consejo Consultivo del IME (CCIME) programs in the cities of Ottawa and Toronto by self identified middle class Mexican immigrants. Chapter VI studies the utilization of Mexican educational and emigration policies directed to building networks of support with and among highly educated professionals and artists, as well as supporting the migratory movement of graduate students in the natural sciences and the social sciences. Specifically, this chapter looks at experiences of Mexican academics, researchers, and artists with the Mexican Global Network, and the experience of academics with CONACYD scholarships in the cities of Toronto, London, and Kitchener-Waterloo.

Chapter VII examines the utilization and lack of utilization of business programs, consular services, and economic policies by Mexican businesspersons in the city of Toronto. Specially, this chapter studies the development of what I refer to as business class citizenship rights by examining the participants' access to commercial services like 
ProMexico and Bancomext, as well as the impact of recent policy changes in the participants' career prospects, and the interconnection between business and politics in the context of migration. Throughout the four chapters containing the research findings of the dissertation I will show the civic, social, and cultural contributions of the research participants to both Mexico and Canada from their own perspectives, and will theorize on the significance of some key aspects of the citizenship practices and citizen-state relations of middle class Mexican immigrants in this country. Lastly, Chapter VIII is the conclusion of the dissertation, in which I summarize some of my research findings, I present some policy recommendations on emigration policies and community development, and leave the readers with some final reflections. 


\section{Chapter II}

\section{Literature Review}

"The only frontiers should be the ones of the mind" Walter Benjamin

Walking around Toronto's City Hall main lobby I saw Elena's artwork, a bodymap presenting her thoughts and feelings on her life as an undocumented immigrant in Toronto. In the middle of a large body silhouette she had written one message "Todos Somos Ciudadanos del Mundo", Spanish for "We Are All Citizens of the World" and she had drawn a maple leaf and a Mexican flag alongside it. Elena's words are a powerful assertion of the expansion of citizenship consciousness beyond the boundaries of the nation-state, and since it is a message presented by an immigrant currently excluded from citizenship rights in the country where she lives and works it is also a message of hope and justice. Elena's imagery and words bring to life the concept of transnational citizenship in the current migratory movement of Mexican citizens to Canada and in doing so her artistic testimony serves to introduce the subject and the context of the present literature review from the standpoint of people who are marginalized.

Elena's story can be found among those of many other Latin American undocumented immigrants in Gastaldo, D., Magalhães, L., Carrasco, C., and Davy, C. (2012). Gastaldo et al. (2012) is an example of the outstanding research being conducted with undocumented Latin American immigrants in Toronto. Goldring and Landolt (2013) is another recent example of scholarship centering on immigrants living in precarious legal status, and it explores different historical and contemporary examples of the concept 
of non-citizenship. Villegas (2014) is a publication dealing with Mexicans living in precarious legal status in Toronto, and it is the latest publication on Mexicans in Canada to date.

Hannah Arendt (1966) argued that, "in a world organized in nation-states, citizenship is the right to have rights" ( $p$ 268). As such, academic research on immigrants excluded from citizenship rights in Canada is not only an important contribution to the study of citizenship and immigration in this country but it is also a scholarly pursuit that makes us question the moral imperatives of an international system that legitimizes ongoing processes of exploitation against the most vulnerable migrants. The scholarship by Villegas, Goldring, Landolt, and Gastaldo among others has shed important light on the experience of Mexican immigrants living in precarious legal status and social conditions in Canada. There is, however, a lack of knowledge about the life and citizenship practices of relatively more privileged Mexican immigrants who have acquired Canadian citizenship or enjoy permanent resident status in Canada and thus are currently less exposed to marginality than those lacking immigration status or living in precarious social conditions such as Mexican temporary workers. My dissertation aims to fill this gap in the academic literature by studying the policies and practices middle class Mexican immigrants residing permanently in Toronto use to participate politically, socially, and culturally in both Mexico and Canada. In this way, my dissertation aims to complement the existing academic literature about Mexican immigration to this country.

This literature review is divided into five sections: 1) Mexican Immigrants in Canada; 2) Globalization, Transnationalism, and Policy Studies; 3) Citizenship Practices of the Mexican Diaspora in the United States; 4) Latin American Immigration in Toronto, 
and 5) Mexican Middle Class Immigration. Each of these five themes represents a piece in the puzzle of trying to understand the Mexican presence in Toronto from a policy and citizenship perspective. The purpose of the literature review is twofold. First, it provides a bird's-eye view on the empirical findings and theoretical refinements conducive to study of Mexican immigration in Toronto. Second, it sheds light on a number of the main research gaps in the area of immigrant citizenship practices in Canada. To this end, this chapter will also include a brief conclusion specifying some of the key areas in which my dissertation makes a contribution to the academic literature on transnationalism, Mexican Diaspora, immigrant citizenship practices, and policy studies.

\section{Mexican Immigrants in Canada}

Academic literature on Mexican immigrants has traditionally focused on the United States (Cardenas and Hansen, 1988; Crowley, Lichter, and Qian, 2006; De Genova, 2005; Striffler, 2007), home to more than thirty million people of Mexican descent. By comparison, Mexican immigration to Canada is a rather small and relatively recent social phenomenon, which is also reflected in the small number of academic publications dedicated to Mexican immigration to Canada (Whittaker, 1988; Gutierrez, Samuel, and Vazquez, 1995; Basok, 2003; Binford, 2005; Mueller, 2005; George, 2010; Villegas, 2014). Such publications have managed to cover a number of important themes, which vary from statistical analysis of the general movement of Mexicans to Canada (Gutierrez, Samuel, and Vazquez, 1995; Mueller, 2005) to specific qualitative studies on issues such as the limited social rights enjoyed by Mexican workers participating in the 
Seasonal Agricultural Work Program (SAWP) (Basok, 2003; Binford, 2005), and the experiences of Mexican undocumented immigrants (Villegas, 2014).

Studies on Mexican migration to Canada have pointed out a number of important observations including; 1) the relevance of Canadian-Mexican trade on the increasing movement of people from Mexico to Canada (e.g. Mueller, 2005; Gutierrez, Samuel, and Vazquez 1995); 2) the significant economic considerations involved in the overall movement of Mexican citizens to the country (e.g. Basok 2003; Binford 2005; Mueller 2005; Gutierrez, Samuel and Vazquez 1995; George, 2010); and 3) the problematic surrounding the implementation of policies which foster the movement of goods and services between Mexico and Canada while obstructing the inclusion of Mexican immigrants into the larger Canadian market economy and society (Basok, 2003; Binford, 2005; Villegas, 2014). In short, whether academics have analyzed Mexican migration to Canada from a market economic perspective (Mueller, 2005; Gutierrez, Samuel, and Vazquez 1995) or from the vantage point of political economy (Basok, 2003; Binford, 2005; Villegas, 2014), there is a tendency to contextualize such migratory movement as a part of the increasing integration of the North American market economy.

Since the signing of the North American Free Trade Agreement (NAFTA), Canada has become Mexico's second largest trade partner and Mexico is the fourth most important market for Canadian goods in the world (Parks, 2011). Governmental cooperation between Canada and Mexico has also become increasingly important with annual inter-parliamentary meetings and bilateral efforts on governance and institutionbuilding in areas as varied as access to information and privacy laws, federalism, Indigenous affairs, transparency and accountability, human rights, modernization of the 
civil service, judicial reform, and more recently public security (Bugailiskis and Rozental, 2012, p.16). In addition, there have been six sub-national cooperation agreements between Canadian provinces and Mexican states, which would likely continue to foster the movement of peoples and goods between Mexico and Canada (Parks, 2011).

The increasingly close commercial and governmental ties between Mexico and Canada and the significant movement of people between the two countries, underscores the importance of studying some of the policy and citizenship dimensions of the CanadaMexico relationship. My dissertation contributes to further understand the interconnected and complex Canada-Mexico relations by illustrating how and why Mexican immigrants contribute as citizens to both Mexico and Canada. Moreover, the study of immigrants' citizenship relations with both their country of origin and residence locates the discussion of immigrant citizenship practices into the landscapes of globalization and transnationalism. For this reason, this literature review also discusses the globalization and transnationalism literatures pertinent to public policy, immigration and citizenship.

\section{Globalization, Transnationalism and Policy Studies}

Policy Studies has increasingly come to terms with the expanding dimension of public policies largely by borrowing important theoretical insights from the field of geography (Castells, 1996; Harvey, 2001). A geographic perspective has helped areas in the policy field to understand policy spaces as areas that transcend national boundaries (Mahon, Andrew, and Johnson, 2007). Vertovec (2009) has described transnationalism as the sustained linkages and ongoing exchanges among non-state actors across national 
borders $^{3}$ (p.3). In the context of the field of Policy Studies, however, transnationalism relates to the policies that transcend the boundaries of the nation state, which include policy processes that cut across domestic, regional, and international arenas (Moran, Rein, and Goodin, 2006). Such transnational policies can include national policies conducted at the transnational level such as the case of Mexican emigration policies (Delano, 2009), regional policies implemented by supranational institutions as in the case of European monetary policies (Fieldman, Watson, and Doyle, 2002), and policies that result from transnational and domestic processes as is the case of Mexican human rights policies, which incorporate the policy objectives of the United Nations as well as those of local and transnational advocacy networks (Muñoz, 2009). Transnationalism is of course a complex social phenomenon, which can be also studied "as a social morphology, as a type of consciousness, as a mode of cultural reproduction, as an avenue of capital, as a site of political engagement, and as a reconstruction of 'place' or locality (Vertovec, 1999, 448)" among other areas beyond the policy field.

A number of scholars have responded to the growing transnational dimension of the policy arena by postulating the need to develop global policies for the better governance of health (Lee, Buse, and Fustukian, 2002), international trade (Woods, 2010), and immigration (Vertovec, 2006) among other highly interconnected policy areas. Others have criticized the social consequences of increasing trans-nationalization

\footnotetext{
3 Academic literature on the effect of transnationalism on the nation-state and its citizens ranges from arguments that transnationalism reduces the authority of the state by creating dependency on globalized commercial and/or political processes (e.g. Albrow, 1997, Strange, 1996, Castels, 2001) to the position that transnationalism has brought about an increase of the coercive power of the state. At the same time, it is still a matter of academic debate whether transnationalism and the nation-state should be understood as opposing concepts or as different but not necessarily mutually exclusive forms of political, economic, and social interactions.
} 
public policies, particularly in the area of immigration (Sassen, 1998) and asylum (Sales, 2007). Such academic debates on how to best approach the development and implementation of public policies in an increasingly interconnected and interdependent world underscores the rising importance of transnationalism for the field of Policy Studies (Moran and Goodin, 2006).

Moreover, despite interesting academic debates on transnationalism and the recognition of supranational institutions as influential transnational policy actors (Dolowitz, and Marsh, 1996) the policy literature continues to take the national level as the primary scale of analysis. Figuratively speaking, the policy literature has adopted a mechanical "Russian doll" conception of nested locales, understanding each scale as capable of being considered on its own (Mahon, Andrew, and Johnson, 2007, p.49). Arguably, such a hierarchical analytical distinction between the local, national and international policy levels does not reflect the growing institutionalization of transnational decision-making processes, global governance bodies, and transnational macroeconomic policies that cut across the traditional levels of governance. Nation-state centrism is not exclusive to the policy literature but it is revealing that most public policy research examines international and globalizing policy processes as exogenous (Cermy, 2001).

The transnational mobility of policy ideas and actors takes place within the larger neoliberal policy regime, which can be defined as an economic, political and ideological discourse guiding the process of global market integration (Chopra, 2010). Transnational policy processes are facilitated by the traditional prevalence of positivist approaches in the field of policy studies, which has been characterized by the utilization of rational 
choice theory and cost-benefit analysis (CBA) as heuristic devises (Fuji-Johnson, 2005). Such a positivist approach emphasizes the importance of issues related to micro/macroeconomics, while overlooking questions of human dignity and social justice, that may be associated with the transnational mobility of policy ideas and actors. By ignoring the human and moral dimensions of policy processes however, the policy literature tends to legitimize the imperatives of the market economy that guide current transnational policy movements.

New theoretical approaches to public policy and the increasing participation of civil society in the policy process are distancing from the dominant position of the neoliberal policy regime and traditional top-down assumptions in policy making. Civil society has the capacity to assert significant levels of engagement in policy processes and policy outcomes (Robinson and Friedman 2007; Cheung, 2011) and innovative approaches such as the Human Capability Approach (Nussbaum, 2011) offer practical frameworks for advancing policies that promote human dignity and the further inclusion of citizens' voices in the development and implementation of public policies. Arguably, a new plurality of voices and ideas can help transform government's traditional approach for policy development and implementation into a more inclusive and bottom up process.

There are important theoretical considerations related to the inclusion of new voices in public policy development and implementation. Public policies are structures that can affect and be affected by different agents. A top-bottom approach to public policy emphasizes the role of structures while downplays the role of agents. Conversely, a bottom up approach privileges the role of agents and downplays the role of structures. Differences of opinions about the role of structures and agency are not limited to Policy 
Studies but rather they are part of a larger debate in the social sciences. Traditionally, materialists favour the role of structures in determining social reality, idealists emphasized the role of agency (Hay, 1995, 2002), and post-structuralists argue that structures do not exist independently from agents but rather that they are co-constitutive (Marsh, 2010, p.214). The position of policy experts on the structure and agency debate is indicative of their ontological and epistemological starting points (Marsh, 2010, p.212), which underscores the serious philosophical implications in studying public policies from: A) a top-bottom approach emphasizing the structural dimension of public policies; B) a bottom-up approach emphasizing the agency and voices of new policy actors; and C) taking both structures and agency into equal consideration as co-constitutive in the development and implementation of public policies.

Moreover, the inclusion of new voices in the policy process is further complicated in areas largely influenced by transnationalism and globalization, as in the cases of citizenship and immigration. Citizenship and immigration are policy areas that have traditionally been utilized by the state to construct desired socio-cultural national characters and to articulate ideas of national belonging. However, it could be argued that contemporary immigration movements are affected by and in their turn affect policies and practices that transcend the boundaries of the nation-state and could potentially transform citizenship policies, and citizenship practices, from national to transnational modes of belonging. In this regard, transnationalism and globalization have the potential to deeply alter fundamental notions of the body-polity and the development and implementation of public policies. 
Given the importance of globalization in policy areas such as immigration and citizenship, it is imperative to elaborate on some of the main characteristics of globalization. In the social sciences, globalization has been conceptualized geographically as a process of increasing time and space compression (Harvey, 1989), economically as an integration of the global markets (Gilpin, 2001), politically as the rise of supranational and interdepending forms of governance (Scholte, 2000), and historically as part of a long process of transoceanic movements of people, goods, and ideas that have taken place since the age of European discoveries in the $15^{\text {th }}$ century (Gunder Franck, 1998). As a multidimensional social phenomenon and multidisciplinary area of study, the precise definition and scope of globalization is a matter of ongoing academic debates, which can vary from hyper-globalists positions arguing that globalization will eventually replace national economic and social relations (Ohmae, 1990), to the opinion of sceptics who argue that globalization is neither a new nor a global social phenomenon (Hirst and Thompson, 1996). In Policy Studies, globalization has been defined loosely as a form of "economic integration, transfer of policies across borders, transmission of knowledge and culture, and reproduction of relations and discourses of power $[\ldots]$ among other processes that encompass the causes, course, and consequences of transnational and transcultural integration (Al-Rodhan, and Stoudmann, 2006. p5)". Thus, in the field of Policy Studies, globalization and transnationalism are treated as comprehensive and largely intertwined concepts.

Critics of globalization such as Pierre Bourdieu (1998) have questioned the neoliberal policy regime imperative in the increasing interconnection of global markets, pointing out its negative effects on the welfare state and its ability to guarantee social 
citizenship rights such as adequate healthcare, a liveable minimum wage, quality public education, and social services. In the study of international affairs, public intellectuals such as Noam Chomsky have centered their critique of globalization on Western foreign policies, emphasizing the need to mobilize against the exploitative expansion of a global market integration marked by the systematic violation of states' sovereignty and violations of human rights (Chomsky, 2012). Others such as William Robinson have questioned the relevance of the nation-state and the inter-national system for the study of globalization, instead describing globalization as the systematic transnational movement of global capital and transnational modes of production that affect negatively the working classes (Robinson, 2004).

Whether looking at the national, international, and transnational domains, academic literature dealing with the political economy of globalization has illustrated the structural inequalities brought about by the neoliberal-policy regime conducive to the increasing interconnection of global markets. On this light, neoliberalism and globalization can be described conjointly as a system, which "attempts to return to a radical capitalism that has no other law but that of maximal profit without restraints" (Mitrovic, 2005, p.43). Such an objective can only be obtained by reducing the level of states' protective measures available against foreign political and economic penetration, and by reversing the historical gains of social citizenship rights in industrialized countries that provide a level of protection against the forces of the market. Academics and other public intellectuals have referred to this process of globalization as "the revenge of the elites" (Klein, 2010) or as "exploitation sans rivages" (Bourdieu 1998, p.43), considering 
neoliberal globalization as "the main weapon in the struggle against the achievements of the welfare state" (Bourdieu, 1998, p.35).

Bourdieu's critic about the impact neoliberalism and globalization has had on welfare states is also shared by scholars studying the impact of neoliberalism and globalization in countries without developed welfare state systems (Torres and Schugurensky, 2002). According to Caramanis (2002), neoliberal forces have created a hegemonic presence that imposes undesirable globalization processes on less powerful countries throughout the world (p. 380). This is exemplified by the role played by supranational institutions such as the International Monetary Fund (IMF) and the World Bank (WB) in coercive neoliberal policy transfers to Third World countries (Dolowitz and Marsh, 1996, p. 348). These policies include privatization of state enterprises, the reduction of tariffs, and the elimination of many social programs, as part of Structural Adjustment Programs (SAP) imposed on developing countries as conditions for foreign loans (Steger, 2003).

In addition, the global transfer of neoliberal policies has been facilitated by large private firms that have mobilized powerful international political-economic actors to overcome the resistance of local players and weaker nation-states to the imposition of a neo-liberal agenda (Caramaris, 2002, p. 380). Such a process has been marked by the use of violence, undemocratic tools of governance, and various forms of repression unleashed by authoritarian regimes, which are often supported by international financial institutions, transnational corporations and Western states (Klein, 2007). This is probably best exemplified in the "adoption" of neoliberal macroeconomic policies by the U.S.-backed government of General Pinochet in Chile during the 1970s and 1980s, a regime that 
opened the Chilean market by reducing state-control of the economy, while at the same time engaging in the disappearance and torture of thousands of Chilean citizens (Klein, 2007). The relation between market liberalization and state oppression is indicative of neoliberal policies that rely on the coercive power of the state while advocating freedom of the market. The global neoliberal economic system therefore reduces aspects of state sovereignty related to the protection of citizenship rights and the public good, while at the same time enhances mechanisms to safeguard the interests of the private sector.

Theorists have also moved the debate on globalization beyond its impact on the nation-state and the labour market, and argue instead for a cosmopolitan political theory that sees the advancing of democratic governance and citizenship in a post-national reality. Jürgen Habermas points out that, “ “.. to resolve the dilemma between disarming welfare-state democracy or rearming the nation state leads us to look to larger political units and transnational organizations that could compensate for the nation state's functional losses in a way which need not snap the chain of democratic legitimization" (Habermas, 2000, p.55). Habermas' approach has been referred to as "global domestic politics," and represents a midway position between a total rejection of globalization and a total submission to market forces (Baker, 2008). In addition, David Held (2010) argues for the development of a multilevel citizenship indicative of an increasing multilayered democracy based on institutions that transcend the limitations of both the nation state and the market to deal with global issues.

While Held's and Habermas' cosmopolitan political philosophies are pragmatic approaches to dealing with the loss of state sovereignty and the reduction of social citizenship rights, cosmopolitanism has also important ethical considerations. 
Cosmopolitanism is a term used to describe a citizen of the world: an individual who believes he/she belongs to a common humanity or world order, rather than to a set of particular customs or traditions (Trepanier, and Habib, 2011, p.1). There have been significant theoretical developments in the field of cosmopolitanism (Nussbaum, 1997; Beck, 1998; Hollinger, 2001) that can shed light on the problems brought about by globalization today. Whether one agrees or disagrees with the position or the feasibility of the international community to advance human development (Nussbaum, 2010) or with the idea of transnational organizations playing an effective role in promoting democracy (Held, 2010) or increasing the welfare of people on a global basis (Beck, 1998; Habermas, 2003), cosmopolitan approaches to global governance have the potential to transform the international policy regime from an ethos of rational egoism, responsive to the imperatives of the market economy, to a transnational political discourse of collaboration and solidarity.

In the study of international politics, an alternative to the cosmopolitan approach to global governance is Chantal Mouffe's (2009) concept of a multipolar order, which acknowledging the ever-present possibility of conflicts and antagonism, it proposes a pluralizing hegemony by constructing counter-hegemonic projects (Tambakaki, 2009, p.101). On the one hand, Mouffe's approach seems feasible in light of rising regional hegemons in the international community, which could potentially challenge Western hegemonic policies in their areas of influence such as the case of Brazil in South America, India in the Subcontinent, and China in the Asia-Pacific region (Robinson, 2015). Specifically, the organization of these countries into an international cooperation agreement for mutual investment known as BRICS, which is independent from 
institutions that traditionally promote Western hegemonic policies such as the International Monetary Fund and the World Bank (Ribeiro, 2015), further supports Mouffe's concept of an emerging multipolar order. On the other hand, a cosmopolitan legal and institutional approach can be instrumental in coordinating efforts among members of the international community to deal with crises that require the cooperation of multiple governments and institutions (Held, 2013).

Both multipolar and cosmopolitan theories tend to be critical of the current neoliberal policy regime and Western hegemony and they are not necessarily mutually exclusive alternatives to the existing unipolar order. Moreover, there is an important difference between the two respective positions when we analyze their philosophical principles in light of the problematic surrounding global immigration. A cosmopolitan approach to immigration policies implies universal freedom of mobility, where human beings are treated in principle as citizens of the world. However, in a multipolar order, marked by conflicts between various hegemonic projects, immigration policies would be constrained by the larger policy regime of competition and differences in priorities between hegemonic powers. Thus, a cosmopolitan approach to immigration policies seems to be ideal for the actualization of the long advocated freedom of mobility as a human right (Bartram, 2010; Dragojlovic, 2008; Pecoud and Cuchteneire, 2007; Ong, 2010).

Irrespective of whether one adopts a cosmopolitan or a Neo-Marxist approach for understanding globalisation, academic research has demonstrated that increasing inequalities brought about by globalization have acted as important push factors for raising levels of migration (Mishra, 2007). This has inspired a significant amount of 
research dealing with exploitation in international labour migration (Yang, 2003), chronic poverty and global migration (Kothari, 2002), poverty and asylum seeking (Boswell, and Crisp, 2004), and environmental refugees (Myers, 2002) among other areas. Academic literature on international poverty and immigrants' lack of social rights presents a sharp criticism to the current form of global capitalism.

Robinson (2004) developed an influential theoretical critique of global capitalism, which he has expanded by applying it to individuals and thus taking the concept of national elite to a transnational context (Robinson, 2012). According to Robinson, industrial and financial changes brought about by globalization have facilitated an increasing number of elites from the developing world to embrace transnational modes of capital accumulation and to distant socially from national oriented elites (Robinson, 2012). The migratory movements of transnational elites and privileged migrants have also been subjects of empirical academic research (Beaverstock, 2002; Yeoh, and Willis, 2005). While most immigrants are not members of a transnational elite they do play a key role in the interconnection of global markets, in the claiming of rights and responsibilities beyond the boundaries of the nation state, and in the expansion of cultural and linguistic plurality. In short, as workers, citizens, and members of a diaspora, immigrants are affected by and are also active participants of an emerging globalized and transnational social reality.

Citizenship practices in the context of migration are an example of transnational social phenomena and they can be analyzed from a variety of mutually inclusive perspectives and areas of research. These areas of research include studies looking at policies and practices regulating the relationship between immigrants and immigrant- 
sending countries (Levitt, Peggy, and de la Dehesa, 2003; Sutherland and Barabantseva, 2011) and on how immigrants affect citizenship practices in their countries of residence (Bloemraad, Korteweg, and Yurdakul, 2008; Martiniello, 2005). Also, it includes studies of how citizenship policies are enacted in response to the increasing presence of immigrants (Money, 1997; Mayda, and Patel, 2004) and how new transnational realities question traditional citizenship regimes based on the territoriality of the nation state (Bauböck, 2005), among other themes. Whether or not increasing migratory movements and the establishments of immigrant communities pose a real challenge to national conceptions of citizenship on both immigrant receiving and emigrant sending countries is still a matter of academic debate.

Similarly, there are different forms to conceptualize transitional citizenship. According to Bosniak (2000), a description of citizenship that moves beyond the nationstate varies "depending on whether we are addressing citizenship as a legal status, as a system of rights, as a form of political activity, or as a form of identity and solidarity"(pg452). One the one hand, transnational citizenship as a legal status is a much reduced social phenomena, since with few exceptions such as the case of citizenship in the European Union (Balibar, 2009) formal legal citizenship in a political community is well entrenched in the parameters of belonging to a nation-state. In most countries as in the cases of Mexico and Canada, legal citizenship can be obtained by birth, ancestry, or naturalization, and studies have demonstrated how in an era of increasingly global migration, legal citizenship can function as a form of distinction and social capital that benefits citizens and disadvantages immigrants equal access to opportunities (Bauder, 2011), and perpetuates global inequality by acting as the main vehicle for the 
preservation of wealth and the allocation of justice (Shachar, 2007). Moreover, while a legal definition of citizenship can offer important insights about formal exclusion and inclusion of immigrants into a political community, it could be argued that a strictly formal and legalistic definition of citizenship is not necessarily conducive to understand the transnational expansion of citizenship in broader social, historical, and economic dimensions.

On other hand, citizenship as a form of political activism and civic participation can shed important light on how immigrants experience and perceive themselves as social actors living in a transnational reality as well as to understand their efforts to enact political change that transcend the national boundaries of the nation-state. The conceptualization of citizenship as a form of active political and civic participation can be traced back to the origins of citizenship in classical Greece where citizenship was largely defined as the participation of free men in the civic life of their city-state and where citizens who did not actively participate on issues of public concern were considered idiōtēs, the linguistic root for the English noun idiot (Heater, 1990). 20 $0^{\text {th }}$ century social theorists saw political activism as a central component of citizenship, and as the main vehicle in the struggle against authoritarianism and imperialism (Arendt, 1966; 1968). In the $21^{\text {st }}$ century, transnational citizenship as a form of political activism and civic participation has been largely framed in the work of transnational advocacy networks, whose political activities enact political change across different nation-states and have the potential to develop into an organized transnational civil society (Keck and Sikknink, 1999; Price, 2003). 
In the context of migration, organized political activism and civic participation by emigrant communities have long predated the formation of political activism of $21^{\mathrm{st}}$ century transnational advocacy networks. For centuries, members of emigrant communities have organized in order to enact political and social changes in their countries of origins (Sheffer, 2003). For instance, in the early twenty-century members of Chinese communities across the world lobbied their respective governments to actively support the formation of the Kuomintang, a political party that aimed to transform China from an ancient monarchy into a modern Western style republic (Duara, 1997). In the case of Mexico, Mexican emigrants in the Unites States have actively participated in Mexican public affairs since the 1860s when patriotic organizations, juntas patrioticas, were established to gather support in the Mexican government's struggles against French military occupation (Delano, 2006). In the context of migration, transnational citizenship can therefore be conceptualized as a form of political and civic engagement that is part of emigrant communities' long history of political and civic participation in issues of public concern.

Similarly, there is a long intellectual tradition of conceptualizing citizenship as a form of identity that transcends the geographical boundaries of a political community. Martha Nussbaum associates the de-nationalization of citizenship with the adoption of a cosmopolitan identity, which refers to the self-identification as a citizen of the world rather than only as a citizen of a particular state or nation (Nussbaum, 2011). Cosmopolitanism dates back to classical antiquity and it can be found in Zeno's "cosmopolis," Diogenes" "citizen of the world," and Cicero's "common right of humanity" (Trepanier and Habib, 2011, p. 1). Despite their differences, all of these 
concepts recognize the universality of the human condition and support an idea of justice and equality for all, irrespective of one's membership to a political community.

Moreover, cosmopolitanism is not the only form of transnational civic identity. For instance, members of international environmental organizations advocate for the adoption of universal civic values indicative of humanity's responsibility to protect the natural environment (Doherty, 2006). Arguably, by emphasizing the fulfillment of responsibilities towards the environment, this type of transnational citizenship identity distances from the traditional cosmopolitan ideal of a community of citizens of the world to instead advocate for a community of environmentally conscious citizens of the earth. Interestingly, the idea of a post-national citizenship based on the stewardship of the natural world is also present in Indigenous views of citizenship. In Canada, Indigenous scholars have advocated for a view of Indigenous citizenship that is rooted in their responsibility to protect the land as well as the animals and people that inhabit it (Borrows, 1999). While Borrows' concept of "landed citizenship" is indicative of a specific Indigenous civic identity in Canada and directed towards the political participation of Indigenous people in the Canadian state, other Indigenous views on citizenship promote a transnational identity based on shared Indigenous culture.

Indigenous nations often extend beyond the political boundaries of modern nation-states and they can actively promote transnational citizenship identities rooted in shared Indigenous cultural and social values. For example, Andean transnational identity and social activism in Bolivia and Peru (Andolina, Radcliffe, and Laurie, 2005) and Mayan transnational activism and identity in the case of Mexico and Guatemala (Warren, 1998), are indicative of well-organized social and political Indigenous movements 
capable to establish Indigenous civic identities and civic practices that move beyond the political boundaries of their respective nation-states. In the context of Mexican migration, Indigenous people have been able to develop complex transnational communities given way to transnational ethnic identities as in the case Mixtecs and Zapotecs in California and Tijuana (Kearney, 2000; Velazco Ortiz, 2005). Examples of Indigenous transnational identities offer alternatives to traditional Euro-centric concepts of civic identity and the de-nationalization of citizenship, and they can shed important light on the development of transnational citizenship identities among Mexicans and other Latin American immigrants whose ethnic and social background can be influenced by Indigenous cultures.

Other forms of transnational identity relevant to the study of transnational citizenship in the context of Mexican migration include Latino and Chicano identities. Whether by funding community organizations or participating in cultural and social movements, many Latin American immigrants in the United States have developed a social and cultural identity that transcend the national boundaries of their respective countries of origin to instead see themselves as Latinos (Mato, 1998; Cravey, 2005). A Latino identity does not imply a uniform or homogenous character, since Latin Americans come from countries that are culturally, linguistically, and ethnically diverse (Chanady, 1994) but rather it is an identity indicative of diverse experiences of migration, marginalization, and community development of Latin American immigrants in the United States (Torres, and Magolda, 2004). In the context of Canada, the development of a Latin American identity could be informed by the complex negotiations in the development of Latin American institutions, celebrations, and social practices of 
immigrants from Latin America living in large urban centres (Veronis, 2006). Mexicans are the largest group of Latin Americans in the United States and in Canada but while Mexicans' struggle for inclusion has been central to the development of a Latino identity in the United States, the relatively recent presence in significant numbers of Mexicans in Canada makes the impact of Mexican immigration in the overall development of a Latin American identity in Canada a subject for further research.

Moreover, among Mexicans in the United States a Latino identity can also coexist with a Chicano or Mexican-American identity. Chicanos represent the second largest minority and one of the oldest immigrant groups in the U.S (Camarillo, 2005). Chicanos organizations have a long tradition of advocating for the rights of Mexican-Americans and Mexican immigrants the U.S and they played an important role in the civil rights movement in the 1960s and 1970s (Rosales, 1996). In this regard, community organizing and the assertion of rights have heavily influenced the historical development of a Chicano identity.

Transnational citizenship can also be conceptualized as a system of rights. The understanding of citizenship as rights is rooted in a Western European tradition of citizen-state relations, in which, according to T.H. Marshall, civil, political, and social rights have been progressively secure by members of a nation-state (1965). At the same time, Marshal argues that access to citizenship rights has been historically linked to social class privilege, which has systematically prevented working class people from the enjoyment of equal rights until the introduction of social citizenship rights in the second half of the twenty century when industrialized countries adopted a welfare state model that provides basic social and economic securities for its citizens (Marshal, 1965). Social 
citizenship rights include access to unemployment insurance, public healthcare, and public education among others but the impact of the historical progression of citizenship rights is largely limited to the experience of members of the wealthy nation-states commonly referred as the Global North. Having said that, less wealthy immigrantsending countries of the Global South such as Mexico have managed to expand access to civil, political, and social rights to their emigrant population such as the right to vote in Mexican elections, to access public legal representation in the Mexican legal system, as well as public education in Mexico (Gutierrez, 1997; Lafleur and Calderon, 2006). While limited, the rights of Mexican emigrants to participate in the political, civil, and social life of Mexico are indicative of the transnational expansion of citizenship as a system of rights in the context of migration.

Interestingly, transnational citizenship as a system of rights can also be understood as part of a long intellectual tradition advocating for universal rights to all members of humanity. The $18^{\text {th }}$ century German philosopher Immanuel Kant developed the concept of a universal right of humanity, which argues that "the people of the earth have $[\ldots]$ entered in varying degrees into a universal community, and it has developed to the point where a violation of rights in one part of the world is felt everywhere" (quoted in Ray, 2007, p. 306). Kant's philosophical ideas about universal human rights represent a powerful assertion of the expansion of civic consciousness beyond the boundaries of the nation-state that have been central to the development of the 1948 Universal Declaration of Human Rights (Donnelly, 2013). Martha Nussbaum has pointed out Kant's debt to the ancient Stoic's cosmopolitan ideals (1998). Also, subsequent United Nations' programs on advancing universal human rights such as the promotion of the 
Human Development Index have also been influenced by cosmopolitan principles

(Nussbaum, 2013). Thus, the conceptualization of transnational citizenship as a system of rights is well rooted in Western intellectual traditions advocating for universal human rights as well as the advancement of citizenship practices and civic identities that reflect a common humanity. In this regard, the conceptualization of transnational citizenship as a system of rights, as a form of political activity and identity, and as a legal status is indicative of how transnational citizenship as social phenomena and area of study cuts across and is largely intertwined with distinct political, social, and legal categories.

Furthermore, there have been important theoretical advancements in the study of transnational citizenship practices in the context of migration. Bourdieu's concept of habitus has been applied in a number of innovative concepts and studies in the context of migration, including citizenship as capital (Bauder, 2008) and social capital and political participation (Morales, and Giugni, 2011), which have contributed to reach broader understandings about immigrants' citizenship practices. Others such as Isin (2007) have moved away from the concept of citizenship practices, arguing that immigrants can enact themselves as citizens by performing acts of citizenship. While acts and actions are interconnected, actions happen because of a decision to perform an act (p23) and therefore acts should be understood as separate from actions. According to Isin current academic focus on actions and practices rather than on acts to describe what citizens do and how they behave tends to "value routine over rupture, order over disorder, and habit over deviation" (p.20). In the context of migration, acts of citizenship are powerful assertions against unjust and exploitative circumstances, which makes this concept 
particularly relevant for studying the civic participation of immigrants facing exclusionary policies and living in exploitative circumstances.

Not all immigrants from the Global South live in precarious social and economic circumstances and there are increasing studies on the migratory movement of high skilled professionals from the Global South to the Global North. This migratory movement is commonly referred to as brain-drain and the policy and human development literature has shown both negative (Faini, 2007) and positive (Docquier and Rapoport, 2012; Ustubici, and Irdam, 2012) consequences of high skilled migration. Whether studies look at the general ethical implications of global poverty for the development of immigration policies targeting high skilled immigrants from the Global South (Oberman, 2015) or at the practical advantages gained by specific groups of high skilled migrants such as Mexican scientists (Marmolejo-Leyva, Perez-Angon, and Russell, 2015), they show an increasing willingness of immigrant receiving countries to attract highly skilled migrants (Gabriel, 2013).

Some studies are critical of the concepts of brain drain and brain gain and they have replaced them by the term brain circulation (Blatchford and Zhang, 2014; Tung, 2008; Lee and Kim, 2010). These studies argue that the migratory movement of highly skilled professionals is neither one-dimensional nor necessarily a permanent loss of human capital since high skilled migrants also tend to return to their countries of origin. Likewise, highly skilled migrants are active social actors, and their migratory decisions to either stay permanently in a country or leave can also affect immigration policies looking to retain high skilled immigrants (Giordani, and Ruta, 2016). Moreover, whether high 
skilled migration should be understood as a positive or negative aspect of global migration is however still a matter of ongoing research.

Immigrant sending countries have responded to the problematic surrounding the increasing numbers of their citizens living in diaspora by developing a number of emigration policies to include them in the political, cultural and economic life of the nation (Barry, 2006; Fitzgerald, 2006; Smith, 2003). Some of these policies, as in the case of Mexico, include the right of emigrants to vote abroad, to access government programs for emigrants, to have official representation in the government as emigrant communities, to maintain dual nationalities, and to pass on Mexican citizenship to their children born outside Mexico (Martin, 2009; Fitzgerald, 2005; Goldring, 2002; Barry, 2002). These rights expand the notion of Mexican citizenship and nationality beyond the territorial confines of the nation-state and suggest a form of citizenship that is national in character and trans-national in practice.

Academic studies of the utilization of Mexican emigration policies by Mexican migrants have centred almost exclusively on the United States (Green, and Weil Editors, 2007; Fitzgerald, 2009; Gordon and McIntosh, 2010; Delano, 2011). Whether studies focus on the avenues supporting the economic contributions of Mexican immigrants back to Mexico (Marcelli, 2005); the increasing political and social involvement of the Mexican diaspora in the United States (Leininger, and Pycior, 2014); and the contradictions between local governmental practices and Mexican emigration policies (Fitzgerald, 2006), they point out a complex citizen-state relationship in which the priorities of Mexican communities in the United States are not necessarily reflected in Mexican emigration policies. Academic literature of Mexican diaspora in the U.S 
however provides a good point of departure to further study the citizenship practices and the utilization of Mexican emigration policies elsewhere in the Mexican diaspora.

\section{Citizenship Engagement of the Mexican Diaspora in the United States}

Mexican immigrants are a traditionally marginalized population in the United States and studies on Mexican immigrant's civic participation in the U.S. can shed important light on frameworks, methodologies, and themes for studying the citizenship practices of Mexican immigrants in Toronto. Despite the fact that the increasing number of Mexican immigrants in Toronto is a relatively new phenomenon, Mexican immigration to Canadian cities can be also examined in light of a long and complex movement of Mexican people to various regions of North America. Academic studies have shown that a considerable number of Mexican immigrants and Mexican-Americans have moved away from their traditional areas of settlement, such as the American southwest, to regions where there is a considerable level of labour shortages including states in the North East and Mid-West (Crowley, Lichter, and Qian, 2006). This migratory movement has been primarily motivated by better economic opportunities than exist in traditional centres of Mexican immigration (Crowley, Lichter, and Qian, 2006; Striffler, 2007).

Currently, the second largest Mexican community in the United States is not located in Texas or New Mexico but closer to the Canadian border, in the city of Chicago (De Genova, 1999). Based on his extensive research on Mexican immigrants in the Chicago area, De Genova (2005) challenges traditional understandings of American social order based on a White-Black binary to place Mexican immigration as a 
fundamental racialized component of current American social order. De Genova also points out that laws and immigration politics have produced an idea of illegality in the United States, which has shaped an image of the Mexican immigrant as the quintessential illegal alien (2005).

A history of systemic barriers and discrimination has not impeded Mexican immigrants to be civically engaged in the United States. Bada, Fox, and Selee (2006) illustrate how Mexican immigrants in the Chicago area have founded a significant number of migrant and labour organizations, as well as established collaborative relations with religious communities and Spanish-language media, which have been conducive for supporting and institutionalizing Mexican immigrant's civic engagement. Empirical studies such as this can provide an important lesson for the study of Mexican immigrants' civic engagement in a city like Toronto where there is a significant number of Spanishlanguage media as well as churches serving Latin American immigrants.

Moreover, the civic participation of Mexican immigrants in the United States is not limited to the American context but also includes civic commitments and acts of solidarity with Mexico. Bada (2011) has illustrated the extraterritorial civic participation of Mexican immigrants in the United States with small municipalities in traditional immigrant sending states like Michoacán. Of particular importance for the study of Mexican immigrants' relation with Mexico is the role of migrant-led hometown associations (HTA) (Goldring, 2002) and immigrants' monetary collaboration via remittances and donations to Mexico (Goldring, 2004). According to Bada (2011) HTAs create opportunities for state-society collaboration that can have significant impact in local community development back in Mexico. Also, Bada (2014) points out the 
intersections between local and transnational civic participation of Mexican immigrants, blurring the divisions between immigrant's civic participation with Mexico and the United States.

According to Goldring (2012) Mexicans in Canada do not organize into HTAs and instead tend to create professional associations. Goldring argues that, "for Mexican immigrants in Canada it is not national political culture but rather factors such as migration networks, social capital, and class that determines organizational patterns" (2012). Mexican immigration to Canada can be contextualized in what Mata (1985A, 1985B) refers to as a professional wave of Latin American immigrants. Since the mid1980s, Latin American professionals, mainly from South America and Mexico, have been immigrating to Canada. Thus, the relatively recent migration of Mexican professionals to Canada is significantly distinct from the much longer and complex migration of Mexicans to the United States. Moreover, due to the cultural, social, religious and linguistic similarities between Mexican immigrants and other immigrants from Latin America, studies about Latin American immigration in Toronto can also shed important light on the subject of Mexican immigration in Canada's largest city.

\section{Latin American Immigration in Toronto}

Latin American immigrants in Toronto have managed to establish a variety of community centres, agencies, cultural and social organizations that point out a significant capacity for community organizing and for providing important social and cultural services (Veronis, 2006, 2007, 2010; Landolt, Goldring, and, Bernhard 2009a). These studies adopt a transnational approach to migration and thus present Latin American 
immigration to Toronto as a movement transcending national boundaries in the migratory and settlement processes. As such, Latin American immigration in Toronto has been conceptualized as a transnational social phenomenon that creates social spaces in the city and defines and redefines itself through constant processes of internal and external negotiations about community organizing (Veronis, 2007, 2010).

Methodologically, most studies about Latin American immigration are qualitative (Veronis, 2006, 2007, 2010; Landolt, Goldring, and, Bernhard 2009a) and tend to utilize in-depth interviews with community leaders and analyze annual reports from Latin American organizations and agencies serving Latin Americans. Overall, these studies present a picture of Latin American immigrants' organizational capacity, which transcends national divisions. At the same time, studies on Latin American community agencies have also revealed tensions among community agencies, pointing out the difficult relationship that large agencies have had between themselves and also with smaller community agencies, among other issues (Landolt, Goldring, and Bernhard, 2009a).

Furthermore, while publications on Latin American immigration in Toronto do not analyze the case of Mexican immigration in particular, their analysis of organizations that provide services to Latin Americans can help understand how some Mexican immigrants in Toronto may access social services (Landolt, Goldring, and Bernhard, 2009a). Also, from a citizenship and transnational perspective, the theoretical approach utilized in studies such as Veronis $(2006,2007,2010)$ could be instrumental to understand the process of how a distinct national group such as Mexicans interacts with and may become part of a greater Latin American community in Toronto. 
Some of the major themes on the study of Latin American immigration in Toronto deal with the subjects of family reunification (Landolt, Goldring, and Bernhard 2009b), health provision (Milosovich, 2009), political activism (Giginiewicz, and Schugurensky, 2004; Landolt, and Goldring, 2010; Landolt, and Goldring, 2010; Landolt, Goldring, and Bernhard, 2011), and the mapping of migratory waves (Mata, 1985a; 1985b). Several barriers have been identified on the subject of family reunification, particularly in the utilization of social services by Latin American refugee mothers trying to be reunited with their children, (Landolt, Goldring, and Bernhard, 2009b). This can be especially relevant to the study of family separation among Mexican immigrants in Toronto since they are the largest refugee group of Latin Americans in the city.

Academics working with the Hispanic community have pointed out that there are important barriers to health services among Hispanics in Toronto (Milosovich, 2009). Also, studies have shown that while Latin American immigrants maintain close relationships with political parties and movements from their countries of origin, their high level of political activism has not translated into active engagement in Canadian politics (Giginiewicz and Schugurensky 2004; Landolt and Goldring, 2010; Landolt, Goldring, and Bernhard, 2011). The relative lack of engagement in Canadian politics and barriers in accessing health services are indicative of a significant level of marginalization experienced by a significant number of Latin American immigrants in Toronto, which can also serve as point of reference to study the exercise of social and political citizenship rights of Mexican immigrants in the city. Lastly, Mata (1985a; 1985b) can help to contextualize the movement of Mexican people to Canada as a 
response to various social and economic factors affecting specific social groups in Latin America such as middle-class professionals.

\section{Mexican Middle Class Migration}

There are a number of perspectives to study and define the middle class. For instance, international economic cooperation agencies and international financial institutions tend to define the middle class based on household income. The OECD defines a global middle class as all those living in households with daily per capita incomes between USD10 and USD100 in Purchasing Power Parity (PPP) terms (Homi, 2010). Other income based definition such as the 2012 World Bank report on the rise of the Latin American middle class defines the middle class in this region as those households with annual incomes between USD14,000 and USD73,000 (Ferreira Edit. 2012). According to the international market intelligence firm Euromonitor, the Mexican middle class are those households who live with an income between USD15,000 and USD45,000, which comprised 47 percent of the total Mexican population (Boumphrey, 2015). Household income provides an economic perspective of who is included and excluded in the middle class and these definitions can be adapted to global, regional, or national realities. Studies based on household income definitions, demonstrate there is an increasing middle class in Mexico, Latin America, and the entire developing world, which tends to have fewer children and spend much more on their education than their working class counterparts (Banerjee and Duflo, 2008).

Social scientists define the middle class by looking at a variety of aspects including types of occupation and levels of education. For instance historians of Latin 
America have looked at the emerging differences between blue collar and white-collar workers to explain the rise of the middle class in Latin American countries (Parker, 1998). Similarly, sociologists often take education and occupation as important factors to determine who is a member of the middle class. For example, Dennis Gilbert defines the Mexican middle class as members of household run by people with non-manual occupations (Gilbert, 2008, p.12). The rise of the Mexican middle class has also been linked with the process of democratization, underscoring the relation between middle class interests and the potential material benefits provided by a Mexican liberal democracy (Walker, 2012). Interestingly, Mexico’s middle class has been particularly hurt by subsequent economic crisis since the adoption of neoliberal economic policies in the 1980s, forcing Mexican middle class parents to prioritize investing in their children's education over most other expenditures (Gilbert, 2008).

As pointed out in the introduction there is little evidence to suggest middle-class Mexicans are immigrating to the United States in greater numbers as a result of increasing economic instability, but rather, they have resorted to taking second jobs or making cuts in household expenses (Ochoa, 2008). There is however evidence showing how social class, ethnicity, and place of origin make significant differences among Mexican immigrants in the United States (Hamilton, 2012; Vallejo, 2012, 2015). For instance, while there are more Indigenous, rural, working class Mexican males than indigenous, rural, working class Mexican females immigrating to the U.S, such gender disparity reduces systematically among Mexicans of a middle class, non-indigenous, and urban origin (Hamilton, 2012). 
Similarly, Vallejo (2015) has pointed out that 1.5 and second generation Mexican American professionals from working class background experienced more subtle racial discrimination in their jobs than their Mexican American middle class counterparts. Vallejo (2012) points out the tendency of Mexican American professionals to join ethnic professional associations and attaining a middle class life style associated with whitecollar work, which reveals the importance of tertiary education for upward social mobility. While there is no empirical evidence connecting the rise of Mexican American middle class with a significant increase in Mexican middle class migration to the United States it is clear that education, ethnicity and social class background matters in the overall experience of upward social mobility of Mexican Americans. In short, both the Mexican and Mexican-American middle class seem to be characterized by educational attainment, white-collar work, and by a relative privileged social standing in compared to their working class counterparts.

Moreover, tertiary education and white collar work has been historically related to white skin privilege in Mexico. In colonial Mexico, the Laws of the Indies and the Royal Cedula of 1765 explicitly denied permission for racially mixed people to received university degrees (Twinan, 2002 p196). Also, the rules of the guilds in Mexico City were formulated in such a restricted way that people of non-Spanish origin could never rise higher than the unskilled, low paid levels (Guthrie, 1999 p297). Access to tertiary education and white collar work were facilitated to people of mixed ethnicity, mestizos, after Mexico's independence in the early $19^{\text {th }}$ century but the growing influence of European racial ideologists such as Spencer's biological determinism made dark skin an 
increasing obstacle to social advancement from the mid $19^{\text {th }}$ century to the end of Mexican Revolution in the 1920s (Hayness, 2000, p.247).

In addition, nationalist political discourses and corporative policies of subsequent Partido Revolucionario Institutional (PRI) governments (1929-2000) represented important steps to include broader and more mestizo sectors of the population such as members of trade unions, teachers, and other workers into the middle class but these changes largely ignored the mostly Indigenous rural population of Mexico whose living conditions has been historically poorer than in the rest of the country (Crespo, 2001). By 1961, fifty years after the Mexican Revolution begin, only 1 percent of all farms processed 50 percent of all agricultural lands, and by the 1990s the continuous pauperization of Indigenous communities in rural Chiapas was at the centre of the Zapatista revolt against the Mexican government's Neoliberal policies (Hayness, 2000, p.247). While nowadays the Mexican middle class may include lawyers, doctors, educators, small business owners, professionals and white-collar workers in a number of occupations who may come from different ethnic backgrounds (Parker and Walker, 2013), it is evident that ethnicity and place of origin has been at the centre of social class stratifications, privilege, and marginality in Mexico.

\section{Conclusion}

Academic studies on Latin Americans in Toronto can provide valuable theoretical and empirical lessons to study the real life challenges experienced by Mexican immigrants living in this city, and their collective responses to issues related to marginality and discrimination. Similarly, the conceptual advancement made by 
academic literature on Mexican immigrants' citizenship practices in the United States can also be applied to the study of Mexican immigrants' civic participation in Canada and in this way further the academic knowledge on the Mexican diaspora's social contributions and struggles across North America. Additionally, since Canadian immigration and citizenship policies have enacted significant barriers to the movement of people from Mexico to Canada, the transnational and globalization literatures can help further problematize the imperative contradictions of the neo-liberal policy regime in North America, which on the one hand facilitates the movement of capital and services and on other hand increasingly restricts the movement of racialized people.

Methodologically, academic studies on Latin American immigrants in Toronto provide important examples on the utilization of qualitative methods such as participatory observation, semi-structured interviews, and arts-based methodologies for producing relevant social scientific knowledge on migration. Moreover, Mojado ethnography (to be discussed in the chapter on research methods) utilized in Mexican American studies can also inform qualitative studies and community-based research with Mexican immigrants in Canada. For instance, the literature review shows that Mexican temporary workers in Ontario experience significant inequalities and limited social rights, which place them in a vulnerable position both as workers and as social actors. A Mojado ethnographic study of the citizen participation of Mexican immigrants living in Toronto would help not only to problematize the exercise of social, civic and political citizenship rights of Mexican immigrants in both Canada and Mexico but also to question the ideas of "community" and "Mexicanness" in light of the efforts by Mexican immigrants in Toronto to reach out 
to other vulnerable Mexicans in urban and rural Canada, as well as to interrogate the positionality of researchers on such issues.

In addition, the literature review also shows the need to fill important gaps in the body of knowledge about Mexican immigration to Canada. First, Mexico has an active role on issues related to emigration as it seeks to maintain and foster an active citizenstate relationship with Mexicans abroad. Thus, there is a need to further understand how Mexican emigration policies and governmental practices respond and relate to Mexican communities in Canada as well as promote and/or deter the increasing migration of Mexican temporary workers, refugees, students, and permanent residents. Second, there is little knowledge on the growing importance of Canada-Mexico relations and how it is further complicated by the migratory movement of diverse groups of Mexican citizens to Canada. This matters because Mexican immigration to Canada seems to be part of the increasing integration of the North American market economy, which also depends on the Canada-Mexico relationship. Thirdly, there is a need to have a better understanding of how Mexican immigrants from different social and economic strata are affected by and respond to Canadian immigration and citizenship policies.

My dissertation aims to fill these research gaps by analyzing, from a policy and citizenship perspective: 1) the relations between Mexicans living in Canada and the Mexican state in light of the utilization of Mexican emigration policies and programs; and; 2) the individual and collective actions by which Mexican immigrants in Toronto respond to Canadian policies affecting vulnerable sectors of the Mexican and nonMexican population in Canada. Answering these questions will shed new light on how the Canada-Mexico relationship also influences the migratory movement of Mexican 
immigrants and how the presence of Mexican immigrants can potentially affect the Canada-Mexico relationship.

The literature shows that the transnational mobility of public policies is not an independent process, but is also a part of - and is shaped by - the wider policy process (Stone, 2000, p.2). In this regard, the study of transnational policy developments is also an indirect examination of the principles informing overall policy processes and public governance. Pierre Bourdieu defines a doxa as an unquestionable orthodoxy that operates as if it were the objective truth across social space in its entirety, from the practices and perceptions of the individual (as paraphrased in Chopra, 2010, p.421). My dissertation recognises neoliberalism as a doxa in the wider policy process and situates the discussion of transnationalism, immigration, and citizenship in relation to: (1) broader social and cultural beliefs based on liberal market economic values embedded in contemporary public governance; and (2) the effect of neoliberalism as a hegemonic discourse in the overall development of citizen-state relations. Specifically, my dissertation addresses both of these issues in Chapter VII by examining the use of policies and services Mexican businesspeople use to maintain active citizens-state relations with Mexico.

The literature review reveals that there is a plurality of understandings about the conceptualization of transnational citizenship, which can be described as a legal status, as system of rights, and as a form of political activity and identity (Bosniak, 2000). As pointed out in the literature review, transnational citizenship as social phenomena and area of study cuts across different political, social, and legal categories. For this reason, my dissertation adopts a holistic approach to transnational citizenship, treating transnational citizenship as a system of rights and a form of citizenship identity and civic 
practices in the context of migration. My dissertation operationalizes this holistic approach to transnational citizenship by exploring 1) how middleclass Mexican emigrants in Canada perceive themselves as citizens and engage in issues of public concern in Chapter IV; and 2) how they are able to benefit from emigration policies and programs offered by the government of Mexico in Chapter V, VI, and VII. Questions of citizenship and social class are largely intertwined and by focusing on Mexican middle class my dissertation centres the study of Mexican transnational citizenship practices in light of larger questions about social class privilege and identity. In this regard, my dissertation aims to make a contribution to the study of Mexican middle class migration and also to the transnational expansion of Mexican citizenship and Mexican social class from a policy perceptive.

The study of the transnational expansion of citizenship practices, identities, and rights of Mexican middle class immigrants is an important contribution to the academic literature on transnationalism and immigration. The transnationalism and immigration literature sheds light on the development of transnational citizenship of wealthy elites from the Global South (Robinson, 2012) and also on how transnationalism and globalization affect the citizenship rights of immigrants living in precarious economic and social conditions. Moreover, there are important questions about how transnational citizenship develops among immigrants who are neither members of wealthy transnational elites nor they live in social and economic marginality, but who rather find themselves in the middle. My dissertation fills these gabs in the academic literature on transnationalism and immigration by studying the exercise of transnational citizenship rights by middle class immigrants. 
Also, the development and migration literatures reveal both positive and negative effects of high skilled migration however they tend to ignore questions about the expansion and contraction of citizenship rights of highly skilled immigrants. Similarly, in the context of Latin American migration to Canada, studies contrast the migratory movement of university educated professionals with that of Latin American refugees (Mata, 1985a, 1985b) but they ignored how transnational citizenship practices develop among Latin American professionals living in Canada. In other words, there is a tendency to ignore middle class migration or to study it in the context of inclusion and exclusion of skilled and highly skilled workers in the labour market but not necessarily in relation to their experiences as citizens. My dissertation fills these gabs in the academic literature by exploring how skilled and highly skilled Mexican professionals in Canada access transnational citizenship rights in the context of migration by utilizing advantageous Mexican policies and programs.

In addition, the transnationalism and globalization literature reveals different liberal, cosmopolitan, and Neo-Marxist theoretical approaches to the study of transnational citizenship practices but it largely ignores: 1) how a plurality of transnational citizenships develop and coexist with one another in the context of migration; and 2) how different forms of transnational citizenships affect the development of immigrant communities. My dissertation answers these questions by studying the expansion of transnational citizenship practices of middle class Mexican immigrants in Canada from a holistic approach that includes both transnational citizenship identities and transnational citizenship practices. 
The literature review suggests there is a racial dimension to the experience of social advantages by Mexican and Mexican American middle class, which can be trace back to Mexico's experience with colonialism and post-colonialism. There is a five hundred year-old history of globalization and immigration in Mexico that has had profound influences on the establishment of social and racial privilege. During Mexico's colonial period (1535 to 1820), members of the high clergy, representative of commercial houses, and colonial administrators settled in Mexico where they filled the ranks of the colonial elite (Brown, 2000). The migratory movement of these colonial elites from Spain to Mexico was strictly regulated and it was part of a complex web of transcontinental and transoceanic movement of ideas, goods, and services that connected Spain to its possessions in the Americas and the Asian Pacific region (Andrien, 2002). This transcontinental and transoceanic interconnection of global markets and peoples has been referred to as the First Globalization (Gunder Frank, 1998) and it is a period in which traditional Mexican ideas of social and racial stratification were established. Accordingly, my thesis will examine Mexican middle class transnational citizenship practices taking into consideration Mexico's long and conflicted history with colonialism and globalization.

Lastly, the literature review reveals the theoretical implications of studying public policies from a bottom-up or top-down approach in light of the structure and agency debate. My dissertation aims at making a theoretical contribution to the structure and agency debate by applying a perspectivist epistemological and ontological position to the study of Mexican immigrants' citizenship practices in Canada and their utilization of Mexican emigration policies. I have develop this epistemology and ontology in light of 
the thought of $20^{\text {th }}$ century Spanish philosopher Jose Ortega y Gasset. In the next chapter on methodology I will explicate how my dissertation's epistemology and ontology balance questions of structure and agency and are ideal to shed light on the transnational expansion of citizenship in the context of migration. 


\section{Chapter III}

\section{Methodology}

"Latinidad Ethnography happens when researchers and the researched use discursive practices in ethnographic inquiry to create a temporary sense of belonging, a "home" where marginalized persons heal from the harsh realities that we experience in mainstream European American society."

Wilfredo Alvarez. Finding "Home" in/through Latinidad Ethnography: Experiencing Community in the Field with "My People"

At the beginning of each interview I was often asked to talk about myself and of what had led me to study Mexican immigration in Toronto. My introductions often felt like an exercise of introspection, sharing parts of my own immigration experience with the research participants, and discussing some similar circumstances we had faced. My positionality as a Latin American immigrant conducting research on Mexican immigrants in Toronto was complex. On the one hand, I could personally relate to many of the participants' experience and also establish a connection based on our common language and similar cultures. On the other hand, I was a researcher asking people who I did not know to share with me their stories of migration and to trust my ability to shed light on their experiences.

Finding the right balance between these two positions when conducting interviews, observing events, and analyzing data was a challenging but also enriching experience that required an appropriate methodology and research methods. Also, equally challenging was the task of finding an adequate ontology and epistemology that would help balance both: 1) the study of overall social and economic structures that influence access to transnational citizenship rights, and; 2) take into serious consideration the 
agency of research participants to overcome social and economic barriers and develop their own citizen-state relations in the context of migration.

In this chapter, I will explicate the ontology and epistemology of my dissertation as well as the research methodology and design I used in conducting my field research. Also, I will briefly discuss the lessons I acquired about research methods through my fieldwork with Mexican immigrants in Toronto and to a lesser extend in other cities in Ontario. The purpose of this chapter is therefore to provide a detailed map of my research activities and also to elucidate on how my positionality as a researcher has both influenced and been influenced by my empirical study.

\section{Ontology and Epistemology: Adapting Jose Ortega y Gasset's Philosophy to the Study of Migration}

As my dissertation evolved, I found that each of the research participants had a distinctive form of being civically engaged and of understanding her/his civic life. Progressively, I realized that while conventional people-centric approaches used in Policy Studies provide me with important insights to understand the development and implementation of public policies in relation to people's capabilities, my overall ontology and epistemology needed further elaborations in order to shed light on some of the most complex aspects related to the research participants' citizenship experiences in the context of migration. My dissertation required the development of an ontology and epistemology that balanced both, the participants' agency to determine their own civic lives as well as the overall structures that influenced their citizenship practices and civic values. After a rigorous search, I found in Ortega y Gasset's philosophy the epistemological and ontological basis that my research findings required, in order to be 
inclusive of the epistemic validity of the participants' own civic thoughts and civic actions and also comprehensive of the existentialist dimension of the ongoing "drama" of migration.

Ontology: Reality and Categorization of Being

In his Meditaciones del Quijote (1914) Ortega y Gasset introduces what came to be his main philosophical dictum, "I am I and my circumstances" (p45). Ortega referred to his philosophy as ratio-vitalism and presented metaphysics as the quest for an ultimate reality found in the life of an individual in a given society at a given time in history (Ortega y Gasset, 1914). According to Edwards (1979), Ortega attempts to go beyond the opposition of both Idealism in its ontological priority of the self and of Realism's assertion of the priority of things the self knows, and instead presents a view of reality in which self and things are constitutive to each other, each needing the other to exist in a course in which the individual carries a mission of self-fulfillment. When applied to the context of migration, the symbiotic relationship between the individual and his or her circumstances and the idea of self-fulfillment as leitmotiv presents a view of reality or ontology that is:

1) Comprehensive of the unfolding drama of migration in which complex circumstances often contrasts with both immigrants' aspirations and their capabilities.

2) Inclusive of an immigrant's own perspective of his or her own life.

3) Flexible to navigate through: a) the innuendos apparent in the mutually constitutive process of emigration and immigration; b) the blurring lines between seemingly binary categories such as national/citizen and outsider/migrant not always appropriate to describe and reach meaning from current migration experiences; and c) the constantly changing circumstances of migrants' life. 
Ortega's comprehensive, inclusive and flexible ontology provides the philosophical basis for adopting a more life-centric epistemological approach for the study of migration, which consists of placing immigrants' lives, in their biographical meaning, at the centre of social-scientific investigations of migration. A life-centric epistemological and ontological position for the study of migration rests on the recognition of both the ontological legitimacy of immigrants' diverse and changing circumstances and the epistemological value of immigrants' perspectives on their own lives.

Immigrants' circumstances can vary from social and personal conditions of relative privilege to the outmost marginality, suggesting an inherent multiplicity of migration experiences. The application of Ortega's basic categorization of being "I am I and my circumstances" to the context of migration underscores the indivisibility of immigrants' experiences from their lives' circumstances. Ortega's concept of being is conducive for valuing migration experiences with civic engagement in light of their unique circumstances, whether these are oppressive or redemptive ${ }^{4}$. In addition, immigrants' circumstances are not only diverse but also subject to change and Ortega's dynamic view of life is conducive to appreciate immigrants' civic contributions and citizenship consciousness in the context of their evolving views and changing

\footnotetext{
4 There are other comprehensive theoretical approaches currently used in the study of people's experiences. For example, Kimberlé Williams Crenshaw's Intersectionality theory (1989) looks at the intersection of different social, cultural, and historical structures of power in the development of people's life. Its emphasis however, is generally on the effects of these conditionings rather than on the perspective of people on their own life experiences. Thus, while intersectionality is a very noble approach that sheds important light on people's experience with social inequalities in relation to gender and race (e.g: Bunjun, 2010; Van Herk, Smith, and Andrew, 2011) its emphasis on social-conditionings and structures of oppression is different from the life-centric theoretical approach presented here. For more information see Crenshaw, K.W. (1989), Bunjun, B. (2010), and Van Herk, K. A., Smith, D., and Andrew, C. (2011).
} 
circumstances. In short, based on the centrality of diversity and dynamism of people's lives, this dissertation adopts an ontology that conceptualizes the development of citizenship engagement and citizenship consciousness in the context of migration as rooted in immigrants' dynamic and diverse biographies.

\section{Epistemology: Perspectivism}

Ortega's philosophy offers an epistemology that balances questions of relativity and objectivity in explaining social phenomena. Ortega merges the absolute tendencies of Rationalism and the sceptical inclinations of Relativism on an epistemology based on the point of view of life, to which he refers as Perspectivism. For Ortega, "every life is a point of view on to the universe [and] whatever is seen by one person cannot rigorously be seen by another" (Ortega, 1938, p.146). Thus, according to Ortega, individuals or groups approach reality from their own points of view and their own perceptions of what is true and real, interpreting the same reality differently. For this reason, according to Ortega, each individual perception of reality is distinctive and correct.

For studies on migration, an epistemology inspired on Ortega's philosophy moves beyond interrogations of whether immigrants' citizenship consciousness and their experiences with citizenship engagement are representative of their co-nationals and/or other immigrants in a given society. Instead, it recognizes individual stories of migration as inherently valuable because of the unique perspective they represent. Theorization, interpretations, and compendium of migration experiences become rooted in a respect for individual differences and the epistemological validity of immigrants' points of view. Arguably, the consideration of immigrants' understandings of their own lives distances 
the study of migration from the objectification, infantilization, and racialization of migration experiences based on preconceived notions of immigrant's cultural, social, and racial characteristics.

Ortega recognizes truth or reality as a compendium of vantage points (Ortega, 1923). In a migration context, each individual perception of migration becomes a necessary building block of an encompassing migration reality. Such comprehensiveness implies a process of constant expansion, as new stories of migration become part of an ever-growing migration reality. Thus, compilation of migration stories allows for the representation of a migration reality that is both historically specific and also inherently incomplete. In the fine arts, perspective refers to the technique of representing the depth and length of a multidimensional reality on a two-dimensional surface. Figuratively speaking, each story of migration compares to a distinct color on a palette, allowing the painter to represent a picture of migration. The representation of a migration reality is epistemologically valid, in its historical specificity, as a subjective compendium of unique views that are all equally true. Inspired in Ortega's philosophy, this dissertation adopts a perspectivist epistemology and it contends that the subjective compendium of diverse vantage points of migration could cement the construction of an objective migration reality.

Moreover, epistemology is the study of reality and Ortega's understanding of the complementary relationship between objectivity and subjectivity is indicative of his phenomenological method of inquiry centred on the structures of life experience and consciousness. In this way, Ortega's thought also falls into the camp of existential phenomenologists such as Gottfried Wilhelm Leibniz and Jean Paul Sartre who do not 
see objectivity in opposition to subjectivity and instead centre reality on human existence. Knowledge and existence are dynamic, always open to changing perspectives, circumstances and multiple possibilities for individual and collective action. Thus, at the centre of human existence lies the freedom to choose an individual or collective action in response to or in anticipation of life's ever-changing circumstances.

Ortega's position on freedom highlights the role of human agency in determining the outcomes of one's life. Specifically, for Ortega, freedom implies a responsibility to direct one's life into a path of self-discovery and self-actualization, understood as the fulfilment of one's entelequia or vocation (Ortega, 1923). While recognizing that the search for authenticity and self-actualization takes place in the context of ever changing circumstances and evolving personal histories Ortega emphasizes the responsibility of following one's vocation whatever this may be (1923). Malishev and Gonzales (2010) have criticized the vulnerability of Ortega's existentialist position where "a person is charged with the responsibility with regard to his convictions but not because of his convictions (p215)". Such a criticism is in line with larger debates about the lack of universal moral imperatives in existentialism but when applied to the context of migration Ortega's existentialist approach becomes a powerful assertion of an immigrant's capacity for self-improvement and self-actualization in the context of his or her circumstances. The adaptation to Ortega's philosophy to the study of migration can therefore help provide a balance on questions of immigrants' agency and their overall social and economic circumstances. This matters since even though immigrants' struggles for achieving their aspirations can be considered acts of freedom, responsibility 
and courage these are also influenced by immigrants' overall circumstances in relation to social, cultural, legal and economic structures.

There is also an existential dimension to immigrants' responsibilities for selfactualization. The quantification of the migration experience based on immigrants' abilities to generate income, and the categorization of immigrants' civic character based on their interactions with and contributions to mainstream society place significant responsibility on migrants to succeed in the market economy and civil society, as well as to manage the overall social, legal and economic circumstances in immigrant receiving countries. In the Canadian context, this is a process understood as a dual responsibility in which immigrants are expected to respect Canadian laws and values, while Canadian laws and institutions aim to respect immigrants' cultural, social, and religious practices (Kelley, and Trebilcock, 1998). Arguably, the concept of dual responsibility is one of the cornerstones of the Canadian multiculturalism, which attends to provide a legal, social, and cultural framework to balance immigrants' freedoms and responsibilities in Canadian society.

An epistemology inspired in the thought of Ortega y Gasset expands the concept of responsibility in the context of migration by placing the journey of self-discovery and self-actualization at the centre of the migration experience. Such an existentialist component provides a level of depth to explore migrants' self-fulfilment, and complement current knowledge on migrants' contributions with a deeper understanding of their own perspectives, motivations, satisfactions, and frustrations with their participation in society. Exploring the existential dimension of the migration experience brings the study of migration close to a work of philosophical archaeology excavating 
trough layers of ongoing biographies to find, in the words of Kant, that "which renders necessary a certain form of civic thought and action" (Kant quoted and translated in Wood 2002, p20). Arguably intersecting immigrants' citizenship engagement with their biography and consciousness provides existentialist meaning that complements social scientific knowledge of migration.

An ontology and epistemology inspired by the thought of Ortega y Gasset provide the study of immigrants' citizenship practices with a philosophical line of inquiry that sheds light on the biographical, self-perpetuating, and existentialist dimensions of migration and citizenship. The epistemological and ontological centrality of experiences and perceptions has been fundamental for how I conducted my research and understood my empirical findings. For instance, since my thesis adopts an interpretative epistemological assumption I am not claiming that my research observations with Mexican immigrants are necessarily objective. In this light, the creation and dissemination of knowledge in my dissertation is indicative of the participants' perceptions about their civic engagement and their utilization of public policies as well as of my own interpretation of the participants' perceptions. The non-objective nature of my empirical study is the result of serious epistemological an ontological reflections about the nature and study of reality, which has led me to adopt an interpretive epistemological assumption inspired in the philosophy of Jose Ortega y Gasset. The epistemological rejection of objectivity and the emphasis on the interpretation of reality is part of a long philosophical tradition that can be traced back from the ancient Stoics to contemporary non-positivist philosophers and I positioned my empirical study in line of this intellectual tradition. 


\section{Research Methodology}

The field research for my dissertation was conceived and designed as a critical ethnographic study. Critical ethnography utilizes regular ethnographic methods to gather data but also takes into serious consideration issues of power dynamics as well as prevailing social, political and economic structures (Harvey, 1990). Critical ethnography's emphasis on structures was ideal to further balance my epistemology and ontology and it allowed me to explore the civic life of the research participants in light of complex social, economic, and political circumstances. The specific ethnographic methods that I utilized in my investigation were participant observation and in-depth interviewing (Madison, 2012). The rationale for adopting critical ethnography as my research methodology was to help me analyze the dominant conceptual frames underneath immigration and emigration policies and practices affecting the civic engagement of my research subjects. Critical ethnography is suitable for researching potentially marginalized populations and it has been utilized in studies with Mexican immigrants in the United States (De Genova, 2005).

Specifically, I relied on Mojado ethnography used in Chicano and Latino Studies in the United States (e.g. Murillo, 2003) as the main critical ethnographic approach for my dissertation research. Mojado (wetback) refers to Mexicans and other Latinos who cross the nation-state territorial border into the United States, and are socially, politically, economically, as well as legally constructed as "illegal entrants," and "newcomers" (Murillo, 2003 p.7). Mojado ethnography moves against the idea of the objective, neutral observer, and stresses and problematizes the positionality of the Chicano or other Latino researcher in light of the "other", reflecting on the blurred boundaries when "other" 
becomes researcher, narrated becomes narrator, translated becomes translator, native becomes anthropologist, and the overall process when one emergent and intermittent identity continuously informs the other (Noblit et al, 2004 p.166). As a Latin American and an immigrant myself, I find Mojado ethnography to be an ideal guide for selfreflecting about my own positionality when conducting research with Mexican immigrants in Toronto. Specially, I found Mojado ethnography to be very useful for understanding elements of social class and political exclusion when conducting participatory observation in community events. Also, in this regard, I found Thomas (1993) particularly helpful for learning how to do participatory observations.

I immigrated to Canada from Peru when I was seventeen years old and I have worked in community development with Latin American immigrants in Toronto before starting my PhD at Ryerson University. As a native Spanish speaker and fellow immigrant from Latin America living in Toronto I generally occupied a mixed position between an insider and outsider when it came to observing and participating in community activities organized by the research participants. It is important to point out, however, that I found that my interaction with research participants could also influence my position as a researcher. In meetings and events organized by the Red de Talentos Mexicanos, for instance, I was asked to share my opinion and to participate as one more member of the organization. In these meetings and events I socialized with academics and artists and found that my position as a researcher blurred significantly between an outside observer and an insider. Having said that, in most community activities, I occupied a middle position in which I could observe and also assist with certain activities but mainly as an invited guest. 
When it came to the study of Mexican emigration and Canadian Immigration policies my dissertation relied on critical policy analysis. Orsini and Smith (2007) describe critical policy analysis as "the desire to speak truth to power" (p.2), seeing the role of the policy analyst as a facilitator of democracy and social justice. They argue that the challenge of a policy analyst is not about adopting new theories but rather about engaging in the critical analysis of policies affecting people today in order to develop actual solutions that help improve people's lives. By utilizing critical ethnography and critical policy analysis my research was conducted with a critical lens, which provided balance to my ontological approach relying on the participants' perspective.

\section{Research Design}

My empirical research examined Mexican immigrants' collective and individual actions in defense or advancement of cultural, social, civic and political rights in Mexico and Canada. For this reason, the main unit of analysis of my investigation was the individual Mexican immigrant, most of which participated in Mexican social and cultural associations operating in Toronto. Most data gathered during my investigation was oral data.

Participants were recruited from various Mexican community organizations. These organizations met periodically in different locations. The list of Mexican community organizations and the contact information of their representative was publicly available online. I contacted the representatives of Mexican community organizations via e-mail to ask for an appointment and discuss the possibility for them to participate in the study. I have attached the recruitment e-mail in the appendix. When organizations 
accepted to participate I asked them to circulate the recruitment e-mail to their members. Also, when I was invited to Mexican community meetings I approached potential participants personally and asked them if they were willing to participate in the study.

I accepted references made by participants about other potential participants. Specifically, I used snowball recruitment method by asking participants to pass information about the study (brief study description attached in appendix) and my e-mail contact information to other potential participants. Those other potential participants contacted me directly when they chose to participate. I made it explicit that participants who referred others for participation did not have knowledge of their eventual decision.

After obtaining the participants' permission, I began conducting a participant observation study with Mexican community organizations in Toronto. I participated in a total on ten events over a twelve-month period between November 2013 and November 2014. These events included four Mexican cultural events, four social community meetings/gatherings, and two community information sessions. The participant observation study was supplemented by forty in-depth interviews with members of these organizations as well with other participants. The research was designed and conducted in a simultaneous process of data gathering, analysis and interpretation. Analyzing and interpreting the data while gathering allowed me to respond to interesting initial findings, and to make inferences of particular situations and observations while at the same time reflecting on the ongoing data collection process. My observations and interviews were oriented to understanding how members of these organizations and other participants utilized and were affected by Mexican emigration and Canadian immigration and citizenship policies in their overall process of civic engagement. 
During the year-long period of participant observation, I attended meetings, which I was invited by the participating organizations and that dealt primarily with issues relevant to my research. I made this explicit by explaining to participating organizations that while the duration of my research stretched for a year I was going to be present at events dealing with civic, social, and cultural engagement that I am exclusively invited to, and that they could ask me to leave the events at any time. Observing the annual cycle of community events allowed me to gain familiarity with how Mexican immigrants organize activities and engaged on issues related to social, cultural, and civic engagement. While I aimed to be a moderate participant, observing the process of community organizing and at the same time contributing to their events and meetings if participants asked for my opinion or suggestions. In some cases I was requested to provide assistance and I participated in Mexican community events as a volunteer.

I had access to interviewing key informants from the following organizations: Fundación Social y Cultural Mexicana, the Asociación Mexicana Canadiense, ENLACE, the Red de Talentos Mexicanos, and Consejo Consultivo del IME (CCIME). The rationale for choosing these community-based organizations was twofold: 1) their different membership reflects the socio-cultural and ethnic diversity of Mexican immigrants; and 2) despite their differences these organizations work conjointly to promote social and civic engagement. Criteria for inclusion of Mexican social and cultural associations was that the organizations be comprised of Mexican citizens living in Canada working in the areas of civic and/or social engagement with Mexican community on a voluntary/non for profit basis. For profit Mexican associations were excluded from the research. Individual participants included in the study were adult Mexican citizens with migratory status in 
Canada who were members of a Mexican social or cultural association and/or have been actively involved in social, civic, or political engagement in Canada/and or Mexico. Due to high level of vulnerability, undocumented migrants were not be part of the research, this was clearly stated to the participants. Also, Mexican immigrants who were not adults were excluded from the study.

Community events were selected based on the importance given to them by participating community members and their relevance to civic, social, and cultural engagement. Hand written notes were taken in order to compile a detailed description of community events, meetings, and activities. The data gathered was divided into five themes and was analysed by looking for patterns and topics that illustrated how the participants organized and worked on issues related to civic engagement. The following themes were developed based on the research questions and the literature review and they were operationalized by interview questions included in the appendix: 1) transnational acts of citizenship; 2) local civic engagement; 3) acts of solidarity; 4) barriers for civic engagement with Mexico and Canada; and 5) community organizing. I stopped gathering information after completion of the year-long observation period, when saturation was also reached.

In addition, interviews with key informants aimed to acquire an in-depth look at the avenues and strategies that Mexican migrants utilize to engage civically both with Mexico and Canada as well as their motivations and expectations in regards to their civic participation. Key informants were recommended by members of the participating organizations and selected based on: 1) their formal leadership role in community organizations; 2) their work in promoting civic engagement and /or solidarity in 
Canada/and or Mexico; and 3) their efforts to raise awareness on issues of social justice in Canada/and or Mexico. These considerations are relevant because they were conducive to covering areas of civic engagement and socio-civic solidarity that are important to the participants themselves, thus allowing development of a narrative reflective of the participants' own interests, concerns, and struggles.

Furthermore, in order to have sampling that was reflective of the socio-economic diversity of Mexican immigration in Canada, part of the key informant selection process was be based on the participants' migratory status, gender, and employment. Each interview lasted approximately one hour in length and, following consent from participants, they were audio-recorded. The interview followed a semi-structured format in order to provide some flexibility in addressing the research questions (included in appendix I). Interviews were conducted in Spanish, as it was the language of choice of all the interviewees, and it was divided into the themes contained in the interview guide. I translated quotes from the text that I used in the dissertation when needed. The number of interviews was determined through an ongoing process of assessing the information needed in order to reach data saturation (Francis, 2010). Interviewees were found at local events organized by Mexican organizations, and through snowball sampling facilitated by other research participants.

The data gathered from the interviews informed the critical ethnographic analysis, description and interpretation of the data. The analysis was conducted by coding the data (Strauss, 1987) in order to organize it and develop narratives from it. The coding chart is included in appendix II. Coding was informed by the data and by searching for patterned regularities in the utilization or lack of utilization of emigration and immigration policies, 
and of the effects or lack of effects of Mexican emigration and Canadian immigration and citizenship policies in promoting citizenship engagement. Descriptions of settings, events, and activities served to introduce some of the research findings and to present the context in which different forms of civic, cultural, and social engagement of Mexican immigrants in Canada and Mexico took place.

The interpretation of the data consisted of: 1) linking the findings to existing Mexican emigration policies respectively; 2) interpreting these links in light of the existing literature; 3) using critical theory perspectives (Habermas, 1998; 2001) to analyze and problematize issues of power relations and inequalities in citizenship rights in the context of North American migration; and 4) using existentialist and phenomenological principles (Ortega y Gasset, 1914; 1930; 1938; 1941) for the classification of distinct types of citizenship practices developed by Mexican immigrants in Canada.

The data that were analyzed and described, are used to inform: 1) the development of recommendations to Mexican emigration and citizenship policies implemented via El Instituto de Mexicanos en el Exterior and the Consejo de Consulta affecting Mexican immigrants in Canada; and 2) recommendations for the development of citizenship and immigration policies developed by the Department of Immigration, Refugee, and Citizenship Canada (IRCC) that affect Mexican immigrants in Canada. Also, the data analyzed and described resulted in recommendations and best practices for community development and transnational civic engagement. Policy recommendation and best practices were developed on inferences made on the data and from critical policy analysis. The combination of ethnographic investigations, critical policy analysis, and 
phenomenological and existentialist inquiry were ideal to both, helping to tell the story of how immigration and emigration policies are influencing and being utilized by Mexican immigrants in Canada as part of their struggle with civic engagement, and contributing to the development and implementation of emigration, immigration and citizenship policies. My methods for recruiting and conducting the field research received approval from the Research and Ethics Board at Ryerson University.

\section{Participants' Discomforts, Risks, and Potential Benefits}

While asking participants to share their experiences with civic engagement in Mexico and Canada could have provoked discomfort due to reflecting on past incidents and/or current situations, the probability of physical and psychological harm was no greater than those encountered in everyday activities since potential participants were invited to participate in the study largely based on their activities as community leaders, activists, or members of community organizations aiming to promote civic engagement, awareness on issues of public concern, and acts of solidarity. These activities implied a level of engagement that seems to be indicative of an openness to share their experiences and concerns as part of their activism. In this regard, participation in this study did not place the participants at a higher risk than they may usually take as part of their active community engagement.

In order to avoid potential discomforts due to reflecting on unpleasant memories, participants were informed and encouraged to take a break, not to answer a particular question, or discontinue participating if they so wished for any reason. Also, to protect the anonymity and particularly due to the political nature of the research, the identity of 
participants was kept private by providing them with pseudonyms. I received explicit permission to name the organizations that participated in the research. Lastly, while participants did not receive compensation in the form of payment, some of the potential benefits of the research for participants include: 1) the promotion of a better understanding of the participants' efforts and struggles with civic engagement; and 2) academic publications and policy briefings which can be utilize for the development of more effective, comprehensive, and humane emigration, immigration and citizenship policies that affect the participants directly.

\section{Field Research}

Prior to my field research, my exposure to participant observation and interviewing techniques prior to my field research was limited to doctoral courses on qualitative methods and methods books such as Angrosino (2007) and Rubin and Rubin (2012) respectively. My practical experience with interviewing techniques was mainly through my work as a research assistant in a project on academic labour migration under the supervision of Dr. Harald Bauder. I tried to complement my knowledge and experience of qualitative research methods in the context of migration by studying examples of qualitative research covered in the literature review section of this dissertation.

The participants' active engagement in acts of solidarity, philanthropy, activism, and community development among other forms of civic participation exposed their social concerns and civic values to members of the greater community. The public realm, however, has traditionally been a world of appearances where "everyone sees what you 
appear to be but few get to experience who you really are" (Machiavelli, 1532-1997 p120). Participatory observation and semi-structured interviews are suitable research methods to gather data on research subjects' activities, experiences, and ideas. But in order to go beyond the world of appearances, such methods need to be applied in the context of comfort and trust. While language fluency, cultural proficiency, and professionalism are imperative in conducting qualitative research, the development of a relationship and atmosphere of trust and comfort requires a sensibility and tact conducive for research participants to share their values and motivations informing their active participation on issues of public concern. Through my field experience I gained insights that helped me set up the right atmosphere for conducting semi-structured interviews and developing relationships for recruiting participants and engaging in participatory observations.

\section{Interviews}

Semi-structured interviews entail a set of questions, yet focusing on questions is distracting and not necessarily conducive to have straightforward answers. Participants talked more frankly when they felt they were listened to, by my showing them the interview questions at the beginning of the interview and not interrupting them. They often provided answers required in the research without the need of asking them questions in a set order. Also, memorizing the research questions and avoiding looking at notes helped keeping fluency during the interview.

To set the tone of the interview, I found it useful to introduce myself openly, telling participants my motivations for conducting the research, and when required I also 
shared with the participants my own experiences with migration, civic engagement, and work with Mexican immigrants. While each of the forty semi-structured interviews felt different, I found that a calming tone of voice and conducting the interview in formal Spanish helped participants answer questions in a straightforward manner. At the end of the interviews, I found that interviewees were more than willing to pass along my contact and information about the study to other potential research participants. This became an important source for getting research participants for my study.

\section{Observation}

The participatory observation component of my empirical study took into serious consideration the need to contribute back to the participants in ways that were useful to them, and I found that giving back to the community had a positive effect on my research experience. Participatory observation provides researchers with the opportunity to witness and take part in complex social processes but it is a research method that requires researchers to be invited and welcome at settings and events. Volunteering at events during my field research provided my observations with valuable insights at the complexities surrounding organizing social and cultural events. Also, volunteering helped me outreach for potential participants more effectively than when observing as an attendee. While the inability of taking notes when volunteering at an event could hinder the collection of valuable information, I found that by offering my help or accepting a request for help in an event contributed significantly to developing a relationship of trust and building future collaborations with participants. ${ }^{5}$ After finishing my research I have

\footnotetext{
${ }^{5}$ For more information on giving back to the community as part empirical research see: Abraham and
} 
kept supporting community events and doing presentations for some of the organizations that participated in my doctoral research, including doing radio presentations and public speaking. Lastly, in regards to note taking, volunteering is not conducive to taking notes but I found the use of mind-mapping and other simple forms of organizing information through diagrams to be a quick and effective way of connecting ideas after having volunteered in an event.

\section{Conclusion}

While the empirical context, research purpose, and methodologies I employed to investigate the citizenship practices of Mexican immigrants with Canada and Mexico were consistent throughout my research, some of the lessons I learned during my fieldwork had practical considerations. At the beginning of research, the working title of my dissertation was "Privilege, Marginality and Transnational Civic Engagement: An Ethnographic Study of Mexican Emigration and Canadian Immigration Policies”. The title was informed by the underlying consideration of racial, economic, and social class differences among Mexican immigrants in Toronto, which could potentially influence the reproduction of privilege and marginality in the context of migration. I commenced my field research under the assumption of finding significant differentiations on the way Mexican immigrants were civically engaged with Mexico and Canada, and on how they experienced citizenship rights and obligations, both in light of ethnicity, migration status, education, professional experience, networks of support, and income, among other socioeconomic considerations.

\footnotetext{
Purkayastha, (2012).
} 
Socio-economic considerations remained key for my empirical research but my original emphasis on socio-cultural structures and economic conditionings evolved into a more comprehensive view of Mexican immigrants' experiences as civic actors in Mexico and Canada in light of their individual and collective organizational capacity, cultural capital, and capabilities to overcome socio-economic barriers. This change was informed by the fact that the overwhelming majority of the participants were skilled and highly skilled professionals who had little experience with marginalization. The participation in and observation of events organized by Mexican cultural, social, and professional organizations in Toronto allowed me to appreciate a relative privileged social class dimension in the different visions and interests among "community actors" engaged in a multifaceted process of community formation. In addition, by listening to the participants' motivations for migration and experiences with civic engagement I became aware that the expansion of the participants' civic identity and citizenship practices was often intertwine with their middle class background. Accordingly, my research findings directed my dissertation into the realm of citizenship consciousness and class identity, providing an existential line of inquiry to the study of citizenship practices and community formation among Mexican immigrants.

The research experience I gained during my fieldwork with Mexican immigrants has had a significant influence on the way I understand the study of citizenship practices in the context of migration. While conducting semi-structured interviews with research subjects and engaging in participatory observation of meetings, events, and other community activities was anthropological in nature, the analysis and theorization of less tangible manifestations of civic consciousness compelled toward a philosophical line of 
inquiry to complement findings obtained from social scientific methods of investigation. Ideas of national identity and belonging are embedded in the realm of consciousness and memory, yet they inform the collective and individual participation of immigrants in issues of public concern. This realization opens a window to study the sensibilities and perspectives laying at the heart of the interconnection between civic thought and civic engagement.

The data collected and analyzed in my research led to in-depth explorations of the expansion of citizenship practices and citizenship rights in the context of migration. In this regard, the interrelations between philosophy and social sciences in the analysis of my research findings also taught me valuable lessons on how to conduct research with immigrant communities, particularly in light of the difficulties of gaining a balanced understanding from the research participants' different opinions of and experiences of community development and civic engagement. Overall, the methodological lessons I learned during my field research have been a key influence on how I now conceive both qualitative investigations of immigrant civic engagement, and the potential of Mexican immigration in Canada. In the following chapters of research findings, I present a detailed examination on the transnational citizenship identities and practices of Mexican immigrants in Canada. 


\section{Chapter IV}

\section{Transnational Citizenship and Middle Class Mexican Immigration in Toronto}

"When we turn to ourselves and we feel again the universe through our own sensibility, we see that the world defined by these philosophies were not indeed the world, but the horizon of their authors"

Jose Ortega y Gasset, El Tema de Nuestro Tiempo. [My own translation]

Citizenship practices are inherently biographical as they evolve in the concreteness of life experiences with the body polity and individual histories of exposure and interactions with national narratives, acts of commemoration, public memories, and political ideologies, among other influences. In the context of migration, the development of citizenship practices become increasingly multidimensional as migrants are also exposed to national narratives, socio-cultural values, and political discourses from immigrant receiving countries, potentially expanding immigrant's awareness of citizenship rights and responsibilities to a more multinational and plural-cultural milieu. Immigrants' citizenship practices develop in an ever-changing context of social and cultural intersectionalities where opportunities for civic engagement and personal growth are linked with immigrants' diverse socio-economic circumstances and capabilities.

In this chapter, I will present a comprehensive picture of how transnational citizenship develops in the context of Mexican middle class migration in Canada by looking into how the participants' social circumstances relate to their citizenship practices and identities. This chapter will be divided into three sections. First, I will provide brief overview of the participants' circumstances and capabilities. Second, based on the participants' experience, I will elaborate on the reasons for migration and the 
social circumstances faced by middle class families immigrating to Canada. Third, I will elaborate on the distinct types of transnational citizenship develop by the research participants in order to shed light on the expansion of citizenship in the context of Mexican middle class migration to Canada. In order to include a variety of voices, this chapter will highlight the perspectives and experiences of research participants who came to Canada in different social, economic, and personal circumstances.

\section{An Overview of Middle Class Mexican Immigrants in Toronto: Social Capital, Place of Origin, and Reasons for Migration}

My investigation about the transnational citizenship practices of Mexican immigrants in Canada is also an exploration of middle-class Mexican migration. With the exception of two participants who moved to Canada in the 1970s, the overwhelming majority or 95 percent of the participants identified themselves as coming from a middle class background in Mexico. As pointed out in the literature review however, defining the middle class can be challenging. Moreover, whether one defines the middle class based on household income (Ferrera, et. al. 2012, Homi, 2010) or occupation and education (Magazine, 2008, Parker, 1998, Vallejo, 2012, 2015) it seems that significant investment in social capital is one of the main hallmarks of the middle class (Banerjee and Duflo, 2008).

The social and human capital of the research participants was indeed notable. In terms of education, thirty-eight (95 percent) of the research participants had university degrees and twenty-one (55 percent) had graduate degrees from Canadian or American universities, including nine participants with PhDs. A significant number of the participants were entrepreneurs, as ten ( 25 percent) were business owners engaged 
mainly in import and export commercial activities. Also, six (15 percent) of the participants were professional artists, including one painter, four musicians, and one dramaturge. Socio-economically, their circumstances were relatively favorable, considering that more than half of the research participants have come to Canada only in the last ten years and just 10 percent of the participants had immigrated before the signing of NAFTA in 1994. In addition, most of the participants enjoyed job security and were very fluent in English.

In terms of places of origin, 67 percent of the participants were original from Mexico City, 15 percent from Monterrey, and 17.5 percent came from other large Mexican cities, including Tampico, Queretaro, and Coahuila. The participants were distinctly urban and not from traditional smaller and more rural states associated with Mexican emigration such as Guanajuato, Michoacán or Zacatecas (Goldring, 2012). In the United States, Mexican immigrants from large urban centres such as Mexico City and Monterrey tend to come from more affluent backgrounds than their rural counterparts (Hamilton, 2015). Also, large urban centres such as Mexico City have been the traditional bastions of the Mexican middle class (Capron, and Gonzales, 2010). Thus, the overwhelming urban origin of the participants seems to be indicative of a middle class Mexican migration.

Furthermore, the participants had ample experience with social, cultural and civic engagement. Among the participants' social engagement and civic contributions, musicians provided music lessons for free to children who cannot afford musical education and perform for free in various community events and fundraisings. Mexican scientists participated in mentorship programs, donated their time to promote community 
events, and engaged in political activism. Business people and entrepreneurs donated blood, worked with the blind, volunteered with people suffering of terminal illness and with the elderly, as well as provided bursaries to Mexican students, and worked closely with NGOs in Mexico supporting education programs. Max Weber's influential work on class stratification associated societal action to common class circumstances and middle class sensibilities indicative of traditional protestant ethics (Weber, 1920). Similarly, the Mexican middle class has been traditionally related to social engagement and civic values (Capron, and Gonzales, 2010). Arguably, the participants' social engagement and civic contributions reflect not only their social capital but also traditional middle class social sensitivities. In short, while ideas of the middle class are largely subjective based on the participants' high level of education, occupations, places of origin, civic engagement, and their own self-identification, they can be seem as part of a relatively recent migratory presence of urban Mexican middle-class professionals in Canada.

The participants' reasons for coming to Canada varied significantly depending of their marital status, career stage, personal aspirations and individual circumstances. Sixteen (40 percent) of the participants immigrated as permanent residents and of this group, ten were married and six of them had dependent children. The main motivation for most of the participants who immigrated with their partners and/or their children in this group was to look for a safer and more stable environment for raising a family. For the other eight participants in this group who were single at the time of their arrival, their main motivation to immigrate permanently to Canada was to further their careers, improve their academic credentials, and also to pursue a change in their lifestyles. 
Fourteen (35 percent) of the participants came to Canada originally as international students. In this group, only three were married and none had dependent children. Their main motive for moving to Canada was to pursue graduate education, improve their English skills, and in to a lesser extend explore the possibility to live and work in Canada permanently. Four (10 percent) of the participants moved to Canada originally through job relocation. In this group, only one of the participants was married at the time of his arrival to Canada. These four participants requested their transfer to Canada because they thought it was an attractive destination to work and to eventually live permanently. Two of the participants came as temporal residents through job contracts, one of the research participants came to Canada as a refugee, and one of the participants immigrated to Canada as a caregiver. Two of the total of forty research participants came to Canada when they were minors.

Grouping the research participants into different categories presents significant challenges, as the terminologies used to differentiate immigrants from one another can fail to capture some of the multidimensional factors involved in the participants' decision to migrate. For instance, most of the participants who arrived in Canada as permanent residents could be considered economic migrants, a common term use to differentiate people who immigrate in search of better economic opportunities and those who immigrate in search of refuge. While the term economic migrant may describe the case of single Mexican professionals whose reasons to immigrate were mainly career oriented, this term does not reflect the motivations of participants who immigrated with their families as permanent residents in response to the increasing lack of public safety in Mexico. Similarly, participants who were transferred to Canada by their companies could 
also be considered economic migrants or even expatriated professionals. Both of these terms however do not reflect the motivations of married participants who asked to be transferred to Canada not because of career-oriented goals but rather to live in a safer and more stable place in which to raise their children.

The concept of international student also fails to capture important differences between participants who did their MBAs and other professional degrees in Canada and those who did their PhDs. On the one hand, most of the participants who studied towards professional degrees pursue their education in Canadian universities because they seriously considered living in Canada permanently. On the other hand, most of the participants who came to Canada to do their $\mathrm{PhDs}$ took this decision based on academic reasons and decided to live permanently in Canada only after living in the country for a number of years. This is an important difference if we also take into consideration that participants who pursued professional degrees relied heavily on their own savings in order to study, while Mexican PhD students had access to funding from both Mexico and Canada. In other words, while studying professional degrees in Canada can be considered an immigration strategy that requires significant financial investment, pursuing a doctoral degree in Canadian universities is almost exclusively an academic endeavour. The only exception in this regard is the case of a Mexican researcher whose decision to pursue a $\mathrm{PhD}$ in Canada was also heavily influenced by the prospect to immigrate to Canada with his wife.

To sum up, the research participants' motivations for migrating are multidimensional and spread across different immigrant categories. Also, while the participants came from privileged social backgrounds and enjoyed considerable social 
capital, there are significant differences in the motivations to immigrate between middle class professionals who came to Canada with their families and those who immigrated when they were single. Such a difference underscores the importance to understand the circumstances pushing middle class families to immigrate as well as the specific factors motivating single Mexican professionals to leave Mexico for Canada.

\section{Mexican Middle Class Families: Fleeing Violence, Overcoming Challenges and Contributing to the Community}

Fleeing Violence

Most of the participants who moved to Canada as a family identified the increasing levels of criminality in Mexico as their major reason to immigrate. This was especially relevant for couples with children. Daniela is one of the participants who immigrated with her husband and children because of the lack of public of safety in Mexico City. She explains:

We had a confortable life in Mexico, so coming to Canada was a bit of an adventure from an economic perspective but we were seeing that the problem with violence was growing everyday. I am talking about the years around 1999 when there started to be an increase of express kidnappings (secuestro express). The lack of security was growing. The son of my closest friends was kidnaped outside a nightclub and most of my friends were afraid something like that may happen to their own sons and daughters. I was becoming concerned, my kids were young but I was worried that I was going to experience the same level of anxiety my friends did when my own kids grew up. We applied to Australia and Canada to immigrate and we were accepted in both countries. We decided to come to Canada because Australia was too far.

Daniela's socio economic circumstances were confortable in Mexico and she feared the rising numbers of kidnappings and overall crime would eventually affect her family. Daniela's fear of abduction is indicative of her privileged economic position but 
also reflects the dramatic deterioration of public safety in Mexico. In 1999, the year

Daniela immigrated to Canada, there were a total of 591 kidnappings reported in Mexico while in 2012 the number of reported kidnappings had increased almost 500 percent to a total number of 2,756 (Sistema Nacional de Seguridad Pública, 2012). Daniela's fear of possible abduction and being victims of organized crime pushed her and her family to immigrate to Canada, a feeling that was also shared by the other participants who immigrated with their children.

Moreover, participants' concerns about public safety also included gun violence and robberies. Fabio moved to Toronto from Mexico City in 2012 with his family after receiving a job offer in his field. He talks about his experiences with lack of public safety and the reasons why he immigrated to Canada with his family.

There were too many social problems in Mexico, and above all was the lack of safety. My relatives and family had been victims of crimes. Once, my wife and I went out with the children and we were caught in the middle of a fire crossing. It was just too much. In 2010 I went to Vancouver to visit a friend of mine who works in the same area as I do. I explained to my friend my increasing concerns about living in Mexico and eventually he helped me to get a job offer in the company he worked but here in the Toronto offices. I had never been to Toronto but moving to Canada with a job offer was great opportunity, I would have not immigrated without having a secured job here first. I decided to accept the job and I am very glad I did because I don't think the social conditions in Mexico are going to improve for many years. It is not a place where you could peacefully raised a family.

Like Daniela, Fabio's main motivation for moving to Canada with his family was the increasing level of criminality in Mexico City. Having said that, Fabio's decision to immigrate to Canada only when he had received a job offer in his field also suggests significant career considerations for moving to Canada.

For other Mexican couples, however, getting away from Mexico's increasing criminality was more important than their career or businesses prospects. Xavier and his 
husband had an advertising and publishing business in Torreon, Coahuila. He explains how his husband and him had to sale their business and moved to Canada because of fears of being victims of violent crimes.

We had a very successful business in Torreon, Coahuila where we employed fifteen people. We had experienced many security incidents but one day we received the news that the husband of one of our employees had been kidnapped. Three days later he was found dead. After that incident my husband and I decided to sale the business, we really thought we could be next. For some time we contemplated the possibility of moving to Mexico City, which is much safer than living in Coahuila, but since my husband is a Canadian citizen and he has many relatives who live here we decided to move to Canada.

Xavier's increasing concerns of being a potential victim of violent crimes is indicative of the harsh social condition in northern Mexico. During Mexico's self-declared war on drug cartels, Xavier's home state of Coahuila experienced a significant rise of murder rates. Between 2008 and 2013 there were over 3,000 violent homicides in Coahuila, which forced thousands of families to abandon their homes (El Universal, August 8, 2015). Clearly for Xavier, moving to Canada and living the rampant criminality of Coahuila behind him outweighed any lucrative business he could enjoy in his hometown.

Xavier's example also reveals some of the nuances surrounding the migratory movement of Mexican middle class families. Xavier's story suggests that Mexico City was also a possible refuge for people wanting to escape increasing violence in northern Mexico. By 2011, the year when Xavier moved to Canada, about 230,000 people were been displaced in Mexico because of drug violence but during that time Mexico City was not as affected by violent crimes as was the rest of the country (Toronto Star, March 26, 2011). This is an interesting detail since 67 percent of the participants in this study came from Mexico City and most of them identified the increasing level of violence to be one of their main reasons for moving to Canada. In other words, most of the participants in 
this study came from a city that is considerably safer than many other large urban areas in Mexico affected by rampant violence and organized crime. Another interesting detail is the fact that Xavier was married to a Canadian citizen. Five (12.5 percent) of the research participants immigrated to Canada because their spouses were Canadians. In this regard, the migratory movement of middle class Mexican families to Canada also takes place in context of the return migration of Canadian citizens who used to live in Mexico.

The cases of Daniela, Fabio, and Xavier show how increasing levels of criminality in Mexico pushes Mexican middle class families to immigrate to Canada and also reveal the fortunate socio-economic circumstances of Mexican middle class migration. Immigrant families need access to significant social capital to qualify for permanent residency through the point system like Daniela and secure a job through personal connections in order to migrate like Fabio. Also, being married to a Canadian citizen like Xavier is a significant advantage to immigrate. Overall, these circumstances were not uncommon among the participants who immigrated with their families as permanent residents.

The fortunate socio-economic circumstances enjoyed by middle class Mexican families immigrating to Canada are desirable features in an increasing neoliberal immigration policy regime that tends to prioritize adaptability to the labour market and self-sufficiency above family reunification, humanitarian concerns, and nation-building considerations (Root, et al, 2014, p16). Thus, the increasing neoliberalization of Canadian immigration policies has not had a direct negative effect on middle class Mexican immigrant families possessing significant social capital. The introduction of neoliberal policies in Mexico, however, has been one of the main contributors to the dramatic 
increase in violence experience in the country (Haynes, 2000; Watt and Zepeda 2012), which coincidently is the main push factor for Mexican middle class families to immigrate to Canada. The decline of traditional farming and national industries since the signing of NAFTA provided the ideal conditions for Mexican drug cartels to increase their marihuana plantations and to expand their operations in cities economically deprived (Watt and Zepeda, 2012). Mexican middle class families have been able to escape the escalating violence in Mexico in a relative confortable position but their significant access to social capital and permanent immigration status in Canada contrast sharply to the precarious social and economic circumstances experienced by less privileged Mexican families also escaping the negative consequences of neoliberalism such as the case of Mexican refugees, undocumented migrants, and temporal agricultural workers in Canada. In this regard, the presence of Mexican families in Toronto is also indicative of the transnational expansion of inequality in the context of Mexican immigration.

\section{Overcoming Challenges and Contributing to the Community}

There was only one participant who came to Canada as a refugee but her case provides valuable insight on the circumstances faced by less privileged Mexican middle class professionals immigrating to Canada. Almudena was a public administrator who worked for the Mexican Federal Government in Chiapas. She enjoyed a relatively confortable life in Mexico but she had to leave her country because she feared for her life and for her family's safety. Unlike, Daniela, Fabio, and Xavier, Almudena did not enjoy economic security when she arrived to Canada, she was not able to work in her 
profession, and she did not reunite with her husband for a significant period of time. She explains how she moved to Canada in 1996 as an asylum seeker.

I used to work in rural Chiapas during a very complicated time. We provided services to the rural communities and I worked with indigenous women. Politically, Chiapas was very divided and in my work we were to help only women who supported the government's party, the PRI. I was a public servant and also a member of the PRI but I felt confident enough in my work to provide services to women irrespective of their political affiliations. This situation eventually became a problem for those who used the denial of essential services as blackmail for political support. The situation escalated to a point that I had not predicted and I had to leave the country. At that time, I was pregnant with my third child and I had to leave my husband behind. He joined me later.

Neither Almudena's professional expertise nor her middle class background made a significant difference in her initial migration experience, which was marked by family separation and significant economic struggles. Almudena's case reveals some of the difficulties experienced by Mexican refugees, which contrast sharply to the relative security enjoyed by most of the other research participants. In this regard, the migratory movement of Mexican middle class families is characterized not only by access to significant social capital but also by the reproduction of social class privileges in the context of migration.

Precarious socio-economic circumstances had a significant effect on Almudena's social, personal, and professional life but they did not determine her personal development nor limited her to a life in Canada in social and economic marginality. For instance, due largely to the precarious circumstances in which Almudena came to Canada she was not able to practice her profession. In addition, her marriage was affected by the overall migration experience, and she eventually divorced from her husband. Despite facing significant personal and socio-economic challenges, however, Almudena has been 
able to buy a house, have a stable job and provide a relatively confortable life for her children in Canada.

Also, Almudena has a long history of helping people in need and she has volunteered for more than ten years with immigrant seniors. She explains: "I help seniors when they are sick or they need support at home. Most of the seniors I help are Hispanic, Portuguese, and Italian. Most of them are widows and they really need company. They are immigrants who have grown old here and I can relate to their need for company and support.” Clearly, Almudena's immigration experience has made her sensitive to the needs of other immigrants, especially those who are in a fragile stage of their lives.

It is also noteworthy that Almudena has been able to pass on her values of solidarity to her children. She explains:

Every time there is big natural disaster in Mexico I try to mobilize people from my church to send donations. I always involved my children on these activities because I want them to learn that they can make a difference, they can help others in time of need. And I want my children to realize how fortunate they are to live in peace and enjoy their lives here while in Mexico there are many young people who do not have those luxuries.

Almudena's words are indicative of a deep commitment to altruistic causes and of solidarity with her country of origin, values that she has been able to incorporate in her family dynamics in Canada. Almudena has been able to overcome some of the socio economic barriers she faced when she came to Canada and she has managed to contribute to causes she feels strongly about. Almudena's example is also revealing since thirteen other participants are quite active in sending donations to Mexico in time of natural disasters as well as five other participants volunteer with their church. Also, another similarity is the fact that she separated from her husband after immigrating to since four 
out of the fifteen participants who immigrated to Canada with their partners disclosed they had eventually separated.

It is not uncommon for immigrant families in Canada to experience significant challenges as part of the settlement process (Edmonson and Lee, 2013) and like Almudena other research participants' experienced serious strains in their family relations. For instance, Nuria is a journalist and an entrepreneur who immigrated to Canada in 2005 with her husband and two daughters. Nuria and her husband's decided to move to Canada in order to provide their daughters with a more sophisticated education and a safer environment but this decision also affected their relationship. She explains:

We thought moving to Canada for some years would be a great experience for our daughters. They could learn English, get exposed to different cultures, and also Canada is very safe in compared to Mexico or the U.S. We came as permanent residents, which implied a significant commitment of resources and time, but our plan as a family was to return to Mexico in a number of years... You cannot really predict what the future departs you. My husband and I have divorced and I am here in Canada with my daughters.

For Nuria, moving the family to Canada was an important decision and a significant investment of time and money and after her divorce she decided not to go back to Mexico. Since that time, Nuria has been able to work as an independent journalist and she currently owns her own business. Also, Nuria spends a significant amount of time and resources being politically and socially active.

As a journalist, she has used newspapers and radio shows as platforms to raise awareness about the deportation of Mexican migrants. Also Nuria helped organized a community response for the imposition of a visa for Mexican citizens in 2009, she explains: "It was important that the Canadian government felt there was a Mexican community in Canada that was critical of what they were doing, so I wrote newspaper 
articles and used the radio show to denounce the imposition of the visa and the increasing deportations, and others did the same, we signed petitions, and we mobilized." Nuria's commitment with the Mexican community also includes supporting Mexican social and cultural activities in Toronto, including organizing public concerts and free cultural events. The organization of cultural activities was also shared by ten ( 25 percent) of the participants, which reflects the importance of culture for middle class Mexican immigrants. Nuria also mentioned that while the Mexican community has supported her cultural activities in Toronto, she has not received any support from the Mexican consulate.

Moreover, unlike most of the participants, Nuria has also become interested in promoting closer ties with Mexican agricultural workers. She explains:

I was invited to a community event organized with Mexican agricultural workers in Southern Ontario and I was so surprised when I met them. They had a proposition for me to do a radio show in which they could talk about their concerns, and share ideas and information. We started the project and it was a hit. Mexicans in Toronto tend to have great misconceptions about Mexican agricultural workers. People in the Mexican community here ignore that many Mexican agricultural workers have been coming to Canada for more than fifteen years, some are university educated, and they are well organized. They are Mexican immigrants too, we are the same but I feel many Mexicans in Toronto are still reluctant to see them in that way. I am proud of Mexican agricultural workers and every time I pick a tomato from Ontario in the supermarket I know a Mexican farmer has harvested it. My work with them has been by far the most fulfilling.

Nuria's comments reveal a disconnection between the Mexican community in Toronto and Mexican agricultural workers in southern Ontario. Also, her comments suggest a sense of elitism by members of the Mexican community in Toronto who would rather prefer to see Mexican agricultural workers as a separate group. 
Promoting cultural events was facilitated by the significant number of Mexican artists willing to collaborate in community activities. 15 percent the research participants were professional artists and two of them immigrated to Toronto with their families. Felisa, for example, is a psychologist and a singer who moved to Canada with her husband and her daughter as temporary residents in 2011. In Mexico, Felisa had a very active social and cultural engagement and when she moved to Canada she continued with her cultural activities by participating in a number of Latin American associations by performing in community events and fundraising for noble causes. For Felisa, performing and playing music has helped her to socialize with like-minded people and to find her place in Toronto. She explains:

I am a forty something year old woman and it is not easy to reinvent oneself at this age. I am trying to earn a place here as a performer doing what I am good at. As an artist in Mexico, I was very involved in human rights activism and supporting efforts against the homicide of women and the improvement of living conditions of incarcerated women and men (feminicidio). Here I am also trying to do my fare share by supporting different NGOs working with women and Latin American immigrants.

Felisa has received awards in Mexico for her activism and her work as an artist but in Canada she is virtually unknown, which has been challenging. She explains: "In Mexico I felt I had a place, which I have earned through many years of hard work but here I have to start from zero and it is more difficult because I feel my English is not at the level where I can express myself fully as an artist." Besides the language barriers Felisa also sees other difficulties to work as a professional in Canada. She explains, I am a psychologist with many years of professional experience in Mexico but in order to practice psychology here I would have to go back to school. Yes, my studies are recognized here but in reality to become an associate psychologist, a counsellor, or to work in anything that deals with psychology I will have to go back to school, which is very expensive if you are not a permanent resident, and until recently I only had a temporary residence. My husband is French and he 
received a job offer to work here in Canada and we decided as a family to try something new in this country. But my husband was the only breadwinner when we came here and it was very difficult for me because I have worked as a professional. I am lucky that I am also a musician and I have focused on that aspect of my life since I came here but now that I have become a permanent resident I am looking to go back to school and get the necessary accreditations to practice counselling.

Fortunately for Felisa, her skills as a musician have allowed her to express her creativity and also earn some money on the side.

Moreover, not all Mexican artists have the possibility to develop artistically in Canada. The example of Jordan provides an interesting insight of how Mexican artists also have to give up their artistic professions in Canada. Jordan was a well recognized theater actor, director, theater instructor, and playwright in Mexico who came to Canada with his wife, a Canadian citizen, in 1998. He explains:

I met my wife in 1994 in a theater festival here in Toronto and after I returned to Mexico we had a long distance relationship for a while. She moved to Mexico City to be with me and we lived and worked there for two years. After that time, my wife wanted to come back to Canada to continue her career here and I liked the idea. We were supposed to live in Canada only for two years but we have been living here for sixteen... When I came here I was able to do some theater but it is very difficult to make a living as a theater actor in Canada and even more difficult if you are an immigrant. I remember, the Mexican consulate expected me to donate my time when they wanted to do some cultural activities, which you cannot always do because it takes a lot effort to do a theater piece. As an immigrant you do not have much support. So, eventually I started working as a teacher and I acted very seldom.

Clearly, Jordan immigrated to Canada to support his wife's decision to return to her country but as an artist he has not been able to practice his profession.

While in Canada Jordan has not been able to actively pursue an artistic career, he has nonetheless tried to be very politically active. He explains: "I follow the local, provincial, and federal politics and I always vote. Also, I have worked with the political party I support by filming political events for free and by participating and also filming 
protests, marches, and other events." Interestingly, while Jordan is politically active in Canada he has neither engaged in political activism with the Mexican community nor been involved in Mexican politics since he moved to Canada. He explains:

I had to cut ties with the political scene in Mexico because it was just too painful to be reminded that I was not there. I was very politically engaged in Mexico and my theater was political. I wanted to be there to see when the PRI lost power, I wanted to be there when there were protests against human rights violations. Here, I ride my bicycle everywhere, I collect rain to water my backyard, I always vote, I protest, and I am politically involved but the feeling to be away from Mexico politically has been hard to deal with.

Jordan's disconnection with Mexican politics and with theater has been a serious personal challenge. For this reason, after eighteen years of living in Canada he decided to return to Mexico. He is currently living in Mexico City and has retaken his work in theater production, teaching, and directing. As before, his theater is very political. $\mathrm{He}$ explains:

In Mexico I am staging plays that explore the colonial origins of racism, xenophobia, and machismo. These are historical issues but they are still very relevant. Racism in Mexico is very orthodox because it is rooted in deep colonial attitudes that have been methodically passed on through generations of poorly educated people and through the socialization of privileged families. Of course some things have changed. In Mexico City gay marriage is legal, people cycle and they are more environmentally conscious but white skin privilege is still huge.

Jordan is a socially and politically conscious artist whose long immigration experience in Canada and his eventual return to Mexico reveal the important role of fulfilling one's vocation. In this regard, Jordan's experience reveals some of the more personal and existential aspects of migration. His lack of participation in Mexican politics for eighteen years went hand in hand with his lack of involvement in theater, revealing a close interconnection between citizenship practices and one's personal circumstances. 
In conclusion, middle class Mexican families immigrating to Canada enjoy different degrees of economic privilege and social capital. Accordingly, middle class families from Mexico use different avenues to immigrate such as the point system, job offers, work relocation, or being sponsored by their spouses who are Canadian citizens. A common push factor among the participants with children was Mexico's rising rates of violent crimes. This is significant since violent crimes in Mexico City, where most participants came from, is relatively low compared to other parts of the country. Also, participants who came with their spouses and/or children tended to be socially engaged and involved is supporting Mexican community activities. Having said that, there is evidence of exclusion of Mexican immigrants who may not fit the profile of Mexican middle class immigrants such as the case of Mexican agricultural workers.

Middle class Mexican families represent a desirable type of immigrants in contrast to refugees who are portrayed as taking advantage of the system (Root,et al., 2014). Emphasis on self-sufficiency and rapid insertion to the market economy may benefit middle class families with significant social capital but it also further institutionalizes the disregard of non-financially remunerated jobs such as traditional women's contributions to the family (Arat-Koç, 1999 p.2012). The masculinization of immigration embodied in the ethos of self-sufficiency is therefore a doubled-edge sword, which on the one-hand benefits privileged immigrant families but at the same time disadvantages immigrant women. This is particularly relevant for immigrant mothers since they could end up raising their children on their own, as it was the case of some of the research participants. 
Ideationally, social class and citizenship are conflicting concepts, as the former emphasizes class distinctions in a society while the latter rests on the principle of equality among citizens (Marshal, 1962). For this reason, it is important to analyze how citizenship practices intersect in the context of Mexican middle-class migration. As pointed out in the literature review, my dissertation conceptualizes transnational citizenship holistically, as a system of rights and a form of citizenship identity and citizenship practices in the context of migration. The next section will show how Mexican middle class immigrants develop various transnational citizenship practices and identities. This section will complement the part on middle class families by showcasing the experiences of participants who came to Canada when they were single.

\section{Types of Transnational Citizenship in the Context of Mexican Middle Class Migration}

I have identified four different types of transnational citizenship identities and practices developed among the research participants. Four of the participants developed a cosmopolitan citizenship identity, eight of the participants saw themselves as Latin Americans and were civically engaged with Latin American associations, ten of the participants perceived themselves as Mexican- Canadians, and four of the participants developed a pluri-cultural citizenship identity.

Interestingly, ten ( 25 percent) of the participants were civically engaged but they did not develop a particular form of citizenship identity in the context of migration and identify themselves only as Mexicans. Most of these participants have lived in the country less than five years while most of the participants who had developed a distinct transnational citizenship practice and identity have lived in Canada for a significantly 
longer period of time. This difference suggest that time is an important consideration for the development of citizenship identities and practices in the context of migration. Also, as it will be illustrated, specific forms of citizenship practices require considerable resources and social relations. I have selected specific examples in order to provide an indepth explanation of the development of these four citizenship practices and identities.

\section{Cosmopolitan Citizenship Practices and Identity}

Cosmopolitanism, the belief in a common humanity and values rather than the identification with a nation-state, has been traditionally related to social elites and bourgeois culture. Based on my research, I found that in the context of migration the development of cosmopolitan citizenship is indicative of privileged social upbringing, deep personal values, and rich cultural experiences. John and Matthew are Mexican immigrants who have developed a cosmopolitan citizenship identity. Their examples will shed light on how the development of a cosmopolitan citizenship in the context of migration is influenced by immigrants' social class and their dynamic and diverse biographies.

John is an architect who arrived in Canada in 2012. He is part of a new wave of young Mexican professionals moving to Canada looking for new career opportunities and personal development. John has a long history of environmental activism in his native Monterrey (Mexico) where he actively promoted environmental conservation and sustainable means of transportation such as cycling. John is non-religious and he is an active member of an association promoting values of secularism and scientific reasoning in Toronto. John's civic engagement in Toronto includes activism in environmental 
conservation, developing awareness of secular thought, and promoting cycling as an alternative means of transportation.

John is more than willing to support Mexican community activities but he does not feel inclined to be an active member of any emigrant community. On this point, John explains:

I never felt a hundred percent Mexican. Mexican culture is impressive and Mexico can be a nice place to live but I was looking to develop my life in a more cosmopolitan and international environment, which is one the reasons why I moved to Toronto. Now, I feel more at home here [in Toronto] than in Monterrey.

Toronto's multicultural environment is a big attraction for John because it allows him to socialize with people from different parts of the world with whom he shares similar interests and values. Also, John has found other Mexicans living in Toronto who share his interests. He explains: "In Toronto, I am developing friendships with many likeminded Mexicans and other Latin Americans. I invite them to the activities I am involved in, so socializing is not just about partying but also a way to contribute to the place where we live." Moreover, John's civic engagement in Canada does not exclude his participation on issues of public concern with Mexico as he has managed to keep in touch with Mexican fellow environmental activists. John explains: "I am still a board member of an environmental organization I co-founded in Monterrey. I try as much as can to attend the meetings via Skype and I share with them the environmental practices and knowhow I learn in Toronto.”

Matthew is from Mexico City and he arrived in Canada in the late 1990s with only nine hundred dollars in his pocket. At the time Mathew came to Canada he was a young professional and while his family supported his decision to immigrate he could not 
count on their financial support. Matthew started working in a café and eventually went on to finish a Masters degree. Mathew's migration experience has been a major contributor to developing a cosmopolitan consciousness. He explains, "I see my migration experience as a journey of constant learning and cultural exposure. In a city like Toronto you meet people from all over the world, that allows you to build multicultural relationships and see our common humanity irrespective of cultural differences."

Matthew's cosmopolitan identity evolved over time. For many years Mathew saw himself primarily as Mexican and felt a strong calling to live in Mexico and work for his country's development. After finishing graduate school and gaining Canadian working experience, Mathew eventually went back to Mexico and worked for the government but his experience did not meet his expectations. Mathew explains: "Corruption, racism, inequality are so widespread in the Mexican government that I realized that there was little I could do as a public servant. It was a reality check." Matthew decided to come back to Canada and pursue a career in the private sector. Currently, Mathew is a private banker and due to his job he spends ten days a month in Mexico City, which allows him to support a local NGO in the Mexican capital. Also, in Toronto he is involved with members of the Mexican community trying to raise the profile of Mexican professionals, "the stereotype of Mexicans here is far from being that of a well educated and competent professional, and our goal is to change negative perceptions."

After living for many years in Canada, Mathew has come to see himself as a cosmopolitan citizen. He explains: "I am very proud of being Canadian and Mexican, and I am also very proud of my Lebanese roots but I define myself more as a globalized 
cosmopolitan citizen than with any nation-state or culture in particular". Matthew is married and he is also a father and his cosmopolitan civic consciousness has become a core family value. He explains: "I want my children to be cosmopolitan, to be openminded and accept people from different parts of the world. I want them to grow up with people with different cultures, race, and religions, so in the future they can move anywhere in the world." Furthermore, Matthew sincerely wants that the same rights and privileges enjoyed by his children to also be enjoyed by children living in less favourable circumstance. For this reason, Mathew has become critical of many governments' "unwillingness to denounce human rights abuses against children in places like Palestine." In the future, Mathew sees himself being more involved in Canadian politics. He explains, "I am always being a very political person and once I am more established I would like to contribute to politics in Canada."

John and Matthew's cosmopolitan consciousness illustrates how the development of citizenship consciousness and engagement in the context of migration is rooted in immigrants' dynamic and diverse biographies. While John and Mathew are relatively young Mexican professionals and share a cosmopolitan citizenship identity, their civic practices differ significantly and they are indicative of their diverse personal histories and interests. Matthew's commitment to the professional development of Mexicans abroad is unrelated to John's active promotion of secular values, and John's reduction of his environmental footprint by cycling everyday to work is very distant from Matthew's lifestyle of constant air travelling. John and Matthew's cosmopolitan consciousness is not indicative of their shared social concerns, interests, or political values but rather of their shared belief in a common humanity. 
Also, there is a social class dimension to John and Mathew's cosmopolitan citizenship. Both John and Mathew went to private schools, were exposed to different cultures in Mexico, and they had the opportunity to travel abroad before coming to Canada. In addition, John and Matthew learned English fluently in Mexico and both arrived as permanent residents. John and Mathews' social class background, rich cultural experiences, language expertise, and immigration status was also shared by two other participants who developed a cosmopolitan citizenship identity. Unlike Mathew and John, these other two participants came to Canada with their partners but their similar privileged and culturally rich social upbringing can also help to explain their inclination to identify themselves as citizens of the world. Thus, there seems to be a correlation between the development of cosmopolitan citizenship and a relatively privileged upbringing. In short, the concrete actions by which John and Mathew express their cosmopolitan citizenship and their detachment from a single national culture are diverse and indicative of their own complex and privileged biographies.

\section{Latin American Citizenship Practices and Identity}

In the context of migration, a Latin American community is an evolving concept constructed through concrete individual and communal efforts in light of diverse interests and vantage points of migration and identity. Eight Mexican immigrants taking part of this study developed what I refer to as a Latin American citizenship identity, by which they see themselves not only as Mexicans but also as members of a larger cultural and linguistic Latin American community in Toronto. Most of these participants were business professionals who participated in Latin American institutions, and shared spaces 
for social interaction. The examples of Dorothy and Mary show how middle class Mexican professionals develop a Latin American identity and contribute to the formation of a middle class Latin American community

After graduating as an engineer from Monterrey's Technological University, Dorothy came to Toronto in 1999 to study English and to look for professional opportunities in the Canadian market. Dorothy went back to Mexico to work as an engineer and in 2001 arrived again in Canada, this time as a permanent resident. In Mexico, Dorothy was not very civically engaged but in Canada she became a more active citizen, following Mexican politics, and contributing to Mexican community activities. Through her civic engagement, community activities, and business practices Dorothy has developed a more Latin American civic consciousness. She explains: "Something wonderful that my experience in Canada has given me is that I came here as a Mexican but then I became a Latin American, I feel that in my heart."

Dorothy's Latin American consciousness has translated in concrete civic actions and long-term commitments. She is an active member of Latin American and immigrantbased associations as well as in a non-for profit organization. For instance, Dorothy is a founding member of an important not-for-profit Hispanic organization promoting commerce and she also sits on the board of directors of one of the largest organizations serving immigrants in the GTA, in which she advocates for Latin American immigrants.

Also, Dorothy has become an active supporter of business, diplomatic relations, and community events promoting Canada-Latin American relations. Moreover, according to Dorothy, despite significant community efforts, "Latin Americans are still a small part of the Canadian mosaic" and there is a long way to go for Latin Americans to be a more 
established and recognized community. Dorothy explains: "there is still much ignorance in Canada about Mexico and Latin America in general, as well as too many unfounded stereotypes." Dorothy supports networking events where Latin American professionals can get to know one another as well as professionals from outside the community. She believes that supporting professional organizations and promoting large community events to be an important aspect of developing a Latin American community that can eventually have a bigger impact on Canadian society.

Mary came to Toronto in 2001 to study English and moved permanently to Canada in 2003. In Canada, Mary changed the way she perceived herself civically. She explains: "When I arrived to Canada, I did not know I was a Latina, I thought I was only Mexican." In Canada, Mary became more acquainted with other Latin Americans than she has had in Mexico and she realized that, "there were much more similarities than differences between Mexicans and other Latin Americans." Also, Mary became critical of the lack of balance in the way Latin Americans were portrayed in Toronto. She explains: "At the time, people just focused on the level of High school drop-outs and not on the many Latin American families that invested considerable time and effort in their children's education."

Mary started an MBA program and funded a group in the university to raise awareness about business opportunities between Canada and Latin America. She explains: "people did not know much about Latin America and I wanted to show that there were many opportunities to explore." After she graduated, Mary went on to cofound a Latin American MBA Association that supports Latin American businesspersons in Canada. Mary explains that in that organization members are executives from different 
banks and corporations who "work together for a common cause." Mary takes her experience in the corporate world and puts it into practice in her community work supporting Latin Americans in Toronto trying to succeed in the business sector. Mary explains:

When you come here people don't know who you are, you don't come from a Canadian family with a network in this city. You need to build a network and expose yourself for people to notice you. As a community, we also need to improve the way we brand ourselves and how we establish networks of support.

Also, in Mexico, Mary was not civically engaged but she has become much involved in supporting of Mexican immigrants in Toronto. Mary community engagement aims to promote community integration among Mexicans in Toronto and she explains that:

... most Mexican immigrants in Toronto are well educated and self-relying in terms of covering their basic needs and for that reason it is not easy to really engage them, many Mexicans don't even look for services in Spanish sometimes. This can be perceived as indifference.

Despite the difficulties, Mary helps promote Mexican traditions and cultural activities and tries to make a difference with Mexicans living abroad. Also, through her work Mary has visited Mexican communities in Calgary, Montreal, Vancouver, and in Toronto where she often tries to support community activities.

Dorothy and Marys' civic engagement largely consists on donating their time and expertise to Latin American organizations, using their professional connections to support upcoming Latin American professionals, and sponsoring community events. Such a form of community engagement is not connected with Latin American community centers, which traditionally have provided services to working class Latin American families, including refugees, as well as the most marginalized members of the Latin 
American community. Rather, Dorothy and Mary's vision of community is closer to a new range of non-for-profit professional organizations such as the Hispanic Chamber of Commerce, Latin American MBAs Alumni Network (LAMBA), Latin American Project Management Association, and the Canadian Council for the Americas (CCA) among others, which provide spaces for Latin American businesspersons to interact with each other and with people interested in doing business in Latin America. The other six participants who developed a Latin American citizenship identity were also selfidentified middle class Mexicans who participated in these business-oriented institutions. Thus, the adoption of a Latin American identity in the context of Mexican middle class migration to Canada seems to be strongly related to community-based business associations.

Similarly, Vallejo (2012) connects the rise of Mexican-American middle class community with the development of professional and business associations. Similarly, professional interests and community development are not mutually exclusive but rather complementary from the viewpoint of middle class professionals like Mary and Dorothy who try to build their careers, engage in business with Latin America, and/or providing services to Latin Americans in Canada. Professional associations, chambers of commerce, and other non-for profit organizations supporting Latin American business initiatives thus become important building blocks in the development of an entrepreneurial and commercially vibrant immigrant community.

In short, Dorothy and Mary are businesswomen and their vantage point of migration and community is indicative of their business interests and expertise, which is also shared by other middle class Latin Americans businesspersons and professionals. 
Arguably, their subjective vision of a Latin American community in Toronto helps build an emerging community reality forged by the organized and institutionalized efforts of Latin American entrepreneurs and businesspersons to support each other and to raise the profile of the Latin American community.

\section{Mexican-Canadian Citizenship Practices and Identity}

I define Mexican-Canadian identity as the citizenship identification and active participation with both the Canadian and the Mexican polity. Based on my research, a Mexican-Canadian citizenship identity tends to develop among Mexicans who have grown up in Canada and/or have lived in Canada for a significant part of their lives. Ten of the participants perceived themselves as Mexican-Canadians. The examples of Elizabeth and Norah will illustrate how a Mexican-Canadian identity develops in the context of migration.

Elisabeth grew up in a small town near Mexico City and she came to Toronto in 1976 as a domestic worker. Elizabeth explains about her background:

At home we were very poor. I went to school without shoes and I had two changes of cloth a week. I stayed in school for only two years and thereof I was employed as a domestic worker. When I was twenty-eight years old the family I used to work with in Mexico City introduced me to some family friends of them who hired me to work for their son's family here in Toronto.

In her new job in Canada, Elisabeth started making five hundred dollars a month and on Wednesdays she had a full day off. Eventually, every Wednesday she started volunteering in a hospital with Spanish-speaking patients. Elizabeth got that volunteering position through a Spanish-speaking Catholic parish, in which she became an active supporter of Latin American immigrants. Elizabeth recollects her volunteer years: 
In the hospital, I volunteered as a sort of chaplain, helping the sick but we also tried to help them find work, and keep them company. I remember when patients died of leukemia, they could not even move and I used to get so sad because they did not have any family here. I did not have family here either, I understood what it was to be alone, and we kept each other company.

Elizabeth worked as a housekeeper for a number of families in Toronto until she became an independent worker. Elizabeth explains: "A Peruvian lady sold me her cleaning business. I did not have money to pay her at the time, we knew each other and she sold me the business on credit, she said I could pay her later, and so I did". Elizabeth was successful in her business as well as in bringing her family to Toronto. With the years, she came to own a number of businesses and she is now retired. Currently, Elizabeth dedicates her time going to Church and visiting parishioners who find themselves alone. She is also a philanthropist providing financial aid to Latin American immigrants when needed. In addition, Elizabeth goes to Mexico every year and helps financially a small number of people in her town.

While Elizabeth's civic engagement and philanthropy has been with Latin American immigrants in general and she feels very much part of a Latin American community, she describes herself primarily as a Mexican-Canadian. She explains, "I love two countries with all my heart, Canada and Mexico. I have been in many places, all around Europe and the Middle-East but these two countries, Canada and Mexico, I love the most". Moreover, Elizabeth has become very critical of both the Canadian and Mexican governments. She argues that despite the good relationship between Canada and Mexico, Mexicans have to ask for visas and immigration does not give Mexicans refugees a fair chance. Elizabeth elaborates on this point:

Immigration [CIC] divides families, often they send the father home and the mother and children have to stay here alone. It is a very cruel practice. Immigration does not understand that too many people are suffering from 
violence in Mexico, and things seem to be getting worse. All of that affects Mexicans living here.

According to Elizabeth, life in Canada has become harder not only for Mexican immigrants but immigrants in general. She concludes that:

Now it is more difficult to make a living and for people to get papers but other communities deal with harsher situations than us. Alone with our problems, we see only poverty and difficulties, I know is not easy, it has never been easy, but we should also consider the suffering of others. We could see life in a more positive light by helping others.

Elisabeth's life commitment helping those who find themselves sick and alone is indicative of an existential awareness based on her own experience with solitude in the context of migration. In addition, her work with the sick is rooted in her religious beliefs. Elizabeth's civic engagement is a concrete manifestation of her spirituality and existential sensibilities, which allows her to see her own suffering in the suffering of others and thus by helping others she also finds meaning and solace to her past and present afflictions. Elizabeth's ongoing work of philanthropy in Mexico and in Canada is localized in communities where she has a personal history. Her work of philanthropy is therefore indicative of strong sentiments of belonging and a deep sensitivity to poverty. In short, Elizabeth's civic engagement and consciousness have an existential depth that sheds light on the interrelation between immigrants' own personal histories with loneliness, suffering, and poverty and their acts of solidarity with migrants experiencing similar situations. Lastly, Elizabeth's migration experience is also powerful assertion of immigrants' capacity to overcome significant levels of marginality and at the same time maintain a life-commitment to principles of solidarity.

Norah came to Canada in 1998 with her family when she was a child. She graduated from high school and university in Toronto and for most of her life Norah was 
not an active participant in Mexican community activities. In recent years however, Norah has become much more involved in supporting what she sees as a growing Mexican community. In 2011 with the support of some friends she funded an NGO to promote Mexican cultural and social activities. She explains: "It all started when we decided to organized a posada navideña [Mexican Christmas celebration]. More than seven hundred people came, it was a big success and a big surprise." Currently, Norah and her friends plan events like posadas every year as well as the Day of the Dead celebration in Toronto among other activities.

Norah believes that with increasing numbers of Mexican immigrants arriving in Toronto, Mexican-Canadian children can grow up with the best of both worlds. Her community engagement centres on promoting free family oriented cultural and social activities for Mexicans in Toronto. Norah explains:

Mexicans have children in Toronto or bring their kids when they are still young. Mexican families need accessible cultural activities for their kids to get to know Mexican traditions, folklore, and culture, so Mexican children in Toronto can grow up in a strong and culturally vibrant community.

Norah explains that there are significant challenges in community activities with Mexicans in Toronto, including the logistics of the Mexican presence in the Great Toronto Area: “In Toronto, Mexicans don't have a barrio where most of us work and live. Mexican families are dispersed across the city. This makes it difficult to organize events and engage in community building." According to Norah while the number of Mexican restaurants and stores is growing, there is still a long way to go for Mexican businesses to sponsor large community events and engage in partnerships to support community activities. On this point Norah explains that: 
To find sponsors for organizing free Mexican cultural events and free community activities is probably the most challenging part of community building. Often you find yourself spending your own money to fill up the gaps, which is fine but it is not sustainable.

Despite the challenges, Norah has ventured to organize a number of community events, and in the summer of 2014 she organized a weeklong Mexican festival celebrating Mexican cuisine and culture, which counted on the participation of many Mexican restaurants, artists, volunteers and the support of some institutions. Norah explains that organizing that particular event has been one of the most demanding and time-consuming community activities she has been engaged with but also "one of the most rewarding."

Norah is a professional with a full time job and while planning and organizing community events implies significant time and financial commitment, her community engagement is indicative of her growing sense of responsibility as a Mexican-Canadian. She believes that Mexicans in Canada should be more actively engaged with Mexican newcomers to the country. She explains: "We need to let them know that they are not alone, that we are here to help them and support them, even if its only emotional support. It can be as simple as providing more information sessions for Mexican families and then take it from there." Norah also thinks that as a community, Mexican-Canadians have a responsibility to be engaged in acts of solidarity with Mexico, especially in times of need such as natural disasters. For example, she explains that:

... In 2013 there were big hurricanes in Mexico and we organized a fundraising for the Mexican Red Cross. I felt that in Canada [as a country] we did not do much to help, and that bothers me. But in fairness, the Mexican Consulate did not organize something to really help those in need in Mexico either. That is one the reasons why we need to build a stronger community. 
Norah has lived in Canada for most of her life and according to her she has always felt very comfortable in a Canadian environment. Interestingly, since engaging in Mexican community activities, she finds herself socializing with Mexicans more than ever before. Norah explains that her sense of responsibility and her identification with the Mexican community have been a later development but if she is going to be civically engaged she feels that her priority should be "to be involved with Mexicans living here [Canada]." In short, Norah's community engagement has become an important part of her everyday life and it has influenced the way in which she sees herself civically as a Mexican-Canadian.

Arguably, Norah has the choice of "blending in" the Canadian mainstream as a young professional. Norah does not need to identify herself as a visible minority and by growing up and being educated in Canada she has become fluent in the English language as well as acquainted with Canadian cultural and social values. Her choice to become actively involved on building a Mexican community in Toronto is an assertion of her Mexican background and it is also indicative of the complex and evolving sense of cultural awareness and civic responsibility that can flourish among citizens who have grown up in the context of diaspora. In this regard, the interconnection between Norah's community engagement with her biography and civic consciousness as MexicanCanadian provides an existential meaning to the processes of acculturation in the context of migration.

Elizabeth immigrated to Canada as an independent adult more than two decades before Norah came to Toronto with her family as a child. Their generational, educational, and occupational differences are indicative of the diverse composition of the Mexican 
presence in Toronto. Similarly, the other eight participants who developed a MexicanCanadian citizenship identity also had distinct professional and educational backgrounds and like Nora and Elizabeth they had lived in Canada for a significant period of time. Having said that, none of these participants had experience as significant levels of marginality in Mexico as in the case of Elizabeth, and only one of them came to Canada as a minor as in the case of Nora. In this regard, the examples of Nora and Elizabeth are quite unique but the development of Mexican-Canadian civic identity reveals the importance of time in the development of citizenship identities in the context of migration as well as the unique experiences and sensibilities of Mexican-Canadians. Like their biographies, the civic participation of Elizabeth and Nora's are distinct and also revealing of the interconnection between their journeys of self-discovery and selfactualization in the context of migration as well as the development of a MexicanCanadian citizenship identification. While the concrete expressions of their identification with both the Canadian and Mexican polities differ, Elizabeth and Norah's civic identification as Mexican-Canadians is rooted in their commitment with their own ideas of community and solidarity.

\section{Pluri-cultural Transnational Citizenship Practices and Identity}

I define pluri-cultural transnational civic consciousness as the identification and solidarity with various cultural heritages and cultural groups, which in its concrete manifestation and development transcends the geographical and ideological boundaries of the nation state. Unlike cosmopolitan citizenship, a pluri-cultural transnational citizenship is not based on the idea of a common humanity, universal values, or a 
common world order but rather on the identification with particular cultures. A significant number of the participants in this study were professional artists whose diverse forms of civic engagement were intimately related to their art and also to a deep sense of solidarity and identification with Indigenous, Latin American, and Mexican cultures. Through the examples of Thomas and Catherine I will illustrate how Mexican artists' develop a pluri-cultural transnational citizenship identity.

Thomas came to Toronto in 1999 from Mexico City, with the hope to develop as an artist and to become financially independent from his parents. In Mexico, Thomas' experiences with civic engagement were very limited but in Canada he has had a long artistic commitment working with Indigenous people and marginalized populations. Since childhood Thomas has been attracted to "Indigenous cultures and the land" and in the context of migration to Canada he has "developed a strong identification with indigenous people." According to Thomas, Canada's Indigenous people deserve much more respect by immigrants and Canadians since "we all live in their lands." Also, Thomas has a deep admiration for Canada's Indigenous culture, which has influenced his own artistic development. For more than ten years, Thomas has been a member of dance group performing Aztec dances and he includes Canadian Indigenous performers to join his group in Mexican artistic celebrations.

According to Thomas, the traditional Mexican and Latin American sense of community and identity share important similarities with Canada's Indigenous people and "it should be natural that Mexicans and other Latin Americans immigrants identify with Canada's indigenous people and their struggles." For this reason, Thomas' engagement promoting Mexican arts and culture is compatible with celebrating Canada's 
indigenous culture and art. For instance, for the past six years, Thomas has organized the Day of the Dead festivity at Artscape Wychwood Barns as both a community get together in indigenous spiritual festivity. Canadian-Indigenous musicians and dancers join the Day of the Dead celebrations, and for Thomas this is significant not only as a form for acknowledging that in Canada we all are living in Indigenous land but also a way to make the Day of the Dead a Canadian ceremony. Thomas explains:

For me, it is the biggest festivity of the year, it is when we honour and remember our dead ones. I want people in Toronto to adopt the Day of the Dead as their own ceremony and for it to become part of the larger community. Already, there are many Day of the Dead ceremonies and perhaps some day people here would celebrate the day of the death in the cemeteries like we do in Mexico and Canadians will relate to their death ones differently, without so much sorrow and distress. People celebrate Saint Patrick's Day, a traditional Irish festivity, why not the Day of the Dead, it is a ceremony full of Indigenous spirituality.

Thomas is one of the founding members of an organization supporting Latin American artists in Toronto and has had a long commitment promoting Latin American culture and supporting Latin American community activities. For Thomas, the heterogeneity of Latin American art and culture makes it difficult to categorize and there is a plurality of opinions and often disagreements among Latin American artists on the direction community cultural activities should take. Moreover, for Thomas, absence of more collaboration between Latin American artists with Indigenous communities in Canada is not only about different understandings of culture between Latin Americans whom may or may not identify with Indigenous people but it is also indicative of the significant amount of time required to build relationships with Indigenous communities in Canada, which "can be very hermetic." As in the case of most immigrants, artists' circumstances and time availability also change over time and is not always possible to maintain long community commitments. Thomas explains: 
I have a daughter and I have to make a living like everyone else. Increasingly, I find myself overwhelmed with work and I feel like not organising cultural events for the community but then community members encourage me to continue and also support me on my efforts. [At the end], I find myself involved in community activities but it is not getting easier.

In short, Thomas migration experience has been a fundamental act of freedom centred on pursuing artistic and personal growth. Thomas's civic consciousness and civic engagement are rooted in an appreciation for Indigenous cultures, respect for the land, and a search for authenticity in his artistic expression.

Catherine is a classical musician who arrived to Canada in 2010 to pursue a $\mathrm{PhD}$ and a career in music. Catherine studies the musical tradition of Mayan people and as part of her program she is learning ethical practices for working with Indigenous People based on the example of works with Inuit communities in Northern Canada. Catherine identifies as Mexican, Latin American, and also as Navajo and she has always been involved in the cultural aspect of social engagement. Catherine explains, "In Mexico, I grew up with people that were very active in doing fundraisings to support musicians who could not afford to buy new instruments. I grew up being very civically engaged with different social causes."

Before immigrating to Canada, Catherine did a Masters degree in Music in an American university and she lived for many years in the United States as an artist in residence. In the U.S., Catherine was involved in cultural activities with the Latin American community and worked to provide scholarships for Latin American students. Comparing her experience with civic engagement in the United States and in Canada, she explains: “As a Latin American artist I was very active in the United States [while] here in my experience as a Latina I find the university to be more disconnected from social issues." 
In Canada, Catherine's civic participation centres on musical education and supporting community activities. Catherine provides free music classes to children from low-income families in Toronto and she does fundraising with an organization called Music Box to support Latin American children who want to learn music but who lack the financial means to access a musical education. Also, for many years, Catherine has been involved in El Sistema, an association that provides classical music training and instruments to underprivileged children. According to Catherine "most Latin American musicians are involved in El Sistema in one way or another."

In Toronto, Catherine participates as a musician in Mexican cultural celebrations and she has started working with the Mexican Consulate to try to promote cultural activities for Mexican immigrants. As a Mexican classical musician, Catherine has encountered many preconceptions about Mexican music and she has been actively engaged on promoting awareness about Mexican classical music and folklore. In Toronto, Catherine has started to introduce Mexican classical music in her recitals. She explains that, "it is fascinating to see how people react. They have no idea about Mexican classical music."

While promoting Mexican culture has been at the centre of Catherine's migration experience, she is also involved in promoting other Latin American musical genres and has come to identify herself very strongly with Latin American musicians. She explains: "In Mexico, you grew up playing everything, and by living in the United States and Canada I found that other Latin American musicians are just the same, as Latin American musicians we are very versatile and open to play anything." Catherine's artistic openness has been conducive to embracing a number of different yet complementary cultural 
heritages, expanding not only her artistic interests but also her civic consciousness and civic engagement.

In short, music has been at the centre of Catherine's migration experience involving her work as a classical musician, her civic engagement teaching music to Latin American underprivileged children, and her academic studies of Mexican indigenous musical traditions. She explains, "I feel very grateful that my life has being enriched by music, and I want to share that with others". In the context of migration, Catherine's engagement sharing her musical talents with others has helped her develop a pluricultural civic consciousness.

For artists like Thomas and Catherine, their decision to immigrate has offered them the possibility to expand their artistic horizons and to pursue their vocations in relatively favourable contexts. This is similar to the experiences of the other two Mexican artists who were able to develop their artistic careers in Canada and also identified with different parts of their cultural background. As the majority of Mexicans, the four participants who developed a pluri-cultural citizenship identity are mestizos, mixed of Indigenous and Spanish ancestry, and through their immigration experience they have come to identify with their Indigenous, Mexican, and Latin American background in a profound way. Their immigration experiences have also exposed them to new social and political realities, enriching the character of both their citizenship identities and artistic expressions. 


\section{Conclusion}

There is no common Mexican immigration experience in Toronto but rather a collection of immigrants' distinct points of views and circumstances that constitute a pluralistic migration reality. Mexican immigrants' relationships with the Canadian and Mexican body polities are diverse and variable, and include cosmopolitan, linguisticcultural, bi-national, and pluri-cultural examples of citizenship practices and civic identifications. Such a multiplicity of citizenship identities and practices bears testimony to the ever-changing and pluralistic character of the migration experiences of Mexicans in Toronto.

The participants' different types of citizenship practices also reveal the inseparability of immigrants' civic growth and their circumstances. The development of a cosmopolitan citizenship was facilitated by some of the participants' culturally rich upbringing, and the identification with the Latin American community was indicative of the participants' business interests and their desire to socialize with likeminded Latin American professionals. These two types of citizenship required significant social capital and therefore can be viewed as rather exclusive citizenship practices. Mexican-Canadian citizenship practices centred on providing Mexican immigrants in Canada with the support they may need and organizing accessible cultural and social activities. While this type of citizenship practice is inclusive of broader segments of the Mexican immigrant population it also requires access to material resources and time to invest in community activities and to engage in philanthropic endeavours. Similarly, a pluri-cultural citizenship practice requires exposure to different cultures and time to reflect and explore different aspects of ones' cultural identities, in this case Indigenous, Mexican, and Latin 
American. While none of the research participants were Indigenous people, the four artists who developed a pluri-cultural citizenship identity had the opportunity to be exposed to Indigenous cultures in Canada, which led them to also identify with the Indigenous part of their Mexican Mestizo background. In short, the transnational expansion of citizenship practices in the context of middle class Mexican immigration to Canada is inextricably linked to the enjoyment of relatively adequate social and economic circumstances, which allow immigrants to dedicate the necessary time, effort, and resources in being civically engaged.

Citizenship practices need time, resources, and the adequate conditions to develop but these are luxuries not enjoyed by all Mexican immigrants in Canada. Just like access to permanent residence allows middle class Mexican immigrants to spend time and contribute to the Canadian polity, the provisional and precarious immigration status of Mexican temporary agricultural workers and refugee claimants can be interpreted as tangible barriers to develop citizenship practices and civic identifications. In this regard, the expansion of citizenship practices takes place in a context that benefits immigrants with significant social capital but discounts less privileged immigrants from being potential citizens. The next chapter looks at how Mexican emigration policies are used by Mexican middle class immigrants to provide a Mexican middle class community. 


\section{Chapter V}

\section{Policies and Practices: Building Relations with Emigrant Communities}

"From the perspective of the individual person there appears the res publica."

Historia como sistema, Ortega y Gasset.

On Thursday May 20, 2014, a group of Mexican citizens got together on the Ottawa-Gatineau campus of Mexico's Autonomous University (UNAM) to welcome the Executive Director of the Institute of Mexicans Abroad (IME), a Mexican governmental institution dedicated to foster relations between the government of Mexico and Mexican emigrant communities. A day later, IME’s Executive Director met with Canadian representatives of CCIME, IME's volunteer counselling body representing Mexican communities across the United States and Canada. Meetings between members of Mexican emigrant communities and Mexican officials represent a significant development in the institutionalization of citizen-state relations in the context of the relatively small and recent Mexican immigration flow to Canada.

The CCIME-IME conference in late May in Ottawa could not have been better timed. 2014 marked seventy years of Canada-Mexico diplomatic relations and the twentieth anniversary of the North American Free Trade Agreement (NAFTA) between Mexico, Canada, and the United States. The insertion of Mexico to a North American neoliberal policy regime and the increasing movements of people, services, goods and ideas within North America have brought Canada and Mexico commercially and governmentally closer, but it also has had major impacts on Mexican citizenship rights at home and in the context of migration (Bugailiskis, and Rozental, 2012). For Mexican 
emigrants attending the IME-CCIME conference in Ottawa, this was an opportunity to share their concerns and experiences in the exercise of citizenship rights and obligations with Mexico, and to discuss their aspirations as emigrant communities.

That evening, IME volunteers enthusiastically put together an interactive live videoconference option to follow the conference online but despite their efforts to reach a wide audience, the number of followers was very low. This was reflected in the group of research participants in my study: five of them, (12.5 percent) had a direct experience with IME and only three of the forty participants ( 7.5 percent) actively participated in IME's meetings and events. Thus, IME was not a widely used emigration strategy by which the research participants maintained an active citizen-state relation with Mexico. For those who did participate in IME however, their involvement meant a significant commitment of time, effort, and resources. In this chapter I will explore the experiences of the participants working with IME through CCIME in the cities of Ottawa and Toronto.

This chapter is divided into three sections. The first section consists of a brief introduction to the historical development of Mexican emigration policies. The purpose of this section is to locate IME and CCIME in light of Mexico's long and complex efforts for building relations with its emigrant communities. In the second section I will present the experiences of research participants with IME and CCIME, focusing on community development and to a lesser extent on political organizing. In the third section of this chapter, I will conclude by shedding further light on the relationship between Mexican emigration policies and the communitarian aspect of immigrant civic engagement. 


\section{Introduction to Mexican Emigration Policies}

IME and CCIME are part of a long Mexican governmental tradition of enacting policies and developing practices to protect and procure the support of its emigrant population. As early as the 1860 s, the Mexican government established a number of citizen-based organizations known as Juntas Patrióticas in order to get financial assistance and political support of Mexicans emigrants in the United States (Delano, 2006). At the time, Mexico was under French occupation and the Juntas Patrióticas initiative provided the government of Benito Juarez with much-needed financial support to continue the struggle against the French (Delano, 2006).

The Mexican government also has long experience providing services to its emigrant population, particularly in the area of repatriation. During the 1907 and 1908 economic recession in the United States, the Mexican government managed to repatriate and provide consular services to more than a hundred thousand Mexican citizens returning from the United States (Delano, 2011). At the beginning of the twentieth century, the Mexican government had gone through a relatively long period of modernization championed by the cientificos, a group of technocrat followers of the positivist thought of August Comte (Priego, 2016). The modernization of the Mexican civil service went in hand with the adoption of a policy regime that reflected Social Darwinian principles of racial superiority and included discriminatory policies against Mexico’s Indigenous people as well as the generous sponsorship of European immigration (Priego, 2016) ${ }^{6}$.

${ }^{6}$ Under the leadership of the cientificos, liberalism and modernization became increasingly synonymous and Mexico embarked on a path of rapid trade liberalization, abolishing internal taxes and 
The outbreak of the Mexican Revolution (1910-1920) started a period of major political changes in Mexico, which eventually replaced the political discourse of westernization with a more nationalistic political rhetoric (Knight, 1990). In terms of the development and implementation of emigration policies however Mexican governments during and after the Mexican Revolution continued with the model established in prerevolutionary years. Reminiscent of Benito Juarez's Juntas patrióticas, president Francisco I Madero founded a number of Clubes Liberales in the United States to get the support of Mexicans emigrants for his plans of transforming Mexico into a liberal democracy (Garcia-Acevedo, 2003). Similarly, President Venustiano Carranza established a number of Juntas Constitucionalistas in the United States to get support and legitimacy for his dictatorial regime (Garcia-Acevedo, 2003).

Between 1910 and 1920 over one million Mexicans had immigrated to the United States and subsequent Mexican governments established government sponsored civil society organizations, comisiones honorificas mexicanas, to provide support to Mexican emigrants in the U. S. and to promote solidarity with Mexico. The relationship between the Mexican government and Mexican emigrant organizations was also indicative of the limited policy capacity of the government at the time, which in 1920 only counted fiftynine Mexican consuls to serve over a million Mexican citizens living in the U.S. (Garcia Acevedo, 2003). Moreover, it is evident that by the early $20^{\text {th }}$ century Mexico had a well-

structural barriers for foreign trade (Priego, 2016). For the cientificos, Indigenous people and indigenous communal lands or ejidos represented obstacles for Mexico's liberalization and modernization of the agricultural sector. Bringing European farmers to settle land that belonged to and was occupied by Indigenous people was therefore seen as a suitable solution by the cientificos for both the "improvement" of Mexican agriculture and of the country's Indigenous ethnic composition (Priego, 2016). The inability of the Mexican government to attract large numbers of European immigrants to settle in the country represented a significant failure of Mexico's modernization plan during before the Mexican Revolution. 
established governmental practice of: a) relying on civic organizations to get support from Mexicans emigrants in times of crisis; and b) operationalizing emigration policies that are national/patriotic in character and transnational in practice.

By the mid-twentieth century, Mexican emigration policies were often carried in collaboration with the United States government and responded to the imperatives of the U.S market economy and the political mood in the United States. Some of the major challenges at this time included the repatriation of approximately four hundred thousand Mexicans from the United States at the time of the Great Depression, as well as the signing of the Bracero Agreements between 1942 and 1964 (Fitzgerald, 2009). These agreements facilitated the signing of 4.6 million Bracero contracts for temporary agricultural work in the United States (Fitzgerald, 2009) and were a major step in regulating the migratory movement between the two countries.

In contemporary Mexico, the central government has developed an emigration policy regime that looks well beyond repatriation and seeking emigrants' support in times of political crisis. Since the 1990s, and with the active support of Mexican communities in the United States, the Mexican government has implemented policies and established programs allowing Mexican migrants to exercise their citizenship rights and obligations. Some of these policies include, the Mexican Dual Nationality Law of 1997 and the right of Mexicans for voting abroad passed by the Mexican Parliament in 2005. These policies allow Mexican migrants to exercise their civil and political rights respectively (Gutierrez, 1997; Lafleur and Calderon, 2006). Also, the Paisano Programs aiming at protecting the rights of Mexican emigrants returning permanently or temporarily to Mexico, as well as the Secretary of External Affairs (SRE) Programs for Mexican Communities Abroad 
(PCME) such as $2 \times 1$ and $3 \times 1$ programs that double or triple the economic contributions of Mexican emigrants to their hometowns and home-states are examples of governmental programs aiming to facilitate the exercise of Mexican migrants' social citizenship rights and civic engagement respectively (Fitzgerald, 2006; 2009).

The Mexican government has also founded a number of important institutions and intergovernmental agencies to further operationalize and coordinate emigration policies and initiatives. These institutions include the National Council for Mexican Communities Abroad (CNCME) and the Institute for Mexicans Abroad (IME), which work in collaboration with the Mexican Ministry of External Affairs (SRE). Together these government institutions and SRE composed the troika of Mexican emigration policies and programs. CNCME is a permanent inter-ministerial commission comprised of eleven council members from different federal ministries with the mandate to promote public policies and governmental practices to meet the demands of Mexican communities abroad (Mexican Presidential Decree: Article 2, 8/08/2002). SRE works as the executive body for the CNCME and collaborates with IME in promoting SRE programs for Mexican emigrants. IME acts as the governmental body in charge of creating spaces and promoting meetings with and between Mexican communities. IME's executive director is appointed directly by the Mexican president and works as a direct channel of communication between Mexican emigrants and the state. ${ }^{7}$ CNCME and IME were both

\footnotetext{
${ }^{7}$ In April 16 2003, Mexican President Vicente Fox announced a decree founding the Institute of Mexicans Abroad known by its Spanish acronym as (IME). According to Article 2 of the presidential decree IME was created with the "objectives to promote strategies, integrate programs, collect proposal, and recommendations from the communities, their members, their organizations, and consulting bodies, that are conducive to elevate the quality of life of Mexican communities abroad, as well as to carried instructions from the National Congress of Mexican Communities Abroad (-My own translation- Presidential Decree: Article 2, April 16 2003).
} 
established by decree by President Vicente Fox in 2002 and 2003 respectively and they represent some of the latest efforts of the Mexican government to centralize emigration programs, policies, and practices.

Moreover, IME's mandates evolved from focusing on supporting Mexican communities in their efforts to achieve a better standard of living to also actively help Mexican communities "integrate" into their country of residence ${ }^{8}$. This change is significant not only because it shows an expansion of the Mexican government's emigration agenda as a strategic partner in community development abroad but also because it further institutionalizes a more transnational view of Mexican citizenship. Such a state-sponsored transnationalism rests on the premise that Mexican migrants can be integrated into their country of residence and remain active citizens to their country of origin, a mutually inclusive process in which the Mexican government sees itself as an active participant. The operationalization of this ambitious undertaking rests largely in the hands of IME's transnational bureaucracy, the collaboration of Mexican communities abroad, and the utilization of the Mexican government's emigrant programs.

In short, while for many immigrant sending countries, extraterritorial governmental practices in the context of migration are a recent phenomenon, the Mexican government has been implementing increasingly transnational emigration policies over more than a hundred and fifty years. Mexican emigration policies have historically focused on the Mexican diaspora in the United States and they relied on the collaboration

\footnotetext{
${ }^{8}$ Eight years later after the promulgation of Article 2, the same article was reformed by Mexican President Felipe Calderon adding to IME's mandate "to strengthen the links [of Mexican immigrants] with Mexico and promote their integration in the societies in which they reside and "desenvuelven" a Spanish transitive verb that can be translated as to living (as in every day live) or integrate in their daily living. (-My own translation- Presidential Decree: Article 2, 14/11/2011.
} 
of Mexican community organizations. Contemporary Mexican emigration policies and programs provide a legal and institutional framework for the active participation of the Mexican diaspora in the political, social, civic, and economic life of Mexico, opening up new possibilities for the transnational exercise of citizenship rights and obligations in the context of migration.

\section{Utilizing IME and CCIME in Canada: The Experiences of Jonathan, Mercedes, and Mary}

Jonathan has been living in Ottawa for the past thirty years and according to him, "IME has been an important step to formalize the relationship between Mexico and its diaspora in Canada." For Jonathan, the Mexican-Canadian diaspora is composed mostly of middle class professionals and he has seen the Mexican community in Ottawa grow from a few dozen families to several thousand people. Jonathan decided to participate in CCIME in order to support his community and to also contribute to Mexico's relations with its diaspora in Canada. He explains: "My work in CCIME focused on providing recommendations for how Mexico can support the Mexican community here [in Canada] and how the Mexican community here can participate in Mexico's public life."

Jonathan believes Mexicans in Canada can contribute to Mexico's development and he has witnessed how Mexicans in Canada "volunteer in Mexican cultural and social activities, help in programs that provide services to Mexico, or go directly to Mexico to make a difference." For Jonathan, making a difference is not only about "sending remittances" or "asking for programs" but it is also about giving "your opinion on issues that concern all Mexicans". As an example, he talks about the advocacy role of Mexican film director Alfonso Cuarón: "Look at Cuarón. It is an excellent example of how a 
Mexican living abroad for many years tries to create social consciousness about what goes on in Mexico. IME opens up direct channels of communication to at least propose public policies to the Mexican government, which could benefit Mexican communities in both Mexico and abroad."

For many years, Jonathan's civic engagement centred on Ottawa, where he joined Mexican organizations, supported children's activities such as Mexican folkloric dance groups, and participated on the board of directors of Mexican organizations. While Jonathan still participates in a number of Mexican social and cultural activities in Ottawa, he is currently interested in contributing to the development and implementation of Mexican policies that support Mexican diaspora in Canada as a whole. He explains:

There are many areas that as citizens we can help with: culture, education, health, all of those aspects contribute to the wellbeing of the community but they need adequate policies to support them. IME creates programs and spaces that help Mexican emigrants to be involved and participate in public policies affecting Mexico and Mexicans living abroad [and] it is one of the main reasons for me to be involved in Mexican public policies.

Jonathan is proud of what the Mexican community in Ottawa has managed to accomplish so far: "we have founded a community school to teach Mexican culture, language and education. We provide gastronomy workshops, traditional dance workshops, and other social and cultural activities". Also, Jonathan thinks that there is still a lot to be done for the Mexican diaspora in Canada to be actively engaged as citizens with Canada and Mexico and he is convinced that "the Mexican government is in a position to help the Mexican diaspora in Canada to be more engaged." He is equally convinced that, "civically engaged Mexican-Canadian communities would be in a great position to help Mexican society as a whole". 
Four hundred kilometers away from Ottawa, Mercedes dealt with the complexities of being a Mexican community organizer in Toronto. Mercedes moved to Toronto in 1985 and since that time her commitments with the Mexican community have centred on cultural and social activities. Moreover, Mercedes was elected as a CCIME representative at the time of an increasing influx of Mexican refugees into the city, which influenced her priorities as a CCIME counsellor. She elaborates on her experience of supporting Mexican refugees: "When we had the great influx of refugees we [CCIME representatives] talked to the Ontario's Minister of Immigration, we talked to the Canadian Minister of Immigration, and we talked to the Mexican Minister of Immigration in order to look for support for how can we help people who do not have the proper information." Mercedes thinks of IME as an important tool for advocacy and community development. For her, doing advocacy for Mexican asylum seekers in Canada was the most important work she ever did with CCIME.

For Mercedes, IME is also an important instrument for demanding services from the Mexican government. She explains her experience pushing for consular services for the province of Manitoba:

Manitoba has a significant number of Mexicans and when we were in Mexico we lobbied tireless the Mexican Government for a mobile consulate for Manitoba. This is a consular office that goes to a specific jurisdiction and provides consular services such as providing passports, birth certificates, etc. Basically you bring all the necessary papers to provide consular services to Manitoba, and the Mexican community there now has it. Mexicans there do not have to travel all the way to Toronto for consular services anymore, which can take as much time as going to Mexico.

IME's institutional support provides Mexicans in Canada like Mercedes with the opportunity to travel to Mexico and lobby Mexican authorities for services in Canada. As in the case of the mobile consulate for Manitoba, lobbying Mexican authorities in face-to- 
face meetings is an effective strategy that can bring important benefits for Mexicans in Canada.

Also, IME offers a significant level of recognition favourable to building connections with Canadian governmental representatives and agencies. Mercedes explains some of the connections she built as a CCIME counsellor: "We managed to build connections between the Mexican government and the Canadian government, in areas of collaboration such as education through Mexican universities and Canadian universities. We also built bridges with city councillors, with political parties such the NDP and the Liberals". While Mercedes values CCIME's institutional support to get important connections in Canada, she is also critical of IME's lack of continuity. She explains: "We build all of these connections for the Mexican community and for the use of the Mexican consulate but they have not been utilized. All the bridges we built and the relations we had were not followed by actual programs or services". Mercedes's frustration with the lack of continuity in CCIME's work is indicative of the organization's structure as a community representative body. CCIME elects new community representatives every two years and new CCIME counsellors bring their own take and style to community building. As such, the working agenda of new CCIME counsellors may not reflect the priorities of their predecessors.

As a businesswoman and community organizer, Mary has been an active supporter of the Mexican consulate's cultural activities, and she has also been engaged in promoting Mexican traditions in Toronto. Mary explains that when she learned about CCIME she quickly "decided to participate in CCIME in order to make a difference." Mary summarizes the focus of her work with CCIME in Toronto: 
When I started with CCIME my original plan was to help integrate the different sectors of the Mexican community in Toronto. I did an activity for people from each group with the purpose of building a better image of Mexicans in Canada; I called this the Corona Project. Corona is a wellknown Mexican beer and when I came to Canada I was surprised to find that Corona was considered a premium beer, so people paid more to drink Corona, my fancy friends from my MBA program drank corona. My objective is to develop such a branding of Mexicans here that people would pay more than what they do now for Mexican workers. The objective is that people associate Mexicans in Canada with honest hard working people, so they are treated as such. That would be a long process that needs to be worked by individual groups and it will take time.

Mary's work agenda for the Mexican community reflects her experience and expertise in the corporate world, which she incorporates into her efforts for community building. Her "Corona Project" is a pragmatic strategy to what she perceives as a shortcoming in the Mexican community, which is that: "Mexicans have not been good at marketing themselves and [in the context of migration] you need to advertise yourself in order to progress because no one knows who you are."

Mary's strategic plan consists of establishing independent working groups that take part of a long project of community branding rather than focusing on more traditional advocacy and community development work. She explains the steps taken so far in her Corona Project:

First, I organized a meeting with thirty people and there have been some initiatives, one of them is a monthly networking event, which changes focus every month. One month can be on personal branding, another month you can have a focus on project management, the objective is to try to cover relevant topics for members of the community and it has been very successful. Now this activity includes people from different parts of Latin America.

Mary views her Corona project as long-term plan for the Mexican community. She is realistic about the feasibility "to complete a long-term project on community integration and branding in a growing immigrant community." Moreover, she is content with her 
efforts for having "at least been able to make the Mexican community think about community branding as a priority."

The experiences of Jonathan, Mercedes, and Mary with CCIME are indicative of their individual expertise and the unique circumstances they faced at the time of their community involvement. Jonathan is an expert in international commerce with many years of experience doing business between Canada and Mexico. He has spent more than half of his life in Ottawa, being actively involved in a relatively small and wellestablished Mexican community. Jonathan's experience and expertise as an immigrant and businessperson allows him to collaborate as an informal advisor in matters connecting Mexico with its diaspora in Canada. Mercedes has more than twenty years of experience working in immigration and her decision to participate in CCIME coincided with the increasing flow of Mexican refugees. Her experience as an immigration expert allowed her to effectively prioritize advocacy work on behalf of Mexican refugees during in Toronto. Mary became involved with CCIME when the influx of Mexican refugees had already declined significantly, and her efforts on community branding reflect her own experience as a corporate executive. Clearly, Jonathan, Mercedes, and Mary's civic engagement and their utilization of emigration policies such as CCIME have been rooted in their diverse biographies and expertise.

\section{CCIME as a Policy of Differentiation: Mexicans in Canada as a Middle Class Community}

Jonathan, Mercedes, and Mary are Mexican professionals who despite their demanding careers and family responsibilities have maintained a strong commitment in supporting the Mexican diaspora in Canada. It is evident that irrespective of their 
differences in areas of expertise and their distinct focus on community development, they managed to work in collaboration with Mexican authorities and utilize IME programs to support of their community work. Moreover, their shared inclination for participating in CCIME also reflects a social class and social identity dimension. This section explores how perceptions about social class and social identity affect the utilization of CCIME as an instrument for institutionalizing social class differences in the context of migration. Jonathan, Mercedes, and Mary thought of the Mexican diaspora in Canada as a predominantly middle class and professional migration. Also, the three CCIME participants emphasized the differences between Mexican immigration to Canada and the much older, larger and complex Mexican migration to the United States. For instance, Mary explains her view of the Mexican diaspora in Canada by highlighting some of the main differences between Mexicans in Canada and the United States: "The Mexican community in Canada is a different migration than in the United States. Most Mexicans in Canada are very educated and they have immigration status, so most Mexicans here can cover their basic necessities and do not need to look for assistance as they might do in the United States." Mary's efforts at community branding are indicative of her conception of the Mexican diaspora in Canada as predominantly middle class, well educated, and intrinsically distinct from the Mexican diaspora in the United States. Jonathan shares Mary's perception about Mexicans in Canada as middle class and different from Mexicans in the United States. Also, he argues that the profile of Mexicans in Canada is different from that of other Latin American immigrants:

The profile of Mexicans in Canada is a very different profile than Mexicans in the United States or to other immigrant communities from Latin America here in Canada. With the exception of Mexicans asylum seekers who came for a number of years to Canada, the majority of Mexicans here come from a middle class 
background and they are well educated and also have some savings. Also, there are many Mexicans whose spouses are Canadians and they have moved to Canada for that reason. Both of these groups have not been expelled from Mexico so they maintain strong ties with the country and they come and go to Mexico.

Jonathan's perception about the Mexican diaspora in Canada is indicative of his experience as part of a community of well educated Mexicans in Ottawa and he clearly understands the Mexican diaspora in Canada as a middle class and educated migration.

Similarly, Mercedes views the Mexican diaspora in Canada as significantly different from that in the United States. She explains, "Mexicans keep their traditions whether they are in the United States or Canada [so] it is natural that we are compared to Mexicans in the United States, which is a very different migration than the one in Canada. Mexicans in Canada, with exception of refugees, are professionals and documented." Hence, Mercedes makes a clear distinction between a Mexican diaspora largely composed of professionals who have immigrated legally to Canada and the less formal Mexican immigration in the United States. Also, Mercedes sees Mexican refugees in Canada as an exception from the trend in middle-class educated Mexican immigration.

Mercedes sees the professional and middle class profile of Mexicans in Canada as a potential asset for community building and for promoting Mexican culture in Canada. Mercedes explains, however, that despite the insistence of CCIME counsellors, Mexican authorities are not very receptive to the idea of opening cultural institutions in Canada. She explains:

The Mexican Consulate does not take advantage of the profile of Mexicans here. We talked to the Tourism Office, and with the Government in Mexico and we talked to the consulate and asked them to instead of spending so much money in advertisement to open a Mexican cultural centre where they could have exhibits, gastronomy, etc. But they do not want to listen. We do many festivals but that is only a few times a year, a cultural centre will showcase Mexico the 365 days of the year, it is an interactive type of advertising for Mexico. 
Thus, for Mercedes, the reluctance of Mexican authorities to establish a cultural organization for the Mexican community in Toronto is not fiscally responsible and a missed opportunity to benefit from the high human capital of Mexicans in Canada.

Moreover, CCIME meetings and working group allow for collaborations between Mexican communities in the U.S and Canada. Mercedes explains her experience working with CCIME counsellors from different cities across North America:

Through CCIME I was able to work with communities in Vancouver, Montreal, and Ottawa, and we worked very cordially. In the States, we worked with Los Angeles, Florida, Atlanta, Chicago and with San Antonio, Texas, and I keep working with them. Mexican refugees also came from the United States. [For example,] around three hundred Mexicans came as refugees from Florida with the help of a community centre there and we managed to put enough pressure to close that community centre because of all the misinformation and misguiding they were providing to potential Mexican refugees. So, we can collaborate and use some of the resources from other communities. A similar thing happened in Salt Lake City. You can talk to people in the United States and say: Hey this is going on in your community and you should be aware of it.

Mercedes's working relation with Mexican communities in the United States is indicative of CCIME's effectiveness for fostering collaborations between Mexican communities across North America. In this regard, perceived differences between Mexican immigrants in Canada with those in the United States are not an obstacle for Mexicans in Canada participating in CCIME to collaborate with their Mexican-American counterparts.

Jonathan, Mercedes, and Mary's opinions about the Mexican diaspora in Canada are inherently subjective as they are based on their own experiences and perceptions. Their shared points of view, however, have materialized in actual community services and overall work agendas with Mexican institutions that promote the development of a predominantly middle class and professional Mexican community in Canada that is 
perceived by its members as significantly different from the Mexican diaspora in the United States.

\section{CCIME and Political Engagement}

CCIME also works as a community partner raising awareness on local issues. For instance, on October 2014 CCIME, in collaboration with two other organizations, hosted a panel discussion with the main Toronto mayoral candidates ${ }^{9}$. The panel discussion centred on immigrants' social, economic and political inclusion in Toronto and it was catered to members of the Latin American community at large. Arguably, such events are indicative of the interest of CCIME's counsellors for promoting awareness about local politics among members of the Mexican community in Toronto.

Interestingly, the only study participant who had run for public office in Canada was acquainted with IME and CCIME and thought about running as a CCIME counsellor himself. Edmund is the first Mexican in Canada to run in Toronto's municipal elections and his civic engagement extends from political organizing to active participation in professional, community, and artistic organizations ${ }^{10}$. Edmund also shares a similar view about the social and educational composition of the Mexican Canadian diaspora as Jonathan, Mercedes, and Mary. He explains:

In the U.S, IME is a strong network of support and I think the Mexican government would like IME to be a strong network in Canada as well but I think there is a big difference between Mexicans in Canada and the U.S. Most

\footnotetext{
9 The two other organizations were: The Latin American Civic Participation Campaign and Las Perlas del Mar.

10 Edmund was involved in the Mexican-Professionals Organization (OPM) where he worked closely with the Mexican consulate and with Canadian institutions. During his time in OPM, this organization went from fifty to two hundred members.
} 
Mexicans in Canada are professionals, you have to meet some very specific requirements to come here while in the U.S you have a more informal immigration. I thought about running for CCIME and some members of MexicanProfessional organization also encouraged me to so but in the end I declined for personal reasons.

Edmund is an architect and his view of the Mexican diaspora in Canada is indicative of his familiarity working with other Mexican professionals and with Mexican institutions. His current political engagement, however, is disconnected from both Mexican institutions and the Mexican community.

The strong correlation between the utilization of CCIME and IME programs and the conceptualization of the Mexican diaspora in Canada as predominantly well educated-middle class professional community further suggests a social class dimension in the operationalization of IME/CCIME in Canada. Moreover, while 95 percent of the study participants are university educated only five had participated in IME/CCIME activities. Thus, despite CCIME's efforts to promote political and civic engagement among middle class Mexican professionals there is no evidence that CCIME's work has resonated with a significant number of Mexican professionals in Canada.

\section{Conclusion: Intersecting IME and CCIME with Ideas of the Common Good and the Community of Value}

There are a number of conclusions that can be derived from the experiences of research participants who collaborated with CCIME. First, the transnational organization and operationalization of CCIME reflects the policy capacity of the Mexican government to work in collaboration with Mexican emigrant communities across the United States and Canada. CCIME can provide a platform for interactions between Mexicans in Canada interested in working with the Mexican government in both providing services 
and promoting integration of and collaboration among Mexicans in Canada and the United States. Also, CCIME provided the necessary resources and institutional support for community representatives across Canada and the United States to meet, network and cooperate with government officials and among themselves.

Second, the small number of participants who had a relationship and/or knowledge about IME reflects that the partnership between the Mexican government and members of the Mexican diaspora in Canada has significant room for improvement in terms of outreach. At the moment, the dissemination and utilization of IME and CCIME in the Canadian context can be understood as a work in progress currently appealing to a small number of Mexicans in Canada. The development of a more comprehensive strategy for community outreach could help reach wider sectors of the Mexican diaspora in Canada.

Third, based on the experiences of CCIME representatives participating in this research, IME can serve as a strategic partner in lobbying the Mexican government to provide services for Mexicans in Canada. Having said that, as an elected body that changes every three years CCIME does not necessarily leads to continuity and long-term community projects. Also, whether the priorities of CCIME representatives are indicative of the larger population of Mexican immigrants in Canada is still a matter of further research.

IME and CCIME activities in Canada further the perception of Mexicans in Canada as a middle-class professional diaspora that is intrinsically different from the less educated Mexican immigrants in the United States. Such a perception could: 1) institutionalize an idea of Mexican asylum seekers in Canada as an exception to a more 
prominent immigration of Mexican professionals; 2) alienate Mexican refugees and former refugee claimants to Canada from participating in community development initiatives organized by IME and CCIME; and 3) disrupt the potential for further collaboration with Mexican emigrant communities in the United States.

The research participants' collaboration with CCIME reflected their professional expertise and their personal ideas on how to best contribute to community building. Also, their efforts for advancing the interests of what they perceived as their community suggests an interconnection between the expression of their creative capacities and the affirmation of their sense of self in relation to a privileged social class identity. Irrespective of their distinct priorities, the participants' utilization of IME reveals a shared idea of the common good, which consisted of the building a middle class Mexican community in Toronto. The participants share conception of the common good, however exclusive and/or contradictory it may be perceived, reflected their authentic sense of self, ideas about community, and feelings of belonging.

The utilization of CCIME and IME programs are conducive to the establishment of what Bridget Anderson refers to as "a community of value". Anderson (2013) defines as a community of value as a community "populated not simply by citizens but by good citizens, imagined law abiding and hard working members of stable and respectable families (Anderson, 2013, 3)." In the context of migration, membership in the "community of value" represents the aspiration of migrants to be seen as highly regarded members of society and not as poor social inferiors. As pointed out by Anderson, "a migrant as imagined in the public debate is not the foreign borne professor, financier, or architect but the person who cleans their house (Ibid, 3)." 
While Anderson's concept of community of value refers to an immigrant/nonimmigrant dichotomy, it could be argued that the utilization of emigration policies and programs such as IME and CCIME in Canada aim to institutionalize an imagined "emigrant community of value" through a dual process of affirmation and differentiation: 1) affirmation of national characteristics compatible with middle class values of their country of residence and country of origin; and 2) differentiation with immigrants, including their co-nationals, who cannot meet these ideals.

Sunera Thobani (2010) problematizes the concept of the national subject, the embodiment of the positive characteristics of the nation, arguing that the exaltation of the national subject goes along with the objectification of the outsider. In this light, the implementation and utilization of CCIME and IME in Canada can also help to exalt a Mexican community in Canada conformed by middle class professionals but at the same time potentially objectify non-professional immigrants and refugees as outsiders. Official meetings between representatives of the Mexican government and of Mexican communities of value could thus become part of a process of exaltation that institutionalizes social class differences in the context of migration. Arguably, such a process of exaltation is further reaffirmed by Canadian immigration policies aimed at welcoming immigrants with social and human capital but excluding other immigrants such as asylum seekers and non-status immigrants (Root, et al. 2014).

There was only one former asylum seeker who took part of this research and she was also a professional and her occupation in Mexico was not significantly different from that of participants who came to Canada as permanent residents or international students. Also, as the other participants she was actively engaged on issues of public concern. 
Thus, emphasis of Mexican diaspora in Canada as a primarily "middle class" and "formal" immigration could marginalize Mexican immigrants in Canada based on immigration status and exclude a large group of civically active members of the Mexican diaspora in this country. Providing services and fostering community practices that recognize Mexican asylum seekers as an intrinsic and valuable part of the complex and diverse movement of people between Mexico and Canada could further the process of social cohesion among the self-described middle class Mexican-Canadian professionals.

Lastly, there is a significant historical dimension to emigration policies and practices aiming to establish a middle class community of value in the context of migration. Mexico's colonial experience (1545-1820) saw the institutionalization of long lasting ethnocentric social and cultural practices, in which Spaniards and their descendants were separated from what was considered the lower sectors of society. For instance, Spanish colonial policies aimed to establish separate social and cultural realities by dividing society into a Republic of Whites (República de Blancos) and a Republic of Indians (República de Indios), and each of these so-called republics had a distinct relationship with the colonial state (Andrien, 2002). Like the colonial metropolis endeavoured to organize colonial society, the Mexican state today attends to arrange the social space of Mexican emigrants into a community of middle class Mexican professionals separate from Mexican refugees and non-status immigrants. In this regard, Mexican emigration policies tailored to middle class professionals are reminiscent of colonial attitudes of class stratification that separates people in exclusive social and cultural spheres according to their ascribed places in the social pyramid. 
In short, programs like IME and CCIME represent a systematic, legalized, and well-funded trans-national process of community cohesion, where current Mexican emigration policies and governmental practices aim and have the potential to institutionalize an "imagined” Mexican transnational community of value, conformed by middle class Mexican emigrants and their descendants. These emigration policies and governmental practices point out to the expansion of the Mexican state's influence beyond its political frontiers, suggesting a form of Mexican citizenship engagement that is national in character and transnational in practice. Moreover, the idea of a community of value in the context of migration is not limited to Mexican emigration policies and programs aiming to maintain relations with Mexican emigrant communities. The government of Mexico has also developed programs to foster relations with and among highly skilled Mexican emigrants. In the next chapter, we will explore how middle class scientists, scholars, and artists benefit from Mexican programs and also utilize state sponsored networks of support in the Canadian context. 


\section{Chapter VI}

\section{Policies and Practices: Building Relations with Highly Skilled Emigrants}

"The nation and the overall community are abstractions of the relationships you build with the people you work and socialize. Our goal is to support the community of Mexican professionals here and promote community integration. The relation with Mexico can come later."

Roger, member of Mexican Global Network Toronto Chapter.

On Saturday October 25th, 2014, a group of Mexican academics, intellectuals, and artists met at a Mexican bar to share their professional experiences and exchange ideas on how to support Mexican community initiatives in Toronto. That evening was the first networking event of the Mexican Global Network (RGMX) Toronto Chapter, an organization dedicated to both fostering collaboration among highly educated and talented Mexican emigrants, and to furthering knowledge transfer, scientific research, and innovation with Mexico.

Created in 2006 through the cooperation of IME, the Mexican Ministry of Finances, the National Council for Science and Technology (CONACYT), and the Mexico-United States Foundation for the Sciences (FUMEC), the Mexican Global Network (RGMX) is the latest strategy of the Mexican government for fostering citizenstate relations with highly educated and artistically talented Mexican emigrants (Red de Talentos, 2016).

Mexico is moving away from traditional policies of repatriating highly skilled emigrants to instead embracing a policy of: (A) institutionalizing networks of collaboration with and among Mexican scientists, intellectuals, and artists living in 
diaspora; and (B) providing the necessary financial support to Mexican scholars and artists to complete their training and education at universities abroad. Such policies and programs support rather than deter the migratory movement of researchers, scholars and artists, constituting a pragmatic governmental response to the increasing emigration of highly trained people, commonly referred to as brain drain.

In this chapter, I will study the utilization of Mexican policies and programs by Mexican scientists, intellectuals, and artists living in Canada. First, I will look at the experiences of research participants with the Mexican Global Network (RGMX) and with CONACYD scholarships in the cities of Toronto, Kitchener-Waterloo, and London Ontario. Second, I will contextualize the utilization and lack of utilization of these policies and programs in light of the participants' wider emigration and immigration experiences, including their professional development and citizenship participation. Lastly, this section will include a brief conclusion and reflection, suggesting that Mexico's pragmatic response to the issue of brain drain can provide significant social and professional benefits for both Mexico and Canada.

\section{The Mexican Global Network (RGMX) Toronto Chapter}

In less than ten years, RGMX has expanded from one to forty-two chapters in nineteen countries, proving to be a promising emigration policy for its more than forty thousand active members around the world. In Toronto, members of RGM are currently working to promote their organization through a number of social, cultural, and professional activities. In 2014, these activities included their participation in the 9th National Conference of Mexican Graduate Students and Researchers in Canada 
(CEIMEXCAN), a seminar on the use of social media for community and business purposes, and organizing a social and networking events such as a Christmas dinner. Ten or 22.5 percent of the research participants were members of RGMX, making this organization the most utilized Mexican emigration program found in my field research. Members of RGMX Toronto Chapter are a group of highly educated professionals, representing a minority of the overall population of Mexican emigrants living in Toronto, and they have a wealth of experiences on RGMX's membership, work agenda, its relations with Mexican authorities, and its scope and limitations as an organization.

\section{Roger: RGMX's Institutional and Work Agenda}

Roger is a mathematician and he is one of the members in charge of RGMX Toronto Chapter. Roger sees the high human capital of RGMX as an asset for the development of the Mexican community in Toronto. He explains: "What motivates me to work in the Red de Talentos is the fact that when I am sitting down with ten Mexicans here everyone has a Bachelors, a Masters or a PhD. What percentage of the Mexican population do we really represent? If this selected group of people cannot do anything to help the community then we should close the shop and move on." Roger understands that the Mexican Global Network is not representative of most Mexican emigrants, but he sees value in establishing a network of highly skilled Mexican emigrants in Toronto to open possibilities for furthering the development of the Mexican community in general.

In order to utilize the Mexican Global Network as an effective tool for community integration and development, Roger argues that the Mexican Global Network needs to work as a space "for supporting its members' goals whether these are business oriented, 
cultural, or academic." For Roger, establishing the organizational basis for mutual collaboration constitutes, "the first step in being a less divided community, at least in the professional sector." For this reason, Roger encourages a work agenda centering on local community development and professional collaboration such as "organizing networking events, and participating in local talks, and academic and non-academic conferences." Thus, the Mexican Global Network is conceptualized as a platform that allows highly skilled Mexican emigrants to benefit professionally from their community relations in Toronto.

The Mexican Global Network also operates as a transnational organization fostering scientific collaboration and knowledge transfer. Members of the Toronto Chapter have managed to establish fluent communication and working collaborations with chapters in different parts of the world. Roger explains:

We collaborate with the Red de Talentos in Boston because they are very similar to our members, mostly originally from the academic world. Now it is just a matter of further collaborating as opportunities arise. Also, there is a Mexican physicist working in Switzerland and he wants to provide science education for Mexican children via internet, and while we are not involved at the moment, other Mexican Global Networks are.

Transnational sharing of information and working collaboration between Mexican Global Networks is not only influenced by similarities in professional expertise but also by the location of each chapter. Roger explains how one of the Mexican Global Networks in China experienced difficulties with Mexican authorities:

The Chinese government was suspicious of them. They saw a bunch of foreigners, getting together periodically, speaking Spanish, and they did not understand what was going own. Fortunately, the Mexican embassy informed the Chinese that they were Mexican academics and their activities were fine. That community probably cannot establish much collaborations or grow too much. 
Thus, members from RGMX Toronto Chapter have the organizational capacity to collaborate with other RGMX chapters but such collaboration depends on sharing similar research interests and also the overall social and political conditions allowing for such transnational collaboration.

RGMX benefits from the institutional and financial support of Mexican government. According to Roger, however, the connections with Mexican authorities do not compromise RGMX's autonomy as an independent and volunteer based organization. He elaborates:

The fact that we receive help from the Mexican government does not mean that we always agree with government policies, or that we can avoid having altercations. Like most governments, the Mexican government is not good at listening and they send someone who presents some solutions and he or she expects you to accept them. They have their own assumptions and we have ours, and we will see how we can establish a more fluent dialogue in the years to come

In short, while the institutional connection with the Mexican government has room for improvement, it has not translated to self-censorship or compromise in light of Mexican governmental policies or politics. Moreover, Roger expects that in the near future the Mexican Global Network Toronto Chapter would "adopt a more business like model" in order to become financially independent from government funding.

\section{Jimena: RGMX's Cultural Dimension}

The Mexican Global Network Toronto Chapter has a strong cultural component. Jimena is a classical musician and her participation with the Mexican Global Network centres on promoting Mexican classical music, poetry, literature, and plastic arts, among other forms of Mexican contemporary arts and culture. Artists like Jimena aim at 
"offering a cultural platform to educate the Canadian public about Mexican art, expand a network of support among Mexican artists in Toronto, and promote cooperation between Mexican artists in Canada and Mexico.” Through the contribution of artists like Jimena, the Mexican Global Network also attempts to work as a cultural organization dedicated to promote Mexican contemporary art in Toronto.

The Mexican Global Network Toronto Chapter can benefit from the high profile and professional connections of Mexican artists living in Toronto. For instance, in 2013 Jimena was chosen by a prestigious Mexican magazine as one of the fifty people who are changing Mexico alongside film directors Guillermo del Toro and Alfonso Cuarón. Also, in 2014 she was the focus of an article by Forbes Magazine Mexico because of her cultural contributions to Mexico. Jimena has been able to maintain professional connections with Mexico's cultural scene by “presenting books, attending conferences, and launching disks in Mexico at least twice a year." In 2014 Jimena gave a concert in Mexico City's renowned Palacio de Bellas Artes and presented her new disk at the Festival Internacional Cervantino, the largest cultural festival in the Spanish-speaking world. Jimena's recognition as an artist and her professional connections in Mexico provide an added value to the Mexican Global Network's cultural work in Toronto and highlight the possibility of maintaining a successful career as a Mexican artist while living permanently in Canada.

\section{Lázaro: The Question of Location}

The Mexican Global Network Toronto Chapter includes members who live outside the boundaries of the Great Toronto Area and whose civic engagement centres on 
the communities where they reside. For instance, Lázaro is a scientist living in KitchenerWaterloo, and he often cannot participate in RGMX meetings or activities taking place in Toronto. Moreover, Lázaro and his wife are actively engaged in raising environmental awareness in the community where they live. He explains:

My wife and I are part of an environmental group. We are only five people and we invite newcomers to participate in outdoor activities. We provide information to newcomers about why the blue bin is important, why we recycle, why it is important to use the green bin for composting. We go to the river and we explain how we keep it clean and why is important. Or we can talk about very basic things like why it is important not to throw garbage on the street and its relation with floods. Currently, I applied to be part of the ecology and environmental advisory committee in the Waterloo Region.

Also, Lázaro specializes in the study of water and he helps organize summer camps and seminars for children where he gives lessons about the importance of water conservation in their community. In short, Lázaro's civic particpation centres on environmental advocacy in the Kitchener-Waterloo area.

Lázaro is also actively engaged in the dissemination of scientific information to Mexican academic institutions. He explains: "I send information about some opportunities here that may be relevant for students in Mexico. Also, I send publications and journals to Mexican students. Often, people ask for a specific article or book chapter and if I can get it I send them, it is just photocopying a chapter from a book and sent it to Mexico. I also send information on how to migrate here.” In this regard, Lázaro's participation as a scientist member of the Mexican Global Network Toronto Chapter is limited to the dissemination of scientific information to Mexico rather than in the active participation in the network's events. In short, Lázaro's civic engagement focuses on the community where he lives and distribution of information. 
Luciana: The Question of Social Relations

Being an active participant of RGMX is also a matter of personal disposition. Lucia is a neuroscientist and while she is formally a member of the Mexican Global Network she is not often engaged in the network's activities. Luciana explains that he is "not the type of person who gets easily involved in groups or social movements" and for that reason she is rather focused on her scientific research and personal commitments. Luciana feels her social life is in Mexico and not in Canada and she is planning to return to Mexico in the short term. She elaborates:

I have my family and my friends in Mexico and I want to share my life with them. Neither my husband nor I are very social, and making real friends is not easy here. We live together and we keep company to each other and that helps to overcome the lack of social life and also I guess we don't have much of a social life because we have each other so we don't make the necessary efforts to build friendships here.

Luciana's personal disposition is not necessarily conducive to being actively involved in large social or professional networks. Thus, while Luciana is a member of RGMX, she is unlikely to take fully advantage of the organization's networking and professional activities.

Moreover, Luciana does participate both civically and politically in Mexican affairs. While she was living in Mexico, Luciana volunteered on and off with the Partido Revolucionario Democrático (PRD) for a number of years. She explains:

My civic engagement was random because it was easier for me to join something that really concerned me about what was going in the country rather than being part of a social movement. In the 2006 elections when Manuel López Obrador [PRD candidate] lost the elections I did actively participate in public protests and civic activities. In 2012 I was in Mexico and I participated as an electoral observant. We could not believe Enrique Peña Nieto had won, the fact the PRI had come back to power it was very difficult to accept. These types of problems moved me deeply and made me want to be more involved politically. 
Thus, Luciana's political and civic engagement was sporadic and often prompted by specific political events. Her commitment with the RGMX is also conditioned by her own personal predisposition to actively participate in social and professional associations. At the same time, Lucia is planning to return to Mexico to be more actively engaged in politics and civil society as well as to contribute to her country's scientific advancement.

In summary, members of the RGMX Toronto Chapter have a variety of interests and focus their participation on professional networking, dissemination of scientific information, or the promotion of Mexican culture, among other areas. RGMX members in Toronto are highly skilled and engaged individuals who have the organizational capacity to establish working collaborations at the local, national, and transnational levels. Thus, while a RGMX is a selective organization, it is also inclusive of their members' interests and their different levels of engagement. Location of residence, personal temperament, and professional priorities are all factors that matter in RGMX members' level of participation.

While RGMX was established to foster ties between highly skilled Mexican emigrants with Mexico, the Toronto Chapter centres primarily on local professional and cultural activities as well as on fostering networks of support among Mexican immigrants in the city. As such, the Toronto Chapter can be best described as a Mexican immigrant collective of scientists, scholars, and artists engaged in a variety of professional and community activities, which are often disconnected from Mexican governmental institutions. 


\section{CONACYD: Mexican Policies and The Movement of Highly Skilled People from Mexico to Canada.}

With exception of Jimena, all members of the Mexican Global Network who participated in this research came originally to Canada to pursue graduate studies at Canadian universities. The fact that the overwhelming majority of RGMX members were former international students is not only indicative of RGMX's selectivity as an organization but also of larger structures of support allowing for the migratory movement of young Mexican scientist and social scientists to Canada.

Through Mexican academic councils such as the National Council for Science and Technology (CONACYD) and the National Council for Culture and the Arts (CONACULTA) the government of Mexico offers scholarships that cover full tuition and living expenses of students pursuing graduate studies abroad. In total, six of the participants received scholarships from the Mexican government to pursue their graduate education in Canada. After completion of their graduate studies, 95 percent of these research participants decided to live permanently in Canada. Thus, while often unintended, pursuing graduate studies in Canada has become a successful immigration strategy for highly skilled Mexicans.

Scholarships provided by CONACYD were the most common mechanism of financial support utilized by Mexicans researchers living in Canada. For instance, Lázaro received a CONACYD scholarship for studying a $\mathrm{PhD}$ in science, which he describes as "nothing short than a blessing". He elaborates: "I have not met a Mexican graduate student who has come to Canada without a CONACYD scholarship. There is no doubt that the CONACYD scholarship offers a big advantage for people who come study abroad and it has been of invaluable help for me". Also, Luciana was a CONACYD 
scholarship recipient and for her this was instrumental for studying her $\mathrm{PhD}$. She explains: "the CONACYD scholarship was very important because tuition as a foreign student is more than double than for Canadian students and I would have not been able to afford it". In short, Lázaro and Luciana would have not simply been able to pursue their doctoral training in Canada without the financial support from CONACYD.

Like other foreign students, Mexican citizens pursuing graduate studies in Canada can also receive financial support from Canadian universities. Roger was awarded a full funding package from the University of Toronto and he is one of the few research participants who completed his $\mathrm{PhD}$ in Canada without a CONACYD scholarship. Moreover, Mexican students receiving funding from Canadian universities can also apply for a CONCYD scholarship, which can result in significant savings for Canadian universities. Gabriel is an engineer who received a full scholarship by the University of Toronto to pursue a $\mathrm{PhD}$ in Engineering. Gabriel explains how receiving a CONACYD scholarship for living expenses also helped his university:

CONACYD is a scholarship that guarantees funding for five years and it also looks good on your CV. When I got it, I received money for tuition and living expenses but I asked them to please give me money only for living expenses because the university here already covered tuition. For me, the CONACYD scholarship was not that financially important because I already had funding but the university here saved money because they deduced from my funding package the money I received from CONACYD.

Thus, CONACYD scholarships do not only facilitate the movement of highly educated professionals to Canada but also benefit Canadian academic institutions by allowing them to save financial resources. Such a financially advantageous state of affairs for Canadian universities is in line with the neoliberal approach to immigration policies, which 
prioritizes the migratory movement of people that bring short-term economic benefits to the country (Ross, et al. 2014).

Furthermore, funding from CONACYD is not restricted to pursuing graduate education in the natural and applied sciences. Vanessa is a Mexican researcher who did a $\mathrm{PhD}$ in the social sciences in Canada and for her, "the CONACYD scholarship works better than most Canadian scholarships". She elaborates on her experience with CONACID: "I moved to Canada in a rush and only with the funding from my university here. I realized the funding was tight and by the second year of my program I applied for the CONACYD scholarship and they paid for my tuition and gave me $\$ 1,000$ a month to live for a period of five years. The CONACYD scholarship worked very well for me and it really made an impact on the way I lived". Clearly, for Vanessa the CONACYD scholarship was instrumental for the completion of her $\mathrm{PhD}$ in social science in Canada.

Also, there are scholarships for Mexican students and artists to pursue graduate education in the humanities and fine arts. Jimena received a scholarship from CONACULTA, which allowed her to further her education in classical music in Lugano, Switzerland. Also, while living in Canada permanently, Jimena received funding from the Fondo Nacional Para la Cultura y las Artes (FONCA) to support her publications on classical music. Jimena values the financial support she received from Mexican cultural institutions and she assures that "funding awards from Mexico have really helped in [my] career".

While CONACYD scholarships are a valuable tool for Mexican students to complete their PhDs in the natural and social sciences in Canada, the participants had also a number of suggestions for the better functioning of CONACYD scholarships. For 
example, Lázaro thinks that CONACYD centres in Mexico are too centralized in a couple of urban areas, which places scientists from universities in the interior of the country at a disadvantage. He elaborates:

There is a reduced number of people who get CONACYD scholarships, usually they come from large public universities near Mexico City and in the center of the country. This is a problem. There is small number of people who get CONACYD scholarships in universities in the interior, and that is an area that needs to improve. Perhaps students from the interior do not know much about CONACYD, perhaps that is because of lack of information, or more importantly because of lack of CONACYD centers outside Merida, Jalisco, Mexico and Monterrey.

Thus, for Lázaro CONACYD‘s centralization on Mexico’s largest cities presents an ongoing problem of exclusion for Mexican scientists working in smaller urban centres. Lázaro's perspective is congruent with the overall observations of my field research, since the general profile of CONACYD recipients who participated in this research is that of a relatively young scientist originally from Mexico City.

Vanessa has also some suggestions for the improvement of the CONACYD scholarship. She explains:

CONACYD works very well but they have reduced funding for extending your studies. Canada helps you when you have finished your $\mathrm{PhD}$ through the highskill workers program. But when you are finishing your $\mathrm{PhD}$ and applying for the work permit you also need support for this transition, and at least in my experience you are left without much support.

Vanessa took over five years to complete her $\mathrm{PhD}$ and the possibility of extending CONACYD funding for an extra year or an extra semester would have provided her with much needed support in her transition for getting a work permit in Canada. According to Vanessa such a transition period is not unusual among CONACYD scholarship recipients in Canada. 
Moreover, CONACYD hopes to promote networks of support and collaboration among scholarship recipients. According to Luciana, however, it is not always feasible to establish such a networks of collaboration. She explains:

CONACYD wants to foster scientific collaboration between scholarship recipients but that is difficult because we come as $\mathrm{PhD}$ students who depend on their supervisors. Also you can't just publish an article with another scientist just because he is Mexican. Scientific collaboration requires more professional connections than that. The more I have done is to meet with other CONACYD recipients, and yes we do have an informal network of support and sharing of information. I mean, it is helpful to meet and talk but CONACYD could work better in this regard.

Clearly for Luciana, there is significant room for improvement in fostering working collaboration among CONACYD scholarship recipients in Canada.

CONACYD requires award recipients to go back to work in Mexico for at least six months and while most participants agree with this condition, they also have a variety of opinions about the feasibility of going back to Mexico. According to Luciana, "it is important and necessary to go back to Mexico for a period of time to share with Mexican students what you have learned abroad". Luciana however, points out that going back to Mexico "is more of a moral obligation that anything else because they do not have any way to enforce it". Moreover, Vanessa explains that in the past CONACYD scholarship recipients were asked to return to Mexico to work at a university "but now contracts with CONACYD expire when you finish your PhD”. Thus, scholarship recipients do not have a legal obligation to return to work in Mexico. For Vanessa "it is only fair" to go back to Mexico and transfer knowledge gained abroad but she points out that salaries for academics in the social sciences and humanities are just very low". Clearly for Vanessa, the lack of competitive salaries for professors in the humanities and social sciences is also a significant obstacle to going back to work in Mexico. 
Lack of adequate scientific infrastructure is another deterrent for going back to Mexico after completion of a $\mathrm{PhD}$ abroad. Gabriel elaborates on his brother's and his own experiences on this matter:

CONACYD has some repatriation incentives but what we do as scientists when we are abroad is very specific and Mexico does not have that type of infrastructure. My gratitude is indebted with Mexico because they gave me this scholarship. They ask you to go back to Mexico, I believe now it is six months, but there is nothing to go back to if they do not have the necessary equipment to conduct your research, which is my case. Something similar also happened to my brother, he did his $\mathrm{PhD}$ in economics at the University of Edinburgh and he was more than happy to go back to Mexico. CONACYD offered him a job in a very small university in the interior and he was wondering well $\mathrm{I}$ got a $\mathrm{PhD}$ in economics only to work in an institution where there is no research.

While lack of infrastructure and research capacity represent a real barrier for the development of Gabriel's career as a scientist in Mexico, his decision to stay in Canada was also informed by his own experiences with limited job opportunities and lack of transparency in Mexican laboratories. He explains, "I worked in two labs in Mexico and one of them was a disaster, you could see the corruption left and right. The other lab was very good, it was well funded and it had good researchers but it is a small lab and there is no room for other scientists". Hence, for Gabriel there are serious systemic and institutional problems in the practice of science in Mexico, which deterred him for going back to Mexico to work as a scientist in his field.

In short, CONACYD scholarships facilitate the permanent migration of highly skilled professionals from Mexico to Canada, constituting a significant financial investment in the human capital of Mexican professionals in Canada. Also, lack of infrastructure for the practice of science and lack of competitive salaries at Mexican universities deter CONACYD scholarship recipients to return to Mexico after completion of their doctoral degrees in Canada. 


\section{Conclusion}

There are a number of conclusions to be derived from the participants' experiences with RGMX and CONACYD scholarships. First, the high number of Mexican academics and CONACYD scholarship recipients living permanently in Canada is indicative of the utilization of higher education as an immigration strategy. This is consistent with my research findings that indicate that twenty-eight of the forty participants came to Canada originally as international students to study English, bachelors' degrees, or to pursue graduate degrees in Law, Business Administration, and $\mathrm{PhDs}$ in different fields.

Second, Mexican scientists and scholars living in Canada prioritize local community development over developing working collaborations with Mexico. Thus, highly educated and talented Mexican immigrants show a high level of adaptability to the Canadian context and they are not necessarily looking for closer ties with Mexico. Third, Mexican scientists, academics and artists living in Toronto have the organizational capacity to utilize RGMX to establish transnational collaborations with other networks. Transnational sharing of information and working collaboration however, is influenced by the expertise of RGMX members and also by location. As such, emigration strategies inclusive of local community development and of fostering transnational networks of support seem to be ideal to build relations with highly skilled Mexican emigrants.

Highly skilled Mexican professionals do not only contribute to the Canadian knowledge based economy, they are also engaged in the communities where they live. Thus, highly skilled migration in the context of Mexican immigration to Canada also highlights the migratory movement of civically engaged people who actively care and 
seek to contribute to Canada. Mexican emigration policies open the opportunity to maintain close relations with Mexican immigrants who can also become potentially influential Canadian citizens. In this regard, RGMX and CONACYD scholarships are pragmatic Mexican governmental approaches to fostering relations with its academics in diaspora.

Moreover, questions remain about the efficiency of the RGMX organization and CONACYD scholarships to mitigate some of the negative economic effects of highly skilled migration from Mexico. In the areas of science and technology, Olavarrieta (2011) has pointed out the need for investing more in tech opportunities to attract Mexican scientists back to Mexico, arguing that there is a need for more adequate policy responses to the ongoing irreplaceable drain of human resources in the country. Olavarrieta's concerns are echoed in the 2013 OECD Reviews of Innovation Policy, which recommends that the Mexican government "expand its public research in order to increase the innovation and technology transfer performance of public research institutions $(\mathrm{OECD}, 2013)^{11,}$. My research findings corroborate these suggestions since even though some CONACYD scholarship recipients and RGMX members were willing to return to practice science in Mexico or to actively collaborate with Mexican universities in scientific projects, the lack of adequate infrastructure and funding were significant deterrents for them to go back to work in Mexico. In short, without further

\footnotetext{
${ }^{11}$ Such policy recommendations have been consisted for a number of years. Since 2009, the $O E C D$ Reviews of Innovation Policy: Mexico has recommended the Mexican government to increase public spending on science and technology. See: OECD. (2009). OECD Reviews of Innovation Policy: Mexico. Paris: OECD Publishing.
} 
investment in research and innovation, the RGMX organization and the CONACYD scholarships seem to be insufficient policy responses to address overall concerns about Mexican highly skilled migration.

Interestingly, the migration experiences of RGMX members and CONACYD scholarship also corroborate some arguments about the economic effects of highly skilled migration from Mexico to the sending of remittances. Quantitative studies point out that highly skilled Mexican migrants send proportionally less remittances to Mexico than non-skilled migrants due their propensity to bring their close relatives to their country of residence (Faini, 2007). With the exception of Gabriel, all RGMX members and CONACYD scholarship recipients did bring at least one immediate family member to Canada and none of them mentioned sending remittances to Mexico. My research findings thus further support the correlation between highly skilled migration and low remittances to Mexico. While this finding was not central to my investigation it is nonetheless significant since the policy and human development literature (Ustubici, and Irdam 2012) has shown the positive impact of remittances in human development for immigrant sending countries.

High-skilled emigration however does not necessarily deplete a country's human capital stock as it can generate positive externalities exemplified in the role of the Indian diaspora in the development of the country's technology sector (Docquier and Rapoport, 2012). In the case of Mexico, Marmolejo-Leyva, Perez-Angon, and Russell (2015) point out that there are tangible benefits of academic mobility for Mexicans looking to further their international scientific collaboration, which in turn can translate to technological advancements for Mexico. While my research shows the benefits of CONACYD 
scholarships for facilitating international professional experiences among the participants as well as the capacity of RGMX to promote networking activities among its members, it is still a matter of further research to determine whether RGMX networking activities and the endowment of CONACYD scholarship eventually translate into significant investment in Mexico's scientific sector and/or in increasing academic collaborations of Mexican emigrants with Mexican universities.

Migrant-sending states that wish to enhance their country's global competitiveness do not only seek to foster relations with their scientists and scholars living abroad but they also develop diaspora strategies aimed at business class emigrants (Ho, 2011). In the next chapter I will explore the policies and strategies Mexican business people in Canada use to maintain active citizen-state relations with Mexico and I will explicate how this relationship can be mutually beneficial. 


\section{Chapter VII}

\section{Policies and Practices: Citizen-State Relations with Businesspeople and the Enjoyment of Business Class Citizenship Rights}

"The way the population is divided up usually reflects an implicit or explicit position concerning the justice and legitimacy of the amount of income or wealth claimed by a particular group"

Capital in the Twenty-First Century, Thomas Piketty

On August 28 2014, ProMexico and the Canadian Council for the Americas (CCA) hosted a meeting with the Director General of Bancomext. According to CCA, the director general's visit was part of the Memorandum of Understanding (MOU) between Export Development Canada (EDC) and Bancomext, which aims to promote closer business relations between Mexico and Canada ${ }^{12}$. This meeting was open to the public but the number of attendees was small, giving it a sense of exclusivity. This is not surprising, however, as the meeting was hosted on a weekday during lunchtime at a law firm on Bay Street, Toronto's financial centre. Many of the attendees were MexicanCanadians working in Toronto's corporate sector and for them the visit of Bancomext's president was not only an opportunity to network with Mexican officials and with other business people but it also served as a reminder of the services available for connecting their business activities in Canada with their commercial interests in Mexico.

12 For more information on the Export Development Canada-Bancomext Memorandu of Understanding and Master Cooperation Agreement see: Government of Canada. (2014). Backgrounder: The Export Development Canada-Bancomext Memorandum of Understanding and Master Cooperation Agreement. Office of the Prime Minister. Retrieved from: http://news.gc.ca/web/article-en.do?nid=817409 


\section{Business Class Citizenship}

Critics of the effects of corporate globalization on citizenship point out how the process of de-territorialization and trans-nationalization of the wealthy elite have had harmful social consequences (Falk, 1999), has given rise to transnational managerial elites (Robinson, 2012), and increased the transmutation of economic citizenship rights from people to global economic actors (Sassen, 1996). In the context of migration, it has long been pointed out that the use of investor programs favours immigration of wealthy businesspeople over other potential citizens (Harrison, 1996), how businesspeople access special mobility rights to move freely across increasingly securitized borders (Sparke 2006), and how emigrant sending states have developed policies and programs to foster relationships with their business elites living in diaspora (Ho, 2011). Thus, studies critical of the relationship between corporate globalization and transnational citizenship underline the increasing access of corporate elites to exclusive citizenship rights in emigration, immigration, border security, and trade, among other interconnected policy areas. Members of wealthy corporate elites, however, represent a minority of the overall businesspeople living in diaspora, which leaves a significant knowledge gap about the exercise of transnational citizenship by emigrants working in the corporate and other business sectors. Studying the citizen-state relations of Mexican businesspeople in Toronto can, therefore, reveal some key aspects of how non-elite businesspeople benefit from government policies and programs in the context of migration.

Mexican professional businesspersons in Canada are not part of a transnational wealthy elite. Only two or 5 percent of the participants immigrated to Canada as middle managers through job relocation and two other participants were relocated in non- 
managerial positions, enjoying relative economic stability and job security ${ }^{13}$. The other research participants working in the corporate sector however had spent their savings to come to study to Canada, have done menial work while attending school, and they have also experienced underemployment for a significant period of time. Thus, their relations with Canadian and Mexican corporations and governmental institutions are more indicative of their professional expertise and their efforts for upward social mobility in the context of migration than significant personal wealth, family connections, or membership in an elite social class.

Moreover, Mexican professionals in Canada do benefit from a number of business and commercial services provided by Mexican trade agencies and Mexican consulates. Banking institutions such as ProMexico facilitate foreign investment, the $3 \times 1$ program offers incentives to Mexican entrepreneurs, and the Mexican consulate and trade commission support business relations between Mexico and Canada (Zamora, 2005). Eight or 20 percent or the participants used services and programs offered by the Mexican government to create business and bring investments into Mexico. In this chapter, I argue that access to these services is part of a growing set of business class citizenship rights, which provide Mexican emigrants with business opportunities and facilitate their work in corporate activities related with Mexico.

At its core, business class citizenship rights embody a mutually beneficial citizenstate relationship that merges private and public interests in the context of migration. Citizenship and social class are conflicting concepts as the former implies social equality while the latter entails social distinctions. Similarly, business activities and civic

\footnotetext{
13 Curiously, these participants did not utilize business services and did not maintain a relation with Mexican authorities.
} 
engagement are also contradictory as the latter is altruistic and lays in the public realm while the former is concerned with profit and takes place in the private sector. Business class citizenship rights are paradoxical and reflect the blurring boundaries between the private and public sectors, and the national and transnational arenas in contemporary public governance.

I use the concept of business class citizenship to describe the exclusive citizenstate relationship businesspeople enjoy with their government in the context of migration. Business class citizenship include: 1) access to public services to advance foreign trade; 2) access to public funding to facilitate imports and exports; and 3) gains from changes in economic policies including tax regimes, privatization of state owned industries and deregulation of market rules. The purpose of this chapter is to explore the exercise of business class citizenship by research participants working in the corporate sector. Also, this chapter aims to reveal the significance of business class citizenship in light of the expansion of citizen-state relations in the context of migration.

\section{ProMexico and the Trade Office: Access to Public Services to Advance Foreign Trade, and Access to Public Funding to Facilitate Imports and Exports}

Walter is an executive in a prestigious business institution. He explains his motivations for maintaining an active relation with Mexican institutions and using business services provided by the Mexican government in Canada:

I have been 15 years in Canada and during that time I have tried to bring investment to Mexico, to bring companies that promote employment, and foster commercial links with Mexico. I have been dedicated to that because it is my job but also because I want to contribute to my country's growth, that is why I have been in touch with the Mexican embassy, consulate, the trade commission, the tourist commission, and in my experience these offices work very well. I have always gone to introduce myself and to offer my help to the Mexican consuls 
arriving in Toronto, and that courtesy pays off because when you want to do business you are better received.

For Walter, bringing foreign investment to his country constitutes a form of civic engagement. The notion of private business as a form of public contribution is facilitated by Mexican governmental services supporting Mexican businesspeople in their efforts in bringing foreign investment and jobs to Mexico. Thus, the utilization of business class services allows maintaining an active and mutually beneficial citizen-state relation inclusive of Mexican emigrants' business interests with Mexico.

Foreign trade works both ways, and the Mexican government also provides services for Mexican businesspersons bringing investment into Canada. Paul, a MexicanCanadian bank executive elaborates on his experience on this regard:

I brought investment from a Mexican bank to Toronto and I asked him [the Mexican consul] for help and he was incredibly helpful. I also got in contact with the people from Bancomext now ProMexico. The Mexican Consulate and ProMexico are very good institutions for Mexicans here, and they need to be used more widely for business.

ProMexico is the Mexican commercial office dedicated to bringing foreign investment into Mexico (Anaya, 2013), and based on Paul's experience, the Mexican consulate and ProMexico office in Toronto also provide competent services for bringing Mexican investment into Canada. In short, whether it is bringing Canadian investment into Mexico or Mexican investment into Canada, both of the above participants were able to enjoy business class citizenship rights and they enjoyed positive working relations with Mexican officials in Toronto.

Not all business activities, however, get the same level of support from Mexican trade offices in Canada. According to Dorothy, a Mexican-Canadian entrepreneur, ProMexico promotes commerce and investment through market analysis, commercial 
missions, and partnerships with schools but it also "favours investment on advanced manufacture over other sectors of the Mexican economy such as agriculture". In addition, in order to extend their areas of business priorities, for Mary the ProMexico office in Toronto should also improve their capacity to deal with increasing client demands and return to previous institutional practices that provided banking support. She explains:

Trade officers are sent for only three to five years and by the time they make the necessary contacts and network they have to leave. I think there needs to be more people hired in the ProMexico office here, they are saturated with work and they cannot cope with all that is needed. They used to be larger when they were Bancomext around eight years ago. Bancomext was a bank that provided loans for people wanting to invest in Mexico and also promoted international commerce and investment while ProMexico deals specifically with international commerce, that is large imports, exports, or you opening a factory in Mexico.

As pointed out by Dorothy, Mexican policies facilitating and promoting trade seem to have shifted from providing banking services and financial support to individuals wanting to export or import Mexican products to focus instead on supporting large corporate investment in the manufacturing industry. In the context of migration, such a corporate focus benefits emigrants working in the corporate sector but offers fewer advantages to Mexican emigrants' looking to import Mexican products into Canada. Hence, there has been an increasing corporatization of business services provided to Mexican emigrants.

The Mexican Ministry of Foreign Affairs (SRE) 3x1 program and IME also offer grants to support Mexican emigrants' entrepreneurship and commercial activities with Mexico. For Dorothy, this grant has potential to benefit Mexican businesspersons in Canada but she is also critical of the way the $3 \times 1$ program is often utilized. She explains:

Programs like 3x1 are important. There are so many businesses in Mexico such as tomato farmers that would like to export to Canada but have no clue on how to do it. That would be a business project that could apply for that grant, an existing 
business in Mexico that wants to export, it generates resources and jobs in Mexico. Also, that has a positive impact for Canada. Sometimes, people use the $3 \times 1$ program to fix roads in their towns origin but that is something the government should do and should not rely for that on civil society, sometimes that is frustrating.

The $3 \mathrm{x} 1$ program triples donations made by Mexican emigrants, and it has traditionally been utilized by Mexican hometown associations (HTA) in the United States. HTAs are numerous in the USA and Mexican emigrants belonging to these associations have used the $3 \times 1$ program to improve infrastructure in their towns of origins. As pointed out by Goldring (2012), however, Mexicans immigrants in "Canada tend to form professional associations instead of HTAs". My research findings verify this conclusion, as research participants belonged to different professional associations but none of them mentioned belonging to or intended to form a HTA in Toronto. The absence of HTAs and the commercial interests of Mexicans in Toronto suggest a way of utilizing Mexican government programs for emigrants that is distinctive of that of Mexican emigrants in the United States. In the Canadian context, commercial incentives such as the 3x1/IME grant seem to be a better fit than the conventional utilization of $3 \times 1$ program that demands collaboration with significant numbers of Mexican emigrants.

In short, the Mexican government offers a variety of services and incentives for Mexican emigrants in Canada to bring foreign investment to Mexico, import products and capital from Mexico to Canada, and engage in commercial activities between the two countries. For Mexican emigrants conducting business with Mexico these services can provide substantive business advantages as well as the enjoyment of an active relationship with Mexican institutions in Canada. Whether the outcome of such a 
business class citizen-state relation contributes or not to the Mexican economy and society is still however a subject of further research.

Economic Policies, Transnational Politics, and International Business Opportunities: Operationalizing the Right to Benefit from Changes in Economic Policies

Business class citizenship also offers significant business opportunities from changes in economic polices such as trade, banking, and tax regulations. For example, Walter explains that relatively recently, "Mexico signed a no double taxation agreement (DTA) with Barbados and people [Mexicans in Canada] working in private banking and wealth management in Canada can take advantage of this business opportunity.",14 Mathew, a participant working in a Canadian bank explained his working experience with DTA: "I work in a Canadian investment bank, and I opened the Mexican market for them. Now, Mexico is the most important growing market in the bank." Mathew had experience working in the public and private sectors in Mexico as well as experience in private banking in Canada, which according to him helped him to provide banking services in wealth management to Mexican clients. This is an example of how business class citizenship also works as it allows individuals with the right set of skills and contacts to expand their business portfolio from changes in economic policies.

Mexican economic policies went through significant changes in the first years of the government of president Enrique Peña Nieto, including the opening of key sectors of

\footnotetext{
14 This tax treaty allows people in Mexico and Barbados to pay identical or similar taxes in either country including Federal Income Tax and Business Flat Rate Tax. See: Government of Barbados and the Government of Mexico. (2008). Convention Between The Government of Barbados and the Government of the United States of Mexico for the Avoidance of Double Taxation and the Prevention of Fiscal Evasion with Respect to Taxes and Income. Retrieved from: http://www.investbarbados.org/docs/DTA\%20\%20Mexico.PDF
} 
the Mexican economy to foreign trade and investment between 2012 and 2013. Chief among these reforms was the opening of the energy sector to foreign investment after seventy years of nationalization of the oil industry (Alvarez, and Valencia, 2015). According to Walter, "for a country like Canada that has an expertise in the energy sector [the energy reform] opens many opportunities for potential businesses." Potential business with Mexico can translate into professional opportunities for Mexican executives in Canada with the right contacts in Mexico. Walter elaborates on his experience organizing an event in Mexico for possible Canadian investment in the energy and mining sectors:

I am not rich or related to any powerful family but through my career I have developed contacts that allowed me to knock the necessary doors in Mexico. I was asked to develop an agenda and I was able to get these necessary contacts in Mexico. We are going to meet with the Mexican Minister of Energy, Minister of Finances, with the Canadian Embassy, with the General Director of Bancomext, ProMexico, and Mining Promotion. For business development those contacts are golden.

Walter was able to build extensive professional contacts with Mexican officials through years of working experience with the Mexican government. His ability to contact important government officials on behalf of prospective Canadian investors is an added value to his professional expertise as a corporate executive specializing in extractive industries and foreign investment. This is another example of how changes in economic policies (in this case the privatization of extractive industries) offer significant professional advantages to Mexican emigrants working in the corporate sector.

Policy and politics are closely intertwined and business class citizenship also offers a platform for political discussion and engagement. Research participants working in the corporate sector have the capacity for organization and resource mobilization to 
host political events and to regularly attend meetings discussing Mexican and Canadian policies. For example, during the presidential campaign of 2013, some of the participants organized a political debate with representatives of Mexican parties. Walter explains:

We organized a debate in the Toronto Board of Trade with people who represented the presidential candidates from the PRI, PAN, PRD, the candidate from the PRI later declined so we only had two candidates. The lady who represented the PRD lives here in Canada, and the PAN representative came from Mexico. We made the event in the Toronto Board of Trade only catering to Mexicans, it was open to the public but the next day we also organized a debate with the business community for the PAN and PRD representatives.

By organizing Mexican political debates in prestigious business locations and by including members of Toronto's business community in these events, Walter can connect his business interests in Canada with his political interests in Mexico. Such synergy between private interests in Canada and Mexican public affairs highlight the sophisticated international dimension in the exercise of business class citizenship rights.

International lifestyles allow some research participants working in the Canadian corporate sector to be politically and civically involved in Mexico. For instance, Mathew's lifestyle as a bank executive and his personal connections have helped him to be politically and civically engaged in Mexico while living in Canada. He explains: "In Mexico I am very involved in politics. I have many friends who are also involved in politics and we have created a group of concern citizens, an NGO to support social development. I can do that because I spend ten days per month in Mexico. So, I basically live in two countries."

Mathew's international lifestyle and his political and civic engagement with Mexico, however, seem to exclude a more active participation in Canadian politics and civil society. He explains: "here in Toronto we have been trying to create a Mexican 
professional business association, and some of the people in this group are already involved in politics here but I am not because my lifestyle of living in two countries does not allow me to immerse myself in politics a hundred percent." In short, while international lifestyle may allow Mexican emigrants to live and work in Mexico and Canada, this is not necessarily conducive to being politically and civically engaged in both countries.

Moreover, Mathew has the desire to enter the Canadian political scene in the future. He elaborates on his interest in politics:

I never thought I was going to be a banker and the human aspect of politics still fascinates me, politics are still in my heart. I would like to be involved and contribute to politics in Canada but I need to consolidate my own finances in order to jump to that next step, and have the freedom to say: well now is the time to give back to Toronto, the community that has given me so much. Because if I am going to be involved in politics I am going to do that in Canada, I just see myself and my family living in Canada and not Mexico.

Mathew's desire to participate in electoral politics in Canada reflects a significant level of commitment to Canadian society. In this regard, Mathew's active civic and political engagement with Mexico is a circumstantial state of affairs, indicative of his lifestyle as a transnational businessperson with interest in Mexico rather than a principally political decision.

Walter and Mathew went to graduate school in Canada, they have both worked in the Mexican public sector and the Mexican and Canadian corporate sectors, and they are politically engaged with Mexico. Their professional profiles and work experience place them in an ideal position to benefit from changes in Mexican economic policies and in the case of Walter to also utilize government business services. Their transnational lifestyle as corporate executives allows them to maintain an active political participation 
with Mexico and also to interconnect their business and political interests. In short, Walter and Mathew provide a good example of the profile needed to access business class citizenship rights in the context of Mexican immigration to Canada.

My research findings reveal that in the context of migration, businesspeople specialized engagement with the market economy allows them to enjoy an exclusive set of rights pertinent to their work in commerce, banking, and investment among other business activities. The correlation between specialized engagement with the market economy and access to citizenship rights is complex and problematic as it shows both regressive and innovative features. First, the enjoyment of business class citizenship rights suggests a return to a more traditional relationship between social class, citizenship and engagement in the market economy. Traditionally in liberal capitalist societies, social class was determined by people's relation to the market economy, which in turn also influenced their access to citizenship rights (Marshall, 1962). The rise of an exclusive business class citizen-state relationship in the context of migration can thus be understood as a regression to a citizenship regime designed and regulated to support the imperatives of the market economy.

Second, the transnational operationalization of business class citizenship is innovative. The exercise of business class citizenship includes the active participation of emigrants in the policy processes. By transforming emigrants into policy actors, the Mexican government has managed to establish working collaborations with its citizens in diaspora to support the country's economic agenda. In this regard, the development of business class citizenship rights suggests an expansion of the liberal citizenship regime in the context of migration that is transnational, collaborative between state and non-state 
actors, and inclusive of the voices and interests of emigrants working in the corporate, financial, and investment sectors.

In short, business class citizenship rights are exclusive, regressive, and innovative, revealing the complex synergy between business and citizenship in the context of migration. Moreover, the highly specialized, transnational and collaborative character of business class citizenship rights also reveal an important social dimension necessary for the acquiring of policy knowledge and the development of professional and political contacts. The next section will look at the social component of business class citizenship rights.

\section{Spaces for Socialization and Policy Knowledge: The Social Dimension of Business Class Citizenship Rights}

The exercise of business class citizenship rights requires access to policy knowledge and spaces for professional and political networking. In the context of migration, Mexican businesspeople access such selective information and networking opportunities by participating in specialized non-governmental organizations, by cultivating relations with Mexican consular representatives, and through the use of technology. Also, participants with access to business class citizenship rights tended to have a high sense of social responsibility, and assumed a number of social commitments. It is thus imperative to explore the non-governmental dimensions of business class citizenship rights

Participants exercising business class citizenship rights reveal a sophisticated understanding of current Mexican economic policies. For example, Paul has a highly 
technical understanding about recent Mexican policies in the energy and

telecommunication sectors. He explains:

The energy reforms were not in the agenda when I came to Canada but everybody knew Cantamel could not produce at high rates any more, and that the budget and Mexico's fiscal responsibilities cannot be supported without Pemex, and Pemex's capacity to get financial support has been declining. [On the other hand,] I am concerned about monopolies because it is something that hurts prospects for business competitiveness and economic growth in Mexico. There are people like Carlos Slim who had made fortunes through monopolies in telecommunications, and one is left wondering which are the actions that Mexican government has really taken to reduce monopolies so far.

Paul's knowledge about Mexico's economic policies allows him to illustrate the inherent contradictions in recent policy changes that promote trade liberalization of key sectors of the Mexican economy while at the same time avoiding necessary structural reforms to improve competitiveness in other sectors. Such reforms in the energy and telecommunication areas were developed and implemented many years after Paul had immigrated to Canada, which also highlights Paul's ability to follow Mexican policies from Canada.

In-depth understanding of the Mexican economy requires up-to-date knowledge about Mexican trade, finances, economic policies, and politics. Eight (20 percent) of the participants, including Paul, regularly attended events and forums dealing with Mexican commerce, economic policies, and politics organized by members of Toronto's business community. The most popular events among the participants were those organized by the Canadian Council for the Americas (CCA). ${ }^{15}$ For Mexicans in Canada interested in Mexican economic policies and politics CCA events provide the prospect of meeting with

\footnotetext{
15 CCA is an organization dedicated to fostering Canada-Latin American relations and it offers MexicanCanadian professionals with the opportunity to be informed about Latin American politics and policies through a series of presentations, panel discussions, and lunch meetings with experts and government representatives.
} 
diplomats, academics, and politicians as well as to interact with businesspeople interested in Mexico and Latin America. ${ }^{16}$

Social media is another way in which participants working in the business sector keep themselves informed about Mexican policies and politics. Robert is a lawyer working in a law firm in downtown Toronto who besides attending CCA meetings also uses technology to inform himself about Mexican policies and political affairs. He explains:

Twitter is very popular in Mexico, and you get to know a lot of what goes on there for instance about the reforms in Mexico, we get links and you get informed about the new policies. My twitter account is eighty percent Mexican and twenty percent Canadian, I use twitter constantly to be informed about Mexican affairs, politics, business, news, etc.

Thus, in the context of migration, Twitter is used as an important tool for maintaining up to date knowledge interactive discussions about Mexican political and economic affairs.

The use of social media does not substitute personal contact with Mexican institutions and Robert also tries to maintain a relation with the Mexican consulate in Toronto. He explains:

The consulate is my main institutional connection with Mexico, for instance to vote. The first thing I did when I came to Canada was to contact the Mexican consulate, to meet with ProMexico, and offered them my help. The consulate provides you with a variety of opportunities to know what goes on in Mexico and to be engaged.

Clearly, Mexican governmental offices are an important institutional link to Mexico.

\footnotetext{
16 In 2014, CCA events included presentations about Mexico's Energy Reforms, the Pacific Alliance, and Mexico City's municipal policies. These events were conducted by the Director of the Woodrow Wilson Mexico's Center, the ambassadors from Mexico, Peru, Colombia, and Chile, and by Mexico City's former mayor Marcel Ebrard respectively. Also, the same year CCA organized gala events with the presidents of Peru, Colombia, and Chile among other dignitaries.
} 
Robert and Paul maintain an active relationship with the Mexican consulate and trade offices, they participate in CCA events, and keep themselves up to date about Mexican political and economic affairs.

Active relations with Mexican authorities and participation in corporate events, however, do not exclude Mexican business people from holding critical positions about the Mexican government or to be civically engaged in activities separate from Mexican institutions in Canada or in Mexico. Robert used to work as a lawyer for the Mexican Ministry of Agriculture in the area of appropriations. He explains his experience with indigenous agricultural communities, ejidos, in the jungle of Oaxaca:

I represented the government that expropriated some of their land, so when I was there I saw that people did not have a place to live, they did not have enough food, and they were living in the streets. I represented a government that was taking advantage of them but I wanted to help them. I told my boss that they were entitled to compensation and if a politician had stolen their land we were going to be responsible for it. We managed to get into an agreement with each of the ejidatarios.

Thus, Robert has an inside perspective of systemic injustices committed against agricultural communities by Mexican politicians and he has been proactive in supporting the communities where he used to work as a civil servant.

Robert had a long experience of engaging in social issues in Mexico and before joining the Ministry of Agriculture, he was in charge of looking for community programs and activities for law students, founded a youth leadership project that provided leadership courses in civic and political engagement, and he volunteered with Mexico's Ministry of Justice by helping people with low-incomes to present lawsuits. Despite his active involvement in issues of public concern in Mexico, Robert's experience in Oaxaca 
still affected him deeply and he explains that even today he feels that he has "unfinished business in Oaxaca":

I still maintain my contact with people working with communities in Oaxaca and I hope to retake that social cause again in the very near future. There are ejidatarios that tell you they do not have much problems that their harvests are going well and export their mangos to the U.S and Canada but they always get half the money because they are told that their mangos arrived all squashed. They have asked me if there are people who can help with that. I am planning to get involved in trading and work with these communities, avoid the middleman and engage in business with them directly.

Robert's entrepreneurial and civic interests are intertwined, seeing potential business ventures with ejidatarios as a way of contributing to a community he feels attached to. He elaborates: "I am here working in a law firm, and that is how I pay my bills, but I also work on my personal projects and I am always thinking of how to help my family and the communities I am involved in, if I could do that for a living that would be ideal."

Moreover, Robert's civic and entrepreneurial interests in Mexico can also be compatible with civic contributions in Canada. Robert volunteers for an NGO working with children in hospitals in Toronto and translates legal letters for them. Also, Robert tried to provide legal advocacy to Mexican agricultural workers in Southern Ontario but he was informed in the Mexican consulate that, "Mexican agricultural workers are already receiving legal support by a Canadian firm."

Paul's civic engagement is also disconnected from Mexican governmental institutions. Paul has been socially engaged for almost thirty years, volunteering with disadvantaged children and adolescents in Mexico. Also, he has volunteered with youth experiencing serious psychological problems, he has been the vice president of a regional association working with people with disabilities, and he brought to Mexico the franchise 
of a British NGO working in the area of youth leadership. In Canada, he is also socially engaged. He explains:

I am involved with Social Ventures Partners in Toronto, they have a model of venture capital where every member contributes with the same amount of money, which then is used to support a social cause. We receive a number of applications from different programs or projects and based on merit we decide to support them, we give them the funds, and also human resources, finances, management, etc., so they can succeed and improve. Also, I donate blood every six months and I am involved with the Alumni Association of Harvard University, where I did my MBA, by supporting students in Canada who are applying to Harvard University.

Thus, Paul's civic engagement in Canada is extensive and his volunteering commitments varied from social entrepreneurship to education and health.

Paul received support from a Mexican professional organization in Toronto and now his volunteering activities also include working with members of this organization. He explains his experience with the Alumni Organization of the Monterrey Institute of Technology (EXATEC), a private university where he studied engineering:

The first thing that I did when I came to Canada was to get involved with EXATEC. They have a program that provides newcomers with guidance and support. When I came here I was by myself only with luggage and you are looking for a job, you need networking, get to know the social and business practices in Canada, and EXATEC members provided me with that. For some years I have been welcoming Mexicans through the EXATEC program, we divide the number of Mexicans who are coming and each takes some. I have gotten to help many Mexicans that way.

Paul is a Mexican businessperson whose civic engagement in Canada extends to members of the Mexican community in Canada and to Canadian society at large. His civic commitments are indicative of his personal history in educational institutions and his sense of responsibility to contribute to the society in which he lives. Thus, while Paul maintains an active citizen-state relation with Mexican authorities in Canada and he has 
also access to Mexican business class services, his civic engagement is separate from Mexican institutions.

On the one hand, the social spaces for the development of business class citizenship rights are highly exclusive. On the other hand, Paul and Robert's experiences with civic engagement show that the exercise of business class citizenship rights can coexist with deep personal commitments to social causes. Such a seeming contradictions reveal that while the exercise of business class citizenship can be considered elitist it is not necessarily uncritical as it can include important elements of social solidarity. Also, the social dimension of business class citizenship rights may suggest that these rights are used as pragmatic tools for professional development and for establishing active citizenstate relations in the context of migration and they are not necessarily indicative of people's civic principles.

\section{Lack of utilization of Mexican Policies and Programs: Alternative to Business Class Citizenship Rights}

Not all Mexican businesspersons in Canada exercised business citizenship rights, maintained an active relationship with Mexican officials in Canada, or utilized Mexican business services. Leo is a practicing business lawyer in Toronto who follows Mexican politics and policies closely but he is disconnected from Mexican governmental institutions. He explains:

As a citizen, I have been able to be informed and maintain an active relation with Mexico not because of any public policy or institution but because of my own efforts. My family still lives in Mexico and I inform myself about what goes on in the country. I have rarely looked for any information or even touched base with the Mexican consulate or with an official Mexican representative. Besides, I don't think there are many official links with Mexico. 
Clearly, Leo does not have an interest to pursue an active relation with Mexican authorities in Canada.

Similarly to other participants working in the business sector, Leo attends CCA events and also meets periodically with other Mexican professionals living in Canada to discuss business prospects. Leo makes a distinction, however, between business meetings and fostering relations with Mexican authorities in Canada. He explains:

There are some initiatives with a focus on business and I participate in a group fostering commercial links with Mexico, the idea is to talk about the areas that need to be improved and look for niches that provide opportunities for Mexicans here... but if you ask me about practices and public policies promoting closer relationships between Mexico and Canada, and Mexican-Canadians, I would say that there is room for improvement.

Thus, Leo sees a significant room for improvement in the relationship between Mexican authorities in Canada and members of the Mexican community in Canada.

Despite being disconnected from Mexican government representatives in Canada, Leo is an active supporter of the Mexican community in Toronto. For Leo, getting the license to practice law in Ontario was a long and challenging process, and his civic engagement with Mexican immigrants centres on supporting and guiding Mexican lawyers coming to Toronto by "providing them with professional guidance, contacts, and information about the practice of law in Ontario." Leo believes that "Mexican-Canadians need to organize and support each other because no public policy or program is going to meet [their] needs and aspirations." For Leo, the practice of law and civic engagement are intertwined and he is "very glad to see that that there are five Mexican lawyers currently going through the process of revalidating their law degrees here in Ontario." While Leo promotes collaboration and mutual support among Mexicans immigrants in Canada, he 
does not receive any support from Canadian or Mexican authorities or utilize services from the Mexican government in Canada.

John is another businessperson who did his MBA at a high-ranking Canadian university and works for a Canadian business institution. John does not use Mexican business services and he does not maintain a citizen-state relationship with Mexico through Mexican authorities in Canada. Moreover, John is very actively engaged in Enlace, a Mexican community organization, which for the last ten years has helped Mexican agricultural workers in Southern Ontario. John elaborates on the work of

\section{ENLACE:}

ENLACE helps Mexican agricultural workers by providing them with legal and medical support and also we to try to make their stay in Canada more pleasant. We help them with their taxes, their parental leave, and other benefits they may not be aware of. In the medical aspect, there is a level of ignorance of possible health risks of working in agriculture and we provide them with guidance about medical services. Also, we organize social events, soccer games, bicycle rides, etc. Thus, ENLACE also works as a social or community club, because we Mexicans get together to do social activities.

Thus, John is a businessperson who is deeply committed to support Mexican agricultural workers in Ontario.

John collaborates with a number of Canadian organizations including the Agricultural Workers Association of Saint Catherin and the Ontario Health and Wellness Association, which have been supportive of ENLACE. John does not, however, receive any support from Mexican institutions in Canada. He explains:

The Mexican consulate is not very helpful. They opened a consulate in Leamington but they provide minimum support to agricultural workers and only help in case of emergency. They do administrative work but they do not provide any guidance and do not advocate for agricultural workers. They avoid supporting agricultural workers. Even in Canada, agricultural workers are not supported by the Mexican government. 
Hence, John is critical of the Mexican consulate and government and he denounces the lack of substantive support for Mexican agricultural workers by part of Mexican authorities.

John's activism with Mexican immigrants is separate from Mexican governmental institutions, and like Leo, he does not receive support from the Mexican consulate and Mexican institutions. John's experience with community work has been a later development in his life, as he "never had any experiences with civic engagement in Mexico," but he has managed to provide significant support to Mexican agricultural workers and to establish important collaborations with civil society organizations in southern Ontario.

Thomas is a bank executive in Toronto whose civic engagement with Mexico is disconnected from Mexican government institutions. He actively supports a Canadian NGO working in the area of education in his hometown. He explains: "this is a group of Canadian expats who live in Mexico periodically and I found it fascinating because they allow me to support efforts in the area of education and connect both of my worlds: Canada and Mexico." Thomas' commitment to the area of education is "very personal" and in Mexico he "had the opportunity and privilege to pay for the career of a young woman who could not afford an education". Underlying Thomas' civic engagement is the belief that "education is key for social development" and "would like to teach and transfer everything [he has] learned abroad to young students in Mexico."

Like Leo, Thomas is also critical of Mexican programs in Toronto. For instance, he explains his view about the $3 \times 1$ program:

I have participated in sessions organized by the Mexican government for Mexicans living abroad presenting programs such as $3 \times 1$ and other programs that 
support business with Mexico and I found them not very clear to say the least. Also, to take advantage of the $3 \times 1$ program and other services you have to organize Mexicans where you live and to organize Mexicans here is not an easy task. I found it easier to work with organizations not connected with the Mexican government.

As such, Thomas prefers to be civically engaged with NGOs rather than with Mexican authorities.

While Thomas' civic engagement as a philanthropist and as an activist in the area of education is disconnected from the Mexican government and its institutions in Canada, he has not always been detached from Mexican institutions. He explains: "When I was living in Beijing the consulate provided information and it had a very fluent communication with Mexicans. But in Toronto I don't think I have received more than three e-mails from the Mexican consulate, here the Mexican consulate takes a very passive role". Thomas's distance from Mexican institutions in Canada is not based on bias against Mexican governmental institutions and representatives in general, but rather it is based on his personal experience with Mexican institutions in Canada which he is able to compare to more active and adequate services provided by Mexican consulates elsewhere.

In short, Mexican businesspeople in Toronto who do not exercise business class citizenship rights are engaged in a number of organized efforts to support Mexican immigrants in Ontario. These efforts are separate from and tend to be critical of Mexican governmental institutions in Canada. The civic contributions of Mexican business people for advancing community development are not necessarily conducive for them to foster close citizen-state relations with Mexico, which contrasts with the experience of their counterparts who choose to exercise business class citizenship rights. Such a state of 
affairs suggests ideological and political undertones in the expansion and contraction of citizen-state relation in the context of Mexican migration to Canada.

\section{Conclusion: Business Class Citizenship and the Transnational Affirmation of Citizenship.}

As it has been shown in this chapter, research participants working in the corporate sector are highly educated professionals who have a sophisticated understanding of Mexican politics and economic policies, frequent specialized meetings for policy and political discussions about Mexico, and tend to be civically and politically engaged. Overall, Mexican emigrants with access to business class citizenship are wellrounded educated professionals with in-depth policy knowledge.

While some of the participants working in the corporate sector enjoyed a special citizen-state relation with the Mexican government by accessing business services provided by Mexican trade offices, and by benefiting from changes in Mexican economic policies, others did not maintain an active citizen-state relation with Mexican governmental institutions and tended to be distant from and critical of Mexican authorities in Canada. The enjoyment of business class citizenship is, therefore, a structural opportunity indicative of individuals' level of comfort in working with Mexican authorities as well as individuals' areas of business specialization.

Citizenship rights and responsibilities for Mexican businesspeople in Toronto include an active engagement with business, politics and civil society. This is apparent, since irrespective of whether participants working in the corporate sector maintained an active-citizen-state relation with Mexican institutions, accessed business-class citizenship rights, or were distant and/or critical of the Mexican government, they tend to be 
involved in NGOs working in Canada and/or Mexico and they were engaged in actively contributing to civil society. Also, the enjoyment of business class citizenship rights is often accompanied by immigrants' active contributions to both Mexico and Canada. This suggests Mexican businesspeople working in the corporate sector have a transnational approach to civic engagement, in which access to business class citizenship is only one aspect of their much larger and complex citizenship experience in the context of migration. In short, access to business class citizenship by Mexican immigrants working in the corporate sector in Toronto reveals an increasing multidimensionality of citizenship in the context of migration, in which business interests, political values, and policy knowledge combine in complex citizen-state relations including the decision to embrace business class citizenship rights or reject it.

Moreover, theoretical insights can help to shed a critical look at the enjoyment of business class citizenship. Bauder (2011) points out the dialectical relation between the citizen and the immigrant by a process of affirmation and negation of citizenship. If citizenship can be defined as the relationship between the individual and the state, negation and affirmation of citizenship can also be understood in light of the services that allow for beneficial citizen-state relations. Mexican businesspeople exercising business class citizenship rights benefit from a privileged citizen-state relation with Mexico, irrespective of their category as immigrants in Canada. Emigrants' access to business class citizenship rights functions as a transnational affirmation of citizenship that can potentially mitigate some of the effects of formal and informal exclusion in the context of migration. Such a line of argument is congruent with my research findings showing that participants with access to business class citizenship rights sought to establish active 
relations with Mexican authorities and trade commissioners shortly after their arrival in Canada.

A transnational affirmation of citizenship has both practical and symbolic considerations. First, access to business class citizenship transforms Mexican citizenship into an added professional value. This is evident, since business class citizenship allows Mexican emigrants to enjoy publicly funded services in support of their business activities with Mexico. Second, business class citizenship can be perceived as contributory rights rather than underserving privileges in the context of migration. Mexican policies and programs benefiting Mexican business people abroad are implemented to attract much desirable foreign trade and investment to Mexico, turning those exercising business class citizenship rights into relevant partners in the country's efforts for economic development. Business class citizenship rights are a source of potential wealth and social prestige.

The enjoyment of business class citizenship reveals how market principles play an important role in the expansion of citizenship practices in the context of migration. This is apparent in the experiences of research participants who tended to see their efforts for bringing foreign investment to Mexico as an important civic contribution. The transmutation of business into civic engagement replaces traditional ideas of philanthropy with a market logic by which citizens can quantify their civic contribution in relation to investment and profit. As a result, it is reasonable to assume that the transnational expansion of capital increasingly determines the expansion of citizenship practices in the context of migration. 
The quantification of citizenship-state relations in the context of migration provides important insights about the private-public characteristics of the neoliberal ethos. Increasingly, business management concepts such as Corporate Citizenship (CC) and Corporate Social Responsibility (CSR) have been postulated as private-public policy alternatives for promoting a larger social role of business. These concepts circumvent the boundaries between the private sector and the public realm by transmuting citizenship rights and responsibilities to private business. In contrast to CC and CSR, business class citizenship sees the bringing of foreign direct investment and similar lucrative commercial activities as civic contributions in themselves, not taking into account normative considerations implied in philanthropy and social responsibility. In this regard, the exercise of business class citizenship is indicative of a regressive tendency in the relationship between businesspeople and the state.

The exercise of business class citizenship epitomizes the inherit contradictions of the neoliberal ethos in the context of migration. It represents the entrepreneurial capacity of the self-reliant immigrant whose professional development is in fact tied to publically funded resources. It embodies the efficiency of public private partnership, which on the one hand manages to bring desirable foreign direct investment to the nation and on the other allows the management of private wealth in tax havens. Finally, business class citizenship exemplifies the transnational expansion of citizen-state economic relations in which business and civic duties are one and the same. 


\section{Chapter VIII}

\section{Conclusion}

"Nothing that one has been, one is, and one will be; one has been, one is and one will be forever. But rather, one has one day become something, which in another day one will stop being"

Ortega y Gasset, cited by Vargas Llosa on "La Fiesta del Chivo". My translation.

Like buildings, stories of migration have façades we can see from the outside, foundations hidden well beneath the earth that grounds them, and doors from which to enter. Also, much like buildings, stories of migration are concrete manifestations of people's creativities and accessibility to resources. My field research on the civic life of Mexican immigrants in Toronto allowed me to study rich stories of migration, to witness the building of a new immigrant community in Canada, and to appreciate the nuances of how social capital and social class facilitate privileged relations with the state in the context of migration. In my efforts to offer comprehensive answers to my research questions, I attempted to explain how the research participants organized themselves in different cultural, social, and professional organizations and how they utilized complex emigration policies in order to advance their community work, professional careers, and individual voluntarism. Through this experience, I came to understand citizenship practices in the context of migration as self-edifying, inherently biographical, and inextricably linked with peoples' socio-economic circumstances. Also, I found empirical evidence on how emigration policies and practices transcend national boundaries and give way to new citizenship identities and affections. 
In this conclusion, I will provide a brief summary of my policy findings as well as a brief presentation of my findings on Mexican immigrants' citizenship practices and identity as a modus vivendi. Also, in this conclusion I will share some insights from my dissertation research in the areas of emigration policies, transnational citizenship, and community development. Lastly, I will briefly historicize the participants' perspectives and draw some final remarks and recommendations for further understanding and supporting Mexican immigrants in their efforts for building communities and contributing to the civic life of Mexico and Canada.

\section{Summary: Emigration Policies}

Looking at the policies and practices Mexican immigrants use to exercise citizenship rights in a transnational context I found that there are three main policy areas through which Mexican governmental institutions support and collaborate with middle class Mexican immigrants in Canada: 1) business; 2) science and education; and 3) community relations. Together, these three policy areas confirmed an overall Mexican governmental strategy for building citizen-state relations with Mexicans in Canada. The policy impact of this strategy, however, is limited as only a selected group of middle class Mexican immigrants in Canada establish citizen-state relations by either participating in activities organized by associations funded by the Mexican government or by receiving services offered by the Mexican consulate and the Mexican trade commission.

The willingness of Mexicans in Canada to serve as liaisons for furthering cultural, educational, and commercial relations between Mexico and Canada could be taken into 
serious consideration by Mexican authorities if these are set as key policy outcomes. The recent launching of the Mexico-Canada Business Class ${ }^{17}$ initiative between ProMexico and the Mexico-Canada Alliance of Commerce provides an idea of the nature of potential future collaborations between middle class Mexican-Canadians and the Mexican government. While middle class Mexican emigrants have moved from being policy targets to becoming active policy actors, the feasibility of Mexicans in Canada for establishing partnerships with the Mexican government and/or becoming eventual policy pushers is still subject to further research.

My research has found that activities by Mexican community based organizations and individual Mexican-Canadians to support human rights, educational programs, indigenous rights, and the rights of Mexican temporal agricultural workers do not receive support from Mexican institutions or utilize Mexican emigration policies. While the criteria of Mexican authorities for providing and denying institutional and financial support to civically engaged community groups and individuals may be indicative of governmental priorities and areas of concern, a small number of research participants did utilize Mexican emigration policies to lobby the Mexican government for some services in support of marginalized groups such as undocumented Mexican migrants and temporary agricultural workers. In this regard, my research found there is significant room for improvement in the utilization of Mexican policies and programs in order to foster solidarity across different sectors of the Mexican diaspora in Toronto.

My research also found that there is a risk that Mexican emigration policies can be systematically used to expand social class differences and reaffirm archaic forms of

\footnotetext{
${ }^{17}$ For more information on this initiative see: http://mex-can.com/index.html
} 
class stratifications in the context of migration. Mexican middle class emigrants accessed a preferential relationship with the Mexican government through the utilization of emigration policies and programs such as CCIME and IME and accessed exclusive business services that allowed them to bring foreign investment to Mexico and profit from changes in Mexico's economic policies. Thus, for middle class Mexican immigrants in Canada, the utilization of emigration policies can be also a form of negotiating privileges with the state and affirm their social status in the context of migration. It is imperative that Mexican emigration policies include direct channels of communication, negotiations, and representation with less privileged Mexican immigrants such as refugees, non-status immigrants, and temporary agricultural workers in order to avoid institutionalizing a two-tier system of citizen-state relations in the context of migration.

It is important to point out, that while the implementation of Mexican emigration policies in Canada is currently going through its initial stage, the overall scope and level of maturity of Mexican emigration policies is considerable. Arguably, if Mexican emigration policies manage to include less privileged Mexican emigrants as part of their target group, they could provide important lessons for other immigrant sending countries looking to develop strategies for furthering citizen-state relations with their diaspora. While this lies beyond the scope of my research, future studies on Mexican emigration policies and transnational citizenship practices may shed important light on this academic field by investigating the potential policy diffusion of Mexican emigration strategies among other immigrant-sending countries in the region.

Lastly, while my research did not find evidence of collaboration between Canada and Mexico in support of their shared citizens, the numerous examples of middle class 
Mexican immigrants' civic engagement could open possibilities for Mexico and Canada to collaborate in supporting emigrant/immigrant transnational civic engagement in the future. As immigrants increasingly define and redefine their civic relations with their countries of origin and residence, building international partnerships and transitional policy capacities could help prepare immigrant receiving countries like Canada and immigrant sending countries like Mexico to meet both, the demands and aspirations of their increasingly transnational and globalized privileged civil society; and the challenges to accommodate the needs of less privileged Mexican immigrants in Canada.

\section{The Civic Character of Mexican Middle Class Immigrants: Transnational Citizenship as Modus Vivendi}

By looking at the participants' civic experiences in terms of the expansion and contraction of citizenship rights and obligations in the context of migration, my research identified a number of distinct types of citizenship practices and identities. The analysis of these research findings relied on a perspecivist ontology and epistemology, which let me acquire in-depth insights about the participants' self-realization as civic actors, to appreciate their unique contributions to the larger Canadian and Mexican communities, and to understand their relations with Mexican institutions in the context of migration.

The different ways in which middle class Mexican immigrants see themselves as citizens and actively participate in the public life of Mexico and Canada suggests that the expansion of citizenship in the context of migration is inherently diverse and indicative of different social realities. Transnational citizenship can be conceptualized as a modus vivendi, a mode of life by which immigrants manage to live civically in distinct and often contradictory cultural, social, and political realities. Such realities include experiences as 
both: 1) emigrants and immigrants; 2) citizens of Mexico and non-citizens of Canada, 3) members of an ethnic minority in Canada and members of an ethnic majority in Mexico; 4) accredited professionals in Mexico and non-recognized professionals in Canada; and 5) native speakers of Spanish and ESL. By establishing unique civic relations with the Canadian and Mexican body-polities, Mexican immigrants participating in this study transformed their seemingly conflicting political, social, and cultural circumstances into a complex yet cohesive civic reality. Research participants were thus architects of their own civic life, and their citizenship engagement with Mexico and Canada is indicative of their capacity to contribute to distinct socio-political realities.

The conceptualization of transnational citizenship as a modus vivendi is also indicative of the provisional nature of transnational citizenship practices and identity. Whether they were international students, under-employed professionals, or a former refugee, the immigration experience of the majority of research participants was marked by a constant effort to succeed in the market economy and to become full members of the community of value. Middle class immigrants' civic engagement changes when the former international student becomes a Canadian university professor, the former underemployed professional becomes a recognized lawyer in the province of Ontario, when the young and single English student from Mexico City grows into a middle-aged mother in the suburbs of Toronto, and when the cleaner with only elementary school education flourishes into a highly successful business woman. My research findings suggest there is a tendency for upward social mobility among middle class Mexican immigrants in Toronto and such changes in economic and social circumstances influence immigrants citizenship practices. While some research participants had a tendency for 
being civically engaged before experiencing significant upward social mobility, it is a matter of further research to determine if there is a causal relation between citizenship engagement and upward social mobility in the context of migration.

Furthermore, immigrants' citizenship practices can be conceptualized as a selfedifying modus vivendi. There is an existential dimension to social, cultural, and civic participation in the context of migration by which middle class immigrants flourish as citizens and member of a community. Whether the research participants developed a cosmopolitan, bi-national, Latin American, or transnational citizenship practices and civic identity, had a significant impact on how they built networks of support, socialized, and on how they perceived themselves. Engaging in civic activities in the context of migration offered the research participants opportunities for socialization that helped them deal with solitude and to eventually develop friendships. Also, their civic contributions often provided them with tangible benefits such as improving their CVs with local experience and furthering connections with government representatives. Irrespective of the participants' motivations for being socially, culturally, and civically engaged, their activities helped them expand their social networks and build their civic characters.

The relation between citizenship practices and personal growth has historically been significant as it continues to be so today. Classical concepts such as Arête and Eudemonia highlight the importance of civic virtue for human development and happiness. In classical Greece, just like in contemporary times, however the development of civic virtue and citizenship practices was indicative of social class stratification, as it was the privilege of the very few. 
Similarly, transnational citizenship as modus vivendi embodies the contradictions in an era of globalization and global migration when middle class Mexican immigrants experience an expansion in their civic involvement and less privileged migrants experience a contraction of their citizenship and human rights. Thus, while middle class Mexican immigrants build their civic character by making a difference in social and cultural contexts that transcends the familial values and expectations of their original political communities, the expansion of their civic character is also indicative the transnational reproduction of social class privilege in the context of Mexican migration.

By virtue of their privileged position middle class immigrants enjoy the freedom to define and redefine themselves civically, adding layers of complexity in the development of civic virtues and opening new possibilities for political, cultural, and social advancement in the context of migration. The expansion of citizenship practices in the context of middle class migration, however, requires adequate avenues of support including governmental programs, policies, as well as strategies for community development. In the following section, I will present some suggestions for supporting the development of a more inclusive Mexican community in Toronto.

\section{Recommendations: The Role of Culture and the Arts for Social Inclusion}

The presence of Mexican cultural, social, and professional organizations in Toronto is indicative of Mexican immigrants' significant organizational capacity. Mexican immigrants' high human capital and their organizational capabilities represent important assets for furthering the process of community formation and development. While Mexican community organizations operate as networks of support and 
socialization for selected groups of Mexican immigrants, my observations suggest that they had limited ability for effective community outreach and collaboration outside very specific groups in the community. Mexican community organizations face challenges in expanding their activities to broader sectors of the Mexican diaspora in Toronto.

Dispersed efforts for community building by Mexican organizations have not necessarily been conducive to establishing long-term community goals and provide innovative communitarian solutions in areas of common concerns.

An explanation for the lack of collaboration among Mexican community organizations is that Mexican immigrants in Toronto are a diverse social group and they do not necessarily share the same interests or experience similar social barriers. The vast majority of research participants did share common cultural interests. Research participants either directly contributed to or were interested on promoting Mexican cultural activities such as Mexican traditional and Indigenous dances, music, culinary lessons, arts and crafts and Spanish language lessons for children. Arguably, the need for more comprehensive outreach, communication, and collaboration strategies by Mexican organizations in Toronto requires the development of a strategic plan to include broader sectors of the Mexican diaspora based on these areas of common cultural interest. Such a proposition is sensible in light of the significant number of the research participants who were professional artists.

A guiding principle for a possible strategic plan for Mexican-Canadian organizations interested in community development could be to maximize their resources through organized collaboration on: 
1. Community work based on Mexican cultural activities with less privileged Mexican immigrant families who could benefit from socialization and community support such as refugees, undocumented migrants, and temporal foreign workers

2. Using Mexican restaurants for community meetings

3. Support social projects of Mexican local artists

4. Establishing collaborations with community media initiatives to raise awareness of issues of social concern

5. Lobbying the Mexican government for funding to open a Mexican Cultural Centre that serves Mexican immigrants and the general public

These areas of possible collaboration are based on the research participants' own suggestions and while some of these suggestions have been formally presented by individual Mexican organizations to Mexican authorities, a joined community effort could be a more effective strategy.

Mexican immigrants in other Canadian cities are working on establishing effective collaborations for community development through cultural activities and the arts. An interesting example of Mexican community building is the utilization of UNAM's Offshore Campus in Gatineau, Quebec as a centre for Mexican cultural activities and community gatherings. UNAM's campus provides lessons on Mexican history, Spanish language, and Mexican traditional and indigenous dances among other forms of art. Also, it provides space for Mexican organizations such as CCIME as well as for local Mexican cultural groups and artists to host their activities. Arguably, by hosting cultural and community activities, the UNAM campus in Gatineau fosters solidarity in the context of migration. A similar cultural or educational institution could be an important asset for supporting Mexican community development in Toronto. In short, 
Mexican artists and cultural institutions can play an important role in promoting solidarity and collaboration among Mexican immigrants in Toronto.

\section{Final Remarks}

Every generation has its own sensibility, vocation, and historic mission and the self-appropriation of oneself and one's circumstances is also an exhortation to fulfill them (Ortega y Gasset 1938, p.71). My research found that immigrants' journey to concrete self-realization as civic actors develop in the context of their personal interests and interpersonal relations. Through their different sensibilities about issues of public concern, their diverse citizenship practices and points of view about their country and community, middle class Mexican immigrants expanded the contours of their civic lives in Canada. The story of these "other" Mexicans also reveals a pending mission to establish effective patterns of collaboration and support with less privileged Mexican immigrants. While middle class Mexicans in Toronto already engage in acts of solidarity through their civic engagement in the areas of education, culture, philanthropy, and community work, the development of new spaces for citizenship-state relations and new types of citizenship practices should be also understood in light of their capacity to respond to the needs of immigrants in less privileged social and economic circumstances.

Twentieth century Mexican philosopher Jose Vasconcelos envisioned the future of Mexico as a universópolis, a place where all races of the world unite to found a new civilization inclusive of all peoples and creeds. I feel that in Toronto, one of the world's most multicultural cities, Mexican immigrants have the capacity to build Vasconcelos' universópolis, adding their rich cultural traditions and social capital to the ever-changing 
Canadian cultural mosaic. The building of a strong and inclusive Mexican community in Toronto could bring seeds of new civic and cultural sensibilities to the city, seeds that could help Toronto further flourish as a locus of multiculturalism and a meeting place for immigrants in the $21^{\text {st }}$ century. 


\section{Appendices}

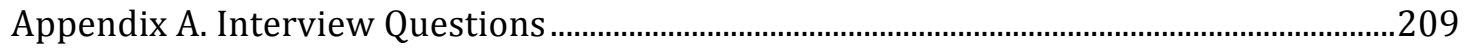

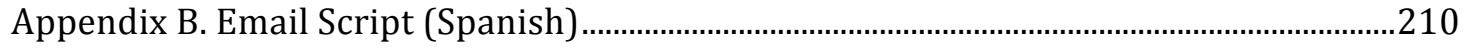

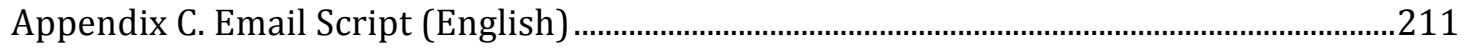

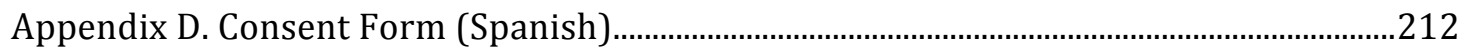

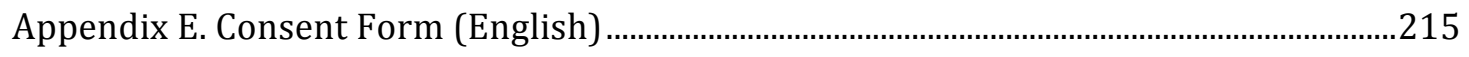

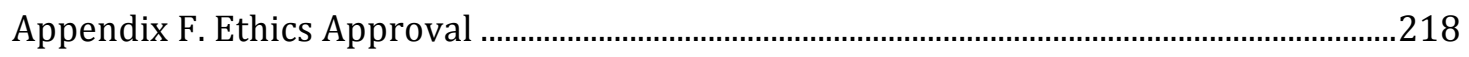




\section{Appendix A. Interview Questions}

Introductory questions:

1. Please tell me about the reasons why you immigrated to Canada?

2. When did you come to Canada?

\section{Transnational Civic Engagement in the Context of Migration}

3. How would describe your involvement in addressing issues of public concern with Mexico and/or Canada?

4. What motived you to be involved in addressing issues of public concern with Mexico and/or Canada?

5. Where you engaged in addressing issues of public concern through social activism and/or community organizing back in Mexico? If yes, do you see a link between your social activism and/or community work in Mexico and your current activism here in Canada?

6. Have your community organizing and/or social activism experience in Canada influenced the way you are involved in addressing issues of public concern as a citizen with Mexico? If so, how?

\section{Policies and Governmental Practices Utilized in Transnational Civic Engagement}

7. In your experience, what would be the main avenues such as laws, institutions, governmental practices, and services that have facilitated your involved in addressing issues of public concern with Mexico and/or Canada? What have been the main obstacles?

\section{Impact of Community Practices Utilized in Transnational Civic Engagement}

8. Which community activities do you think are most relevant to addressing issues of public concern and promote acts of solidarity among Mexican immigrants in Toronto?

9. Have you or your organization promote activities addressing issues of public concern and/or collaborated in acts of solidarity with other Mexican communities in Canada or outside Canada? If yes, where and how, and what has been the impact, if any, of doing such acts of solidarity and/or collaboration?

CONCLUSION: Are there any particular areas that have not been covered in this interview that you would like to share? 


\section{Appendix B. Email Script (Spanish)}

Mensaje:

Estimado [Titulo, Nombre]

Encontré su información en [fuente, pagina electrónica].

Mi nombre es Omar Luján, soy un estudiante de doctorado en el Programa de Estudios de Gestión de la Universidad de Ryerson y estoy buscando participantes para el estudio: "Privilegio, Marginalidad y Participación Cívica Transnacional: Un Estudio Etnográfico de Políticas Públicas Migratorias Mexicanas y Canadienses".

El objetivo del estudio es investigar las formas en que los ciudadanos mexicanos participan cívico-socialmente con México y Canadá, especialmente prestando atención a la utilización de políticas públicas mexicanas y canadienses.

En conjunto, estamos buscando hacer entrevistas a 40 participantes, las cuales se llevaran a cabo en la Universidad de Ryerson o en una biblioteca pública de su elección.

En particular estamos buscando a ciudadanos mexicanos mayores de edad que participan en forma cívico-social y/o promuevan actos de solidaridad con México y/o Canadá.

Si usted cumple con estos requerimientos, nos gustaría invitarlo a participar en este estudio. El estudio conllevará una entrevista de aproximadamente 30 a 60 minutos. Toda información que resulte del estudio será estrictamente confidencial dentro de lo que permite la ley.

Su participación es importante. Si usted está interesado en ser un voluntario en este estudio, por favor contácteme a olujan@ryerson.ca

Adjunta se encuentra la aprobación del consejo de ética de la Universidad de Ryerson y una breve descripción del proyecto. Este e-mail es confidencial.

Estaremos esperando su respuesta. Si usted tiene alguna pregunta, por favor no dude en contactarnos.

Atentamente,

Omar Luján 


\section{Appendix C. Email Script (English)}

Message:

Dear [Title, Name]

I found your contact information on [source, website].

My name is Omar Lujan, I am PhD Student in the Policy Studies Program at Ryerson University and I am looking for participants in the study "Privilege, Marginality and Transnational Civic Engagement: An Ethnographic Study of Mexican Emigration and Canadian Immigration Policies"

The Purpose of the study is to investigate the ways by which Mexican citizens engage civically with both Mexico and Canada, paying special attention to the use or lack of use of Mexican emigration policies and Canadian immigration and citizenship policies.

Altogether, the study aims to conduct interviews with 40 participants, which will be conducted at Ryerson University or at Public Library of your choice.

Of particular interest are Mexican citizens over 19 years old who are engaged in raising awareness on issues of public concern, social-civic activism, and/or promoting acts of solidarity with Mexico and/or Canada.

If you fit these criteria, we would like to invite you to participate in this study. It involves a personal interview of approximately 30-60 minutes. All information resulting from this research will be kept strictly confidential to the extent allowed by law.

Your participation is important. If you are interested in volunteering for an interview, please contact me@ olujan@ryerson.ca

Please find attached the project approval by the Ryerson University ethics board, and a short project description. Furthermore, we treat this email as strictly confidential.

We look forward to hearing from you. If you have any questions, please do not hesitate to ask.

Sincerely,

Omar Lujan 
Appendix D. Consent Form (Spanish)

RYERSON

UNIVERSITY

\section{FORMULARIO DE CONSENTIMIENTO Universidad de Ryerson}

\section{Consentimiento Para Participar en Este Estudio}

Se le pide participar en un estudio de investigación. Antes de dar su consentimiento para ser voluntario, es importante que lea la siguiente información y haga tantas preguntas como sea necesario para estar seguro de entender lo que se le pide que haga.

Título del estudio: Privilegio, Marginalidad y Participación Cívica Transnacional: Un Estudio Etnográfico de Políticas Publicas Migratorias Mexicanas y Canadienses.

Investigador Responsable: Omar Luján, estudiante de doctorado en el Programa de Estudios de Gestión de la Universidad de Ryerson. Los resultados de este estudio contribuirán a la tesis doctoral del investigador responsable.

Propósito del estudio: El objetivo es investigar las formas en que los ciudadanos mexicanos participan en forma cívica-social con México y Canadá, especialmente prestando atención a la utilización de políticas publicas Mexicanas y Canadienses.

Descripción del estudio y su participación: Si acepta a ser voluntario en este estudio usted será invitado a participar en una entrevista que consiste en 12 preguntas sobre su participación cívica con México y Canadá. Siguiente, hay un ejemplo de las preguntas que se le harán usted:

¿Como describiría usted su participación con México y/o Canadá?

¿Que motivo a usted en participar en con México y/o Canadá?

La entrevista duraría aproximadamente entre 30 y 45 minutos y sería llevada a cabo en la Universidad de Ryerson o en una biblioteca pública dependiendo de lo que sea más conveniente al participante. Los resultados de esta investigación serán utilizados para una tesis doctoral y serán puestos a su disposición si es que usted así lo desea. La entrevista será audio grabada.

Compensación: Usted no recibirá ningún tipo de incentivo o compensación por su participación en esta investigación. 
Manejo de riesgos o inconvenientes: Los posibles riesgos por participar en este estudio son muy bajos pero para minimizar posibles molestias que pueden derivar con el recuerdo de memorias poco placenteras usted puede optar por no contestar cualquiera o todas las preguntas o interrumpir la entrevista en cualquier momento.

Posibles beneficios para el participante y la sociedad: Algunos de los posibles beneficios podrían ser: 1) promover un mejor entendimiento del esfuerzo en la participación cívico/social de los participantes; y 2) el posible desarrollo de políticas públicas migratorias más justas, equitativas y humanas.

Confidencialidad: Para mantener la confidencialidad de los participantes, su nombre, cargo u organización no serán revelados a menos que usted lo solicite específicamente. Yo seré la única persona con acceso a los audios de las entrevistas, las cuales serán transcritas exclusivamente por mi persona. Usted puede tener acceso a ambos, la grabación de su entrevista y las transcripciones y puede retirar su permiso para utilizar la información que usted ha proveído en cualquier momento. Con el objetivo de minimizar el movimiento y la posibilidad de pérdida de la información esta será almacenada en Ryerson Arts Network, la cual es una red segura a la que sólo yo tendré acceso. Al mismo tiempo, la información no electrónica recaudada durante la investigación, como por ejemplo apuntes, será guardada en una caja de seguridad por siete años a la cual solo yo tendré acceso.

Carácter voluntario de la participación: Usted puede elegir o no si desea participar en este estudio. Su participación es totalmente voluntaria y la relación entre usted y la Universidad de Ryerson no se verá afectada de ninguna manera, si usted decide participar o no. Al mismo tiempo, usted puede elegir no contestar cualquier pregunta y seguir siendo parte de este estudio.

Si usted decide retirarse de este estudio usted también puede retirar su información. Si este fuera el caso, por favor tenga en cuenta de notificarme en un lapsus de tres meces después de la fecha de la entrevista puesto que cuando el proceso de analizar los datos y/o escribir la tesis doctoral no será posible retirar la información.

Preguntas sobre este estudio: Si usted ahora tiene alguna pregunta sobre este estudio por favor hágala. Si usted tiene alguna pregunta después por favor contácteme vía e-mail a olujan@ryerson.ca o a mi supervisor: Harald Bauder al teléfono al 416-979-5000, ext. 6904 o vía e-mail al hbaduer@GEOGRAPHY.ryerson.ca

Este estudio a sido aprobado por el Consejo de Ética de la Universidad de Ryerson. Si usted tiene alguna pregunta sobre sus derechos como participante en este estudio, por favor contacte a:

Toni Fletcher, Research Ethics Coordinator

Research Ethics Board

Office of the Vice President, Research and Innovation

Ryerson University

350 Victoria Street 
Toronto, Ontario M5B 2K3

416-979-5042 o toni.fletcher@ryerson.ca

Acuerdo:

Su firma indica que usted ha leído la información contenida en este acuerdo y ha tenido la oportunidad de hacer cualquier pregunta que tenga sobre el estudio. Su firma también indica que usted acepta participar en el estudio y se le ha dicho que usted puede cambiar de opinión y retirar su consentimiento en cualquier momento. Se le ha entregado una copia de este acuerdo.

Se le ha dicho que al firmar este acuerdo de consentimiento usted no renuncia a ninguno de sus derechos legales.

Nombre del participante (letra imprenta)

Firma del participante y Fecha

Acuerdo:

Su firma indica que usted ha leído la información contenida en este acuerdo y ha tenido la oportunidad de hacer cualquier pregunta que tenga sobre la grabación de audio de su entrevista como parte de este estudio. Su firma también indica que usted acepta participar en el estudio y se le ha dicho que usted puede cambiar de opinión y retirar su consentimiento en cualquier momento. Se le ha entregado una copia de este acuerdo. Se le ha dicho que al firmar este acuerdo de consentimiento usted no renuncia a ninguno de sus derechos legales.

Nombre del participante (letra imprenta)

$\overline{\text { Firma del participante y Fecha }}$ 


\section{RYERSON
UNIVERSITY \\ CONSENT FORM \\ Ryerson University \\ Consent to Participate in Research}

You are being invited to participate in a research study. Please read this Consent Form so that you understand what your participation will involve. Before you consent to participate, please ask any questions necessary to be sure you understand what your participation will involve.

Title: Privilege, Marginality and Transnational Civic Engagement: An Ethnographic Study of Mexican Emigration and Canadian Immigration Policies

Investigator: Omar Lujan. PhD Candidate in the Policy Studies Program at Ryerson University.

The results of this research will contribute to investigator's doctoral dissertation.

Purpose of Study: The Purpose of this study is to investigate the ways by which Mexican citizens engage civically with both Mexico and Canada, paying special attention to the use or lack of use of Mexican emigration policies and Canadian immigration and citizenship policies.

Description of the Study and your Participation: If you volunteer to participate in this study, you will be asked to participate in an interview consisting of 12 questions related to your experience with civic engagement with Mexico and Canada. Here is an example of the questions you will be asked to answer:

How would describe your involvement in addressing issues of public concern with Mexico and/or Canada?

What motived you to be involved in addressing issues of public concern with Mexico and/or Canada?

The interview will take approximately between 30 to 60 minutes and it will take place at Ryerson University or in a public library depending of the participant's convenience. The research findings will be part of a dissertation proposal, which will be available to the participants if they so desire. The interview will be audio recorded.

Potential Risks and Discomforts: The potential risks of participating in this study are very low but in order to minimize potential discomforts due to reflecting on unpleasant 
memories, as a participant you are encouraged to take a break, choose not answer a particular question, or discontinue participating if you wish do so for any reason.

Potential Benefits to Participants and/to society: Some of the potential benefits of the research may include: 1) the promotion of a better understanding of your efforts and struggles with civic engagement; and 2) the possible development of more effective, comprehensive, and humane emigration and immigration and citizenship policies that affect you directly.

I cannot guarantee, however, that you will receive any benefits from participating in this study.

Payments for Participation: You will not be paid to participate in this study.

Confidentiality: In order to maintain confidentiality to the extent allowed by the law, your name, position, and place of work will not be revealed in this study unless you would specifically request to include that information. I will be the only person to have access to the audio-recorded version of the interview, which will be transcribed only by myself. You can have access to both the recorded interview and the transcriptions. At any time you can take away your permission for using the information you have provided. In order to minimize data travelling and possible loss of information, I will store all electronic data on the Ryerson Arts Network, this is a secure network to which only I would have access. Also, non-electronic data gathered during the study such as hand written notes will be stored in a security box accessible only to myself. Following completion of the study, all data gathered will be kept under secured storage for seven years.

Voluntary Participation and Withdrawal: Participation in this study is voluntary. You can choose whether to be in this study or not. You may also choose not to answer any question(s) and still remain in the study. Your choice of whether or not to participate will not influence your future relations with Ryerson University. If you volunteer to be in this study, you may withdraw at any time without consequences of any kind. If you choose to withdraw from this study you may also choose to withdraw your data from the study. Please be advised that once the process of data analysis and/or the writing of the dissertation are completed it will not be possible for data to be withdrawn. For this reason, in order to withdraw your data from the study you must let me know within a period of three months since the date in which interview was conducted.

Questions About this Study: If you have any questions about the research now, please ask. If you have questions later about the research, you may contact: Omar Lujan at olujan@ryerson.ca

Also for additional questions or concerns about the research, please feel free to contact my supervisor Dr. Harald Bauder at 416-979-5000, ext. 6904 or via e-mail at hbaduer@GEOGRAPHY.ryerson.ca 
This study has been reviewed by the Ryerson University Research Ethics Board. If you have questions regarding your rights as a research participant in this study, please

contact:

Toni Fletcher, Research Ethics Coordinator

Research Ethics Board

Office of the Vice President, Research and Innovation

Ryerson University

350 Victoria Street

Toronto, Ontario M5B 2K3

416-979-5042 or toni.fletcher@ryerson.ca

\section{Signature of Research Participant}

Your signature below indicates that you have read the information in this agreement and have had a chance to ask any questions you have about the study "Privilege, Marginality and Transnational Civic Engagement: An Ethnographic Study of Mexican Emigration and Canadian Immigration Policies" as described herein. Your questions have been answered to your satisfaction, and you agree to participate in this study. You have been given a copy of this form.

Name of Participant (please print)

$\overline{\text { Signature of Participant } \quad \text { Date }}$

\section{Signature of Research Participant}

Your signature below indicates that you have read the information in this agreement and had a chance to ask any questions about being audio recorded for this study. Your signature also indicates that you accept to participate in this study and that you are aware you can stop participating in this study at any time. You have been given a copy of this form.

Name of Participant (please print)

Signature of Participant and Date 


\section{Appendix F. Ethics Approval}

\section{RYERSONUNIVERSITY}

RESEARCH ETHICS BOARD

To: Omar Lujan

Politics and Public Administration

Re: REB 2013-270: Privilege, Marginality and Transnational Civic Engagement: An Ethnographic Study of Mexican Emigration and Canadian Immigration Policies

Date: November 15, 2013

Dear Omar Lujan,

The review of your protocol REB File REB 2013-270 is now complete. The project has been approved for a one year period. Please note that before proceeding with your project, compliance with other required University approvals/certifications, institutional requirements, or governmental authorizations may be required.

This approval may be extended after one year upon request. Please be advised that if the project is not renewed, approval will expire and no more research involving humans may take place. If this is a funded project, access to research funds may also be affected.

Please note that REB approval policies require that you adhere strictly to the protocol as last reviewed by the REB and that any modifications must be approved by the Board before they can be implemented. Adverse or unexpected events must be reported to the REB as soon as possible with an indication from the Principal Investigator as to how, in the view of the Principal Investigator, these events affect the continuation of the protocol.

Finally, if research subjects are in the care of a health facility, at a school, or other institution or community organization, it is the responsibility of the Principal Investigator to ensure that the ethical guidelines and approvals of those facilities or institutions are obtained and filed with the REB prior to the initiation of any research.

Please quote your REB file number (REB 2013-270) on future correspondence.

Congratulations and best of luck in conducting your research.

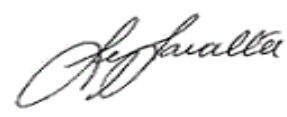

Lynn Lavallée, Ph.D.

Chair, Research Ethics Board 


\section{Bibliography}

Abele, Frances in Orsini, M. and M Smith. (Edit) (2007). Critical policy studies. Vancouver: University of British Columbia Press.

Abraham, Margaret and Purkayastha, Bandana (2012). Making a difference: Linking research and action in practice, pedagogy, and policy for social justice. Current Sociology, 60 (2) 123-141

Agnew J. (2009). Globalization and sovereignty. Plymouth, UK: Rowman and Littlefield Publishers.

Albrow, M (1997). The global age state and science beyond modernity. Cambridge: Polity Press.

Al-Rodhan, N. R., and Stoudmann, G. (2006). Definitions of globalization: A comprehensive overview and a proposed definition. Geneva Centre for Security Policy (GCSP) Occasional Papers, 6 pp.1-26.

Alvarez, W. (2013). Finding "home" in/through Latinidad ethnography: Experiencing community in the field with "my people." Liminalities: A Journal of Performance Studies, 9 (2) 9-2.

Alvarez, J., and Valencia, F. (2015). Made in Mexico: Energy reform and manufacturing growth. International Monetary Fund Working Paper, 15 (45), 1-30.

Anaya, C. P. (2013). Mexico: Opportunities for Italian investments in the automotive industry. The role of Export Promotion Agencies; the case of ProMexico. Puebla, Mexico: Universidad de las Americas. Retrieved from: http://catarina.udlap.mx/u_dl_a/tales/documentos/lni/parrodi_a_c/apendiceB.pdf

Anderson, Benedict. (1998). Imagined communities: Reflections on the origin and spread of nationalism. New York: Verso.

Anderson, Bridget. (2013). Us and then? The dangerous politics of immigration control. Oxford: Oxford University Press

Andolina, R., Radcliffe, S., and Laurie, N. (2005). Development and culture:

Transnational identity making in Bolivia. Political Geography, 24 (6), 678-702.

Andrien, Kenneth. (2002). The human tradition in colonial Latin America. Wilmington, DE: Scholarly Resources Inc.

Angrosino, M, V. (2007). Doing ethnographic and observational research. Thousand Oaks. Los Angeles, California: Sage.

Arendt, H. (1966). The origins of totalitarianism. New York: Brace \& World. 
Arendt, H. (1968). Imperialism. New York: Brace \& World.

Ayres, J. M., Caniglia, B. S., Chabot, S., Giugni, M. G., Hanagan, M., Lewis, T. L., ... and Tarrow, S. (2002). Globalization and resistance: Transnational dimensions of social movements. J. Smith, \& H. Johnston (Eds.). Rowman and Littlefield Publishers.

Bada, Xóchitl, Oscar A. Chacón, and Jonathan Fox, Eds. (2010). Latino immigrants in the windy city: New trends in civic engagement, reports on Latino immigrant civic engagement, No.6. Washington DC. Woodrow Wilson International Center for Scholars.

Bada, Xóchitl, Fox, Jonathan, and Selee, Andrew, Editors (2006). Invisible no more: Mexican migrant civic participation in the U.S. Washington D.C: The Woodrow Wilson International Center for Scholars.

Bada, Xóchitl. (2011). From national to topophilic attachments: A historical analysis of continuities and changes in Chicago's Mexican migrant organizations. Latino Studies 11 (1) $28-54$.

Bada, Xóchitl. (2011). Participatory planning across Borders: Mexican migrant civic engagement in community development. The Latinamericanist, 55 (4) 9-33.

Bada, Xóchitl. (2014). Mexican migrant hometown associations in Chicagoacán: From local to transnational civic engagement. New Brunswick, NJ: Rutgers University Press.

Balibar, E. (2009). We, the people of Europe?: Reflections on transnational citizenship. Princeton, NJ: Princeton University Press.

Banerjee, A. V., and Duflo, E. (2008). What is middle class about the middle classes around the world? The Journal of Economic Perspectives, 22 (2), 3-41A.

Basok, Tonya (2003). Human rights and citizenship: The case of Mexican migrants in Canada. Center for Comparative Immigration Studies Working, UC San Diego, Working Paper, (72) 1-23.

Bauböck, R. (2005). Expansive citizenship_-voting beyond territory and membership. Political Science and Politics, 38 (04) 683-687.

Bauder H. (2011). Immigration dialectic: Imagining community, economy, and nation. Toronto: University of Toronto Press.

Bauder, H. (2008). Citizenship as capital: The distinction of migrant labour. Alternatives, 33 (03) 315-333.

Beaverstock, J. V. (2002). Transnational elites in global cities: British expatriates in Singapore's financial district. Geoforum, 33 (4) 525-538. 
Beck, U. (2002). The cosmopolitan perspective: Sociology in the second age of modernity, in conceiving cosmopolitanism, S. Vertovec and R. Cohen (eds), Oxford: Oxford University Press, pp. 61-85.

Bernhard J, Goldring L, Landolt P. (2009 a). Between grassroots politics and the ethicizing imperative of the multicultural state: Latin American immigrant organizations in Toronto. CERIS, Working Paper No. 73, pp1-23.

Bernhard J, Goldring L, Landolt P, (2009 b). Transnational, multi-local motherhood: Experiences of separation and reunification among Latin American families. CERIS Working Paper No 40.

Bernhard J, Goldring L, Landolt P, (2009 c). The institutional production and social reproduction of transnational families: The case of Latin American immigrants in Toronto. International Migration, 46 (2) 3-31.

Bertram, David. (2010). International migration, open borders debates, and happiness. International Studies Review, 12 (3) 339-361.

Binford, Leigh (2005). The seasonal agricultural workers program and Mexican development. The Canadian Foundation for the Americas, Working Paper Number: 0607 pp.1-13.

Blachford, D., and Zhang, B. (2014). Rethinking international migration of human capital and brain circulation: The case of Chinese-Canadian academics. Journal of Studies in International Education, 18 (3) 202-222.

Bloemraad. I, A. Korteweg, and G. Yurdakul. (2008). Citizenship and immigration: Multiculturalism, assimilation, and challenges to the nation-state. Annual Review of Sociology, 34 (1) 153-179.

Boruchoff, J. (1998). The road to transnationalism: Reconfiguring the spaces of community and state in Guerrero, Mexico and Chicago. University of Chicago, Mexican Studies Program, Center for Latin American Studies.

Boswell, C., and Crisp, J. (2004). Poverty, international migration and asylum (p. 35). UNU World Institute for Development Economics Research.

Boumphrey, Sarah. (2015). Mexico: It's all about the middle class. Euromonitor International. Oct.12. http://blog.euromonitor.com/2015/10/mexico-its-all-about-themiddle-class.html

Bosniak, Linda (2000). Citizenship denationalized. Indiana Journal of Global Legal Studies, 7 (2) 447-509. 
Bourdieu, Pierre (1998). Acts of resistance: Against the new myths of our time. Translated by Richard Nice from the French original Contre-feux. Cambridge, UK: Polity Press.

Brown, Jonathan. (2000). Latin America: A social history of the colonial period. Orlando FL. Harcourt College Publisher.

Bugailiskis, A. and Rozental, A. (2012). Canada and Mexico's unfinished agenda. Montreal: McGill-Queen's University Press.

Bunjun, B. (2010). Feminist organizations and intersectionality: Contesting hegemonic feminism. Atlantis, 34 (2) 115-126.

Burrel and Morgan. (1979). Sociological Paradigm. London: Sage Publications.

Cairns, Alan. (2002). Citizenship and Indian Peoples in Isin and Turner (Eds.) Handbook of Citizenship Studies. New York: Sage.

Calabrese, A. (2004). The promise of civil society: A global movement for communication rights. Continuum: Journal of Media \& Cultural Studies, 18(3), 317-329.

Camarillo, A. (2005). Chicanos in a changing society: From Mexican pueblos to American barrios in Santa Barbara and Southern California, 1848-1930. Dallas, Texas: Southern Methodist University Press.

Cano, G. and Huerta, C. 2004. 02, 12. Organizing immigrant communities in American cities: Is this transnationalism or what? Paper presented at the annual meeting of the Midwest Political Science Association, Palmer House Hilton, Chicago, Illinois.

Capron, Guénola and Gonzales, Alba. (2010) Creating the middle-class suburban dream in Mexico City. Culturales, 6 (11) 1170-1191.

Caramanis, C.V. (2002). The interplay between professional groups, the state and the supranational agents: pax Americana in the age of globalization. Accounting, Organizations, and Society, 27 (4/5), 379-408.

Cardenas G, Hansen H. (1988). Immigrant and native ethnic enterprises in Mexican American neighborhoods: Differing perceptions of Mexican immigrant workers. International Migration Review, 22 (2) 226-242.

Carrigan, William and Webb, Clive. (2013). Forgotten dead: Mob violence against Mexicans in the United States, 1848-1928. New York: Oxford University Press.

Castells, S. (2001). Studying social transformation. International Political Science Review, 22 (1) 13-32. 
Chanady, A. B. (Ed.). (1994). Latin American identity and constructions of difference. Minneapolis: University of Minnesota Press.

Cheung, Peter. (2011). Civic engagement in the policy process in Hong Kong: Change and continuity. Public Administration and Development, 31 (2) 113-121.

Chomsky, N. (2012). Making the future: Occupations, interventions, empire and resistance. San Francisco, CA. City Lights Books.

CIC Background on 2011-12 settlement-funding allocations, December, 072010. Retrieved in February 2nd 2011 from:

http://www.cic.gc.ca/english/department/media/backgrounders/2010/2010-12-07.asp

CIC Background on Bill C-11, June 29, 2010. Retrieved in February 2nd 2011 from: http://www.cic.gc.ca/english/department/media/backgrounders/2010/2010-06 29.asp

CIC Official News Release, April 21, 2008. Retrieved in February 2nd 2011 from: http://www.cic.gc.ca/english/department/media/releases/2008/2008-04-21.asp

CIC Official News Release, July 13 2009. Retrieved in February 2nd 2011from: http://www.cic.gc.ca/english/department/media/releases/2009/2009-07-13.asp

Clarkson, A. (2014). Belonging: The paradox of citizenship. Toronto: House of Anansi Press Ltd.

Columbia University Press Scholte, J.A (2000). Globalization A critical introduction. London: Palgrave.

Cravey, A. J. (2005). Desire, work and transnational identity. Ethnography. 6 (3) 357383.

Crenshaw, K.W. (1989) Demarginalizing the intersection of race and sex: A black feminist critique of antidiscrimination doctrine, feminist theory and antiracist politics. University of Chicago Legal Forum, 1 (8) 138-67

Crenshaw, K. W. (1991). Mapping the margins: Intersectionality, identity politics, and violence against women of color. Stanford Law Review, 43 (6), 1241-1299.

Crespo, J. A. (2001). PRI: De la hegemonía a la oposición, un estudio comparado, 19942001. México, D.F: Centro de Estudios de Política Comparada.

Crow, F.E., and Vertin, M. (2010). Lonergan and the level of our time. Toronto: University of Toronto Press. 
Crowley, M., Lichter, D. T. and Qian, Z. (2006). Beyond gateway cities: Economic restructuring and poverty among Mexican immigrant families and children. Family Relations, 55 (3) 345-360.

Davies, M. (2011). Concept mapping, mind mapping and argument mapping: what are the differences and do they matter? Higher education, 62 (3) 279-301.

De Genova, Nicholas, and Nathalie Peutz (eds). (2010). The deportation regime: sovereignty, space, and the freedom of movement. Durham, N.C: Duke Univ. Press.

De Genova, Nicholas. (2005). Working the boundaries: Race, space, and illegality in Mexican Chicago: Durham, N.C: Duke University Press.

De Leon, P. (2006). Historical roots of the field in The Oxford Handbook of Public Policy. Moran. M and M. Rein and R. Goodin (edt). New York: Oxford University Press, pp. 39-57.

Délano, A. (2009). From limited to active engagement: Mexico's emigration policies from a foreign policy perspective (2000-2006). International Migration Review, 43 (4) 764-814.

Délano, A. (2011). Mexico and its Diaspora in the United States: Policies of emigration since 1848. New York: Cambridge University Press.

Denzin, Norman and Michael D. Giardina (edt). (2007). Contesting Empire, Globalizing Dissent: Cultural Studies After 9/11. Boulder, CO: Paradigm Publishers.

Docquier, Frédéric and Hillel Rapoport. (2012). Globalization, Brain Drain, and Development. Journal of Economic Literature, 50 (3) 681-730.

Doherty, B. (2006). Friends of the Earth International: Negotiating a transnational identity. Environmental Politics, 15 (5) 860-880.

Donnelly, J. (2013). Universal human rights in theory and practice. Ithaca NY: Cornell University Press.

Dong, Andy, Sarkar Somwrita, Nichols, Crighton, Kvan, Thomas. (2013). The capability approach as a framework for the assessment of policies toward civic engagement in design. Design Studies, 34 (3) 326-344.

Dragojlovic, Ana. (2008). Reframing the Nation: Migration, borders and belonging. The Asia Pacific Journal of Anthropology, 9 (4) 279-284.

Dror, Y. (2006). Training for policy makers in The Oxford Handbook of Public Policy. Moran. M and M. Rein and R. Goodin (Edit). New York: Oxford University Press, pp. 80-105. 
Duara, P. (1997). Nationalists among transnationals: Overseas Chinese and the idea of China, 1900-1911. In Ungrounded empires: The cultural politics of modern Chinese transnationalism, 39-60. New York: Routledge.

Dunn, Christopher, Mintz, Eric, Tossutti, Livianna. (2013) Canada's politics: democracy, diversity and good government. Toronto Pearson.

El Universal. (August 8, 2015). Torreon: Desplasados por Zetas retornan a casa. Retrieved from: http://www.eluniversal.com.mx/articulo/estados/2015/08/10/torreondesplazados-por-zetas-retornan-casa.

Evans, P. (2000). Fighting marginalization with transnational networks: Counterhegemonic globalization. Contemporary sociology, 29 (1) 230-241.

Faini, R. (2007). Remittances and the brain drain: Do more skilled migrants remit more? The World Bank Economic Review, 21 (2) 177.

Falk, R. A. (1999). Predatory globalization: A critique. Cambridge, UK: Polity Press.

Favell, A. (2003). Games without frontiers? Questioning the transnational social power of migrants in Europe. European Journal of Sociology, 44 (3) 397-427.

Feldman, R. A., Watson, M., Doyle, P., and International monetary fund. (2002). Into the EU: Policy frameworks in Central Europe. Washington, D.C: International Monetary Fund Press.

Ferreira, F. H., Messina, J., Rigolini, J., López-Calva, L. F., Lugo, M. A., Vakis, R., and Ló, L. F. (2012). Economic mobility and the rise of the Latin American middle class. World Bank Publications.

Fitzgerald, D. (2006). Inside the sending state: The politics of Mexican emigration control. International Migration Review, 40 (2) 259-293.

Fitzgerald, D. (2009). A nation of emigrants: How Mexico manages its migration. Los Angeles: University of California Press.

Francis, J. J., Johnston, M., Robertson, C., Glidewell, L., Entwistle, V. Eccles, M. P., and Crenshaw, J. (2010). Psychology \& Health, 25 (10) 1229-1245.

Gabriel, C. (2013). NAFTA, Skilled migration, and continental nursing markets. Population, Space and Place. 19 (3) 389-403.

Garbutt, Rob, Biermann, Soenke and Offord, Baden. (2012). Into the borderlands: unruly pedagogy, tactile theory and the decolonizing nation. Critical Arts: South-North Cultural and Media Studies, 26 (1) 62-81. 
Gastaldo, D., Magalhães, L., Carrasco, C., and Davy, C. (2012). Body-map storytelling as research: Methodological considerations for telling the stories of undocumented workers through body mapping. Retrieved from http://www. migrationhealth.ca/undocumentedworkers-ontario/body-mapping

Giddens, Anthony. (1979). Capitalism and modern social theory: An analysis of the writings of Marx, Durkheim and Max Weber. Cambridge: Cambridge University Press.

Giginiewicz Jorge, Schugurensky, Daniel. (2004). Ruptures, continuities and re-learning political participation: the experience of Latin American immigrants in Canada. Toronto: University of Toronto Press.

Gilpin, R. (2011). Global political economy. Princeton, NJ: Princeton University Press.

Giordani, P. E., and Ruta, M. (2016). Self-confirming immigration policy. Oxford Economic Papers, 68 (2) 361-378.

Goldring, L. (2010). Temporary worker programs as precarious status: Implications for citizenship, inclusion and nation building in Canada. Canadian Issues/Thèmes

Canadiens, Spring: 50-54.

Goldring, L. (2002). The Mexican state and transmigrant organizations: Negotiating the boundaries of membership and participation. The Latin American Research Review, 37 (3) $55-99$.

Goldring, L. (2004). Family and collective remittances to Mexico: A multi-dimensional typology. Development and change, 35 (4) 799-840.

Goldring, L. and P. Landolt. (2011). Caught in the work-citizenship matrix: The lasting effects of precarious legal status on work for Toronto immigrants. Globalizations, 8 (3) 325-341.

Goldring, L. and P. Landolt. (2012). The Impact of Precarious Legal Status on Immigrants' Economic Outcomes. IRPP Study 35. Montreal: Institute for Research on Public Policy.

Goldring, L. and P. Landolt. (2012). Transnational Migration and the Reformulation of Analytical Categories: Unpacking Latin American Refugee Dynamics in Toronto. Pp. 41-64 in Anna Amelina, Devrimsel D. Nergiz, Thomas Faist, and Nina Glick-Schiller (eds.). Beyond Methodological Nationalism: Research Methodologies for Transnational Studies. London/NY: Routledge.

Goldring, L., C. Bernstein, and J. Bernhard. (2009). Institutionalizing precarious migratory status in Canada. Citizenship Studies. 13 (3): 239-265. 
Goldring, L., J. Hennebry and K. Preibisch. (2009). Temporary worker programs: North America's second-class citizens. Canada Watch. Spring. Retrieved from:

http://s3.amazonaws.com/migrants_heroku_production/datas/237/Goldring_Hennebry_Pr eibish_2008_original.pdf?1313760088

Gordon H Hanson and Craig McIntosh. (2010). The great Mexican emigration: The review of economics and statistics. MIT Press. 92 (4) 798-810.

Government of Canada. (2014). Backgrounder: The export development CanadaBancomext memorandum of understanding and master cooperation agreement. Office of the Prime Minister. Retrieved from: http://news.gc.ca/web/article-en.do?nid=817409

Government of Barbados and the Government of Mexico. (2008). Convention between the Government of Barbados and the Government of the United States of Mexico for the avoidance of double taxation and the prevention of fiscal evasion with respect to taxes and income. Retrieved from: http://www.investbarbados.org/docs/DTA\%20$\% 20$ Mexico.PDF

Green and Weil. Editors. (2007). Citizenship and those who leave: the politics of emigration and expatriation. Urbana: University of Illinois Press.

Grimshaw, J. M. (2010). What is an adequate sample size? Operationalizing data saturation for theory-based interview studies. Psychology and Health, 25 (10) 1229-1245. Guillen, M.F (2001). Is globalization civilizing, destructive or feeble? A critique of five key debates in the social science literature. Annual Review of Sociology, 27 (1) 335-360.

Gunder Frank, Andre. (1998). Global Economy in the Asian Age. Berkeley: University of California Press.

Gutiérrez, D. G. (1995). Walls and mirrors: Mexican Americans, Mexican immigrants, and the politics of ethnicity. Berkeley: University of California Press.

Gutiérrez, C. G. (2006). Del acercamiento a la inclusión institucional: la experiencia del instituto de los Mexicanos en el exterior. Relaciones estado diáspora: Aproximaciones desde cuatro continentes (México City: Porrúa, 2006), 181-220.

Gutierrez, R., Samuel, J., Vazquez, G., (1995). International migration between Canada and Mexico: Retrospects and prospects. Canadian Studies in Population, 22 (1) 49-65.

Habermas, Jürgen. (2000). Crossing globalization's valley of tears. New Perspective Quarterly, 17 (4) 51-57.

Habermas, Jürgen. (2003) Toward a cosmopolitan Europe. Journal of Democracy, 14 (4) 86-100. 
Hajer, M. A. (2000). Transnational networks as transnational policy discourse: some observations on the politics of spatial development in Europe. In W. G. Salet, and W. G. Salet (Ed.), The revival of strategic spatial planning. Amsterdam: KNAW.

Hamilton, Erin. (2015). Gendered disparities in Mexico-U.S. migration by class, ethnicity, and geography. Demographic Research. 32 (17) 533-542.

Harvey, Lee. (1990) Critical social research. London: Unwim Hyman.

Held, D., A. McGrew, D. Goldblatt, and J. Perraton. (1999). Global transformations. Cambridge: Polity Press.

Held, D. (2010). Cosmopolitanism: Ideals and Realities. Cambridge Malden, MA: Polity Press.

Held, D. (2013). Global Covenant: The Social Democratic Alternative to the Washington Consensus. London: John Wiley \& Sons.

Hirst, Paul and Thompson, Grahame. (1996). Globalisation in Question. Cambridge: Polity Press.

Horkheimer, M. and T. Adorno (1947). Dialectic of enlightenment: Philosophical fragments. Translated by Edmund Jephcott, from the German original. Redwood City, California: Stanford University Press

Isin, Engin. (2008). Acts of citizenship (pp. 15-43). G. M. Nielsen (Ed.). London: Zed Books.

Jimenez, L. F. (2008). De paisano a paisano: Mexican migrants and the transference of political attitudes to their country of origin. Unpublished Doctoral Dissertation, Retrieved from ProQuest. Dissertations \& Thesis: http://gradworks.umi.com/33/49/3349193.html

Kant, I. (2002). Groundwork for the metaphysics of morals. (Edited and translated by Allen W. Wood with essays by: J. B Schneewind, Marcia Baron, Shelly Kagan and Allen W. Wood). New Haven, NY: Yale University Press.

Kearney, Michael. (2000). Transnational Oaxacan Indigenous identity: The case of Mixtecs and Zapotecs. Identities, 7 (2) 173-195

Keck, M. E., and Sikkink, K. (1998). Activists beyond borders: Advocacy networks in international politics (Vol. 6). Ithaca, NY: Cornell University Press.

Keck, M. E., and Sikkink, K. (1999). Transnational advocacy networks in international and regional politics. International Social Science Journal, 51 (159) 89-101. 
Kelley, N., and Trebilcock, M. J. (1998). The making of the mosaic: A history of Canadian immigration policy. University of Toronto Press.

Khalil, Samah. (2013). Religious civil society and civic engagement from policy to practice: Sociological study at Cairo. European Scientific Journal. 9 (26) 187.

Kharas, Homi. (2010). The emerging middle class in developing countries. OECD Development Centre. Working Paper. No. 285 4-53.

Klein, N. (2007). The Shock Doctrine: The Rise of Disaster Capitalism. New York: Metropolitan Books.

Kothari, U. (2002). Migration and Chronic Poverty. London: Chronic Poverty Research Centre.

Landolt, P. and L. Goldring. (2009). Immigrant political socialization as bridging and boundary work: Mapping the multi-layered incorporation of Latin American immigrants in Toronto. Ethnic and Racial Studies, 32 (7) 1226-1247.

Landolt, P. and L. Goldring. 2010. Political cultures, activist dialogues and the constitution of transnational social fields: Latin American and Canadian organizing in Toronto. Global Networks, 10 (4) 443-466.

Landolt, P., L. Goldring and J. Bernhard. 2011. Latin American Immigrant Political Incorporation in Toronto: a dynamic and multi-layered social field. American Behavioral Scientist, 55 (9) 1235-1266.

Laver, Michael. (1986) Social Choice and Public Policy. New York: Basil Blackwell.

Lee, J., and Kim, D. (2010). Brain gain or brain circulation? U.S. doctoral recipients returning to South Korea. Higher Education, 59 (5) 627-643.

Lee, K., Fustukian, S., and Buse, K. (2002). An introduction to global health policy. In Lee, K., Fustukian, S., and Buse, K. (Ed), Health policy in a globalising world. Cambridge, UK: Cambridge University Press.

Lee, Sharon M. and Edmonston, Barry. (2013). Canada's immigrant families: Growth, diversity and challenges. Population Change and Life Course Strategic Knowledge Cluster Discussion Paper Series/ Un Réseau stratégique de connaissances Changements de population et parcours de vie Document de travail, Vol. 1: Iss. 1, Article 4.

Leininger Pycior, Julie. (2014). Democratic renewal and the mutual aid legacy of the US. College Station, Texas: Texas A\&M University Press. 
Levitt, Peggy and de la Dehesa, Rafael. (2003). Transnational migration and the redefinition of the state: Variations and explanations. Ethnic and Racial Studies, 26 (4). 587-611.

Ley, David and Smith, Heather. (1997). Immigration and poverty in Canadian cities. RIM Working Paper Series. 97 (8) 1-51.

Li, Peter S. (2002). Destination Canada: Immigration debates and issues. New York: Oxford University Press.

López, A. Ricardo and Weinstein, Barbara. (2012). The making of the middle class: Toward a transnational history. Duke University Press.

Lupel, Adam. (2005). Tasks of a global civil society: Held, Habermas and democratic legitimacy beyond the Nation-State. Globalizations, 2 (1) 117-133.

Machiavelli, Niccoló. (1997). The prince. New Heaven: Yale University Press.

Madison, Soyini. (2012). Critical ethnography: Method, ethics and performance. London: SAGE Publications, Inc.

Magazine, R. (2008). Mexico's middle class in the neoliberal era. The Journal of Latin American and Caribbean Anthropology, 13 (1) 274-276.

Mahon, Rianne, Andrew, Caroline, and Johnson, Robert in Orsini, M. and M Smith. (Edit) (2007). Critical policy studies. Vancouver: University of British Columbia Press.

Malishev, M. and Gonzales J. (2010). Jose Ortega y Gasset. Eidos: Revista De Filosofía De La Universidad Del Norte. 10 (12) 214-235.

Malkin, V. (2004). We go to get ahead: Gender and status in two Mexican migrant communities._Journal of Latin American Perspectives. 31 (5) p75-99.

Marcelli, E. A. (2005). Transnational twist: Pecuniary remittances and the socioeconomic integration of authorized and unauthorized Mexican immigrants in Los Angeles County. IMR; International Migration Review, 39 (1) 69-102.

Marmolejo-Leyva R, Perez-Angon MA, and Russell JM. (2015). Mobility and international collaboration: Case of the Mexican scientific diaspora. PLoS ONE, 10 (6): e0126720. doi:10.1371/journal.pone.0126720

Martiniello, M. (2005). Political participation, mobilization and representation of immigrants and their offspring in Europe. Willy Brandt Series of Working Papers in International Migration and Ethnic Relations, 1 (05) 1-23. 
Mata, Fernando. (1985a). The four immigrant waves from Latin America to Canada: Historical, demographic and social profiles. Unpublished manuscript, Toronto: York University.

Mata, Fernando. (1985b). Latin American immigration to Canada: Some reflections on the immigration statistics. Canadian Journal of Latin American and Caribbean Studies. 10 (20) 35-40.

Mato, D. (1998). On the making of transnational identities in the age of globalization: The US Latina/o-Latin American case. Cultural Studies, 12 (4) 598-620.

Mayda, A. M. (2006). Who is against immigration? A cross-country investigation of individual attitudes toward immigrants. Review of Economics and Statistics, 88 (3) 510530 .

Mayda, A. M. and Patel, K. (2004). OECD countries migration policies changes. Appendix to International migration: A panel data analysis of the determinants of bilateral flows. IZA Discussion Paper. No. 1590. Retrieved from:

http://ftp.iza.org/dp1590.pdf

Miloslavich-Vera, Carmen. (1999a) Breast screening pilot program for Hispanic women in Toronto and follow-up of women who were screened at OBSP Centres. Hispanic Development Council, (Conference Report). Retrieved from: http://duberlisramos.tripod.com/PDFs_Research/breast-cancer-report.pdf

Miloslavich-Vera, Carmen. (1999b). Building sustainable services and strengthening the Hispanic community beyond the year 2000. Hispanic Development Council, (Conference Report).

Mintz, E, David C and O Croci. (2009). Politics, power and the common good: An introduction to political science. Toronto: Pearson.

Mishra, P. (2007). Emigration and wages in source countries: Evidence from Mexico. Journal of Development Economics, 82 (1) 180-199.

Mitrovic, L. (2005). Bourdieu's criticism of the neoliberal philosophy of development: The myth of mondialization and the new Europe. Philosophy, Sociology, and Psychology, 4 (1) $37-49$

Money, J. (1997). No vacancy: The political geography of immigration control in advanced industrial countries. International Organization, 51 (4) 685-720.

Morales, Laura and Giugni, Marco. Ed. (2011). Social capital, political participation and migration in Europe: Migration, minorities and citizenship. Basingstoke: Palgrave. 
Moran, M., Rein, M. and Goodin, R. E. (2006). The Oxford handbook of public policy. Oxford: Oxford University Press.

Moreno-Brid, Juan Carlos, and Napoles, Pablo-Ruiz, and Rivas Valdivia. (2005). NAFTA and the Mexican economy: A look back on a ten-year relationship. Official Report for the United Nations. Retrieved from: http://networkideas.org/featart/jul2005/NAFTA_Mexican_Economy.pdf

Mouffe, Chantal. (2009). Democracy in a multipolar world. Millennium, 37 (3) 549-561.

Mueller, Richard. (2005) Mexican immigrants and temporary residents in Canada: Current knowledge and future research. Migraciones Internacionales, 3 (1) 32-56.

Muñoz, A. A. (2005). The emergence and development of the politics of recognition of cultural diversity and Indigenous peoples' rights in Mexico: Chiapas and Oaxaca in comparative perspective. Journal of Latin American Studies, 37 (03) 585-610.

Muñoz, A. A. (2009). Transnational and domestic processes in the definition of human rights policies in Mexico. Human Rights Quarterly, 31 (1) 35-58.

Murillo, Enrique G., Jr. (2004). Mojado: Crossing along neoliberal borderlands. In Postcritical Ethnography: An Introduction, edited by G. W. Noblit, S. Y. Flores, and Enrique G. Murillo, Jr., 155-179. Cresskill: Hampton, 2004.

Myers, N. (2002). Environmental refugees: a growing phenomenon of the 21 st century. Philosophical Transactions of the Royal Society B: Biological Sciences, 357 (1420) 609613.

Noblit, G. W., Flores, S. Y., and Murillo, E. G. (2004). Postcritical ethnography: An introduction. Cress, NJ: Hampton Press.

Nussbaum, M. (1997). Kant and cosmopolitanism. In Essays in Perpetual Peace: Kant's Cosmopolitan Ideal, Bohman, J, and M. Lutz-Bachmann (Edit) Cambridge, Massachusetts: MIT Press.

Nussbaum, M. C. (2011). Creating Capabilities: The Human Development Approach. Cambridge, MA: Belknap Press of Harvard University Press.

Oberman, K. (2015). Poverty and immigration policy. The American Political Science Review, 109 (2) 239-251.

OECD (2009), OECD Reviews of Innovation Policy: Mexico 2009. OECD Publishing, Paris.

Ohmae, K. 1990. The Borderless World. London: Collins. 
Orsini, M. and Smith, M. (2007). Critical policy studies. In M. Orsini and M. Smith (Eds). Critical policy studies. Vancouver, BC: UBC Press.

Ortega y Gasset, J. (1914/2015). Meditaciones del Quijote y otros ensayos. Madrid: Alianza Editorial SA.

Ortega y Gasset, J. (1930/2015). La Rebelión de las masas y otros ensayos. Madrid: Alianza Editorial SA.

Ortega y Gasset, J. (1938/2015). El tema de nuestro tiempo ( $2^{\text {nd }}$ printing). (Manuel Granell, Intro.). Madrid: Espasa.

Ortega y Gasset, J. (1941/2008). Historia como sistema y otros ensayos de filosofia. $\left(5^{\text {th }}\right.$ printing). Madrid: Alianza Editorial SA.

Ortega y Gasset, J. (1957/2013). El hombre y la gente $\left(10^{\text {th }}\right.$ printing). Madrid: Alianza Editorial SA.

Ortega y Gasset, J. (1964/2015). España invertebrada. Bosquejo de algunos Pensamientos Históricos ( $31^{\text {st }}$ ed., $4^{\text {th }}$ printing). (Federico Trillo-Figueroa, Intro.) Madrid: Espasa.

Ortega y Gasset, J. (2015). Misión de la universidad ( $2^{\text {nd }}$ printing). (Santiago Fortuño Llorens, Intro.). Madrid: Catedra.

Parker, David S. and Walker, Louise Editors. (2013) Latin America's middle class: unsettled debates and new histories. Plymouth, UK: Lexington Books.

Parker, David. (1998). The idea of the middle class: White-collar workers and Peruvian society, 1900-1950. Pennsylvania: Pennsylvania State University Press.

Parks, David. (2011). Beyond trade: Sub-national diplomacy between Canada and Mexico. Canada-Mexico Initiative, Policy Brief March 2011.

Pecoud, Antoine and Paul de Cuchteneire (edt). (2007). Migration without borders: essays on the free movement of people. New York: Berghahn Books.

Perales, H. R., Benz, B. F., and Brush, S. B. (2005). Maize diversity and ethnolinguistic diversity in Chiapas, Mexico. Proceedings of the National Academy of Sciences of the United States of America, 102 (3) 949-954.

Price, R. (2003). Transnational civil society and advocacy in world politics. World Politics, 55 (04) 579-606.

Quayson, Ato. (2007). Area studies, diaspora studies, and critical pedagogies. Comparative Studies of South Asia, Africa and the Middle East, 27 (3) 580-590 
Ray, B. N. (2007). Citizenship in a Globalizing World. New Delhi: Kaveri Books.

Reitz, Jeffrey. (2005). Tapping Immigrants' Skills: New Directions for Immigration Policy in Knowledge Economy. Institute for Research in Public Policy, 11 (1) 1-14.

Ribeiro, G. L., and Dwyer, T. (2015). Social, political and cultural challenges of the BRICS. Cape Town: Langaa RPCIG.

Rivera-Batiz, F. L. (1999). Undocumented workers in the labor market: An analysis of the earnings of legal and illegal Mexican immigrants in the United States. Journal of Population Economics, 12 (1) 91-116.

Robinson, M., and Friedman, S. (2007). Civil society, democratization, and foreign aid: Civic engagement and public policy in South Africa and Uganda. Democratization, 14 (4) 643-668.

Robinson, W. I. (1998). Beyond Nation-State Paradigms: Globalization, sociology, and the challenge of transnational studies. Sociological Forum, 13 (4): $561-594$

Robinson, W.I. 2004. A theory of global capitalism: Production, class, and state in a transnational world. Baltimore: Johns Hopkins University Press.

Robinson, W.I. 2012. Global capitalism theory and the emergence of transnational elites, Critical Sociology, 38 (3) 349-363.

Robinson. W.I. (2015). The transnational state and the BRICS: A global capitalism perspective. Third World Quarterly, 36, (1) 1-21.

Rogers, Gayle. (2012). Modernism and the New Spain: Britain, cosmopolitan Europe and literary history. Oxford: Oxford University Press.

Root, J., Gates-Gasse, E., Shields, J. and Bauder, H. (2014). Discounting Immigrant Families: Neoliberalism and the Framing of Canadian Immigration Policy Change. RCIS Working Paper 1014/7.

Rosales, F. A. (1996). Chicano!: The history of the Mexican American civil rights movement. Houston, Texas: Arte Público Press.

Rose, Richard. (1993) Lesson drawing in public policy: A guide to learning across time and space. New Jersey: Chatham House.

Rosenblum, M. R. (2004). The transnational politics of US immigration policy. San Diego, California: Center for Comparative Immigration Studies-University of California Press. 
Rubin and Rubin (2012). Qualitative interviewing: The art of bearing data. ( ${ }^{\text {rd }}$ Edition). Los Angeles, California: Sage.

Sales, R. (2009). Understanding immigration and refugee policy: contradictions and continuities. Bristol: Policy Press.

Salter, Mark (2011). Enhancing the movement of people between Canada and Mexico: Policy Brief March 2011. Canadian Foundation for the Americas. Retrieved from: http://focal.ca/images/stories/pdfs/CMI_Salter_Enhancing_the_Movement_of_People_be tween Canada and Mexico March 2011.pdf

Sánchez, George. (1993). Becoming Mexican American: Ethnicity, culture, and identity in Chicano Los Angeles, 1900-1945. New York: Oxford University Press.

Sassen, S (1996). Losing Control? Sovereignty in an age of globalization. New York: Columbia University Press.

Sassen, S. (1998). The de facto transnationalizing of immigration policy. In Jopkee, Christian. Et. Challenge to the nation-state: Immigration in Western Europe and the United States. New York: Oxford University Press.

Sistema Nacional de Seguridad Publica. (2012). Cifras sobre secuestros. Retrieved from: http://editor.pbsiar.com/upload/PDF/cifras_secuestros.pdf.

Shachar, Ayelet. (2007). The worth of citizenship in an unequal world. Theoretical Inquiries in Law, 8 (2) 367-388.

Shollte, J.A. (2000). Globalization: A critical introduction. London: Mcmillan.

Smith, M. P. (2003). Transnationalism, the state, and the extraterritorial citizen. Politics \& Society, 31 (4) 467-502.

Smith, M. P., and Bakker, M. (2005). The transnational politics of the tomato king: meaning and impact. Global Networks, 5 (2) 129-146.

Statistics Canada (2011). National Household Survey (NHS) Data Tables: Table Number 99-010-X20126 Retrieved from: http://www12.statcan.gc.ca/nhs-enm/2011/dp-pd/dt$\mathrm{td} / \mathrm{Rp}-$ eng.cfm? $\mathrm{LANG}=\mathrm{E} \& A P A T H=3 \& D E T A I L=0 \& D I M=0 \& F L=A \& F R E E=0 \& G C=0 \& \mathrm{GID}=$ $0 \& \mathrm{GK}=0 \& \mathrm{GRP}=0 \& \mathrm{PID}=105411 \& \mathrm{PRID}=0 \& \mathrm{PTYPE}=105277 \& \mathrm{~S}=0 \& \mathrm{SHOWALL}=\mathrm{Yes}$ $\& \mathrm{SUB}=0 \&$ Temporal $=2013 \& \mathrm{THEME}=95 \& \mathrm{VID}=0 \& \mathrm{VNAMEE}=\& \mathrm{VNAMEF}=$

Steger, M. (2003). Globalization: A very short introduction. New York: Oxford University Press. 
Stone, D. (2008). Global public policy, transnational policy communities, and their networks. Policy studies journal, 36 (1) 19-38.

Strange, S. (1996). The retreat of the state: The diffusion of power in the world economy. New York: Cambridge University Press

Striffler, Steve. (2007) Neither here nor there: Mexican immigrant workers and the search for home. American Ethnologist, 34 (4) 674-688

Sullivan, S., Spicer, A., and Böhm, S. (2011). Becoming global (un) civil society: counter-hegemonic struggle and the Indymedia network. Globalization, 8 (5) 703-717.

Sutherland, Claire and Barabantseva, Elena (2011). Diaspora and citizenship. Abingdon, Oxon: Rutledge.

Taylor, C. (2007). The malaise of modernity. Toronto, Ont.: House of Anansi Press Ltd.

Taylor, C., and Gutmann. (1994). Multiculturalism: Examining the politics of recognition. Princeton, N.J: Princeton University Press.

Thomas, J. (1993). Doing ethnography. Thousand Oaks, CA: Sage.

Trepanier, L and Khalil M. Habib (Edit) (2011). Cosmopolitanism in the age of globalization: Citizens without states. Lexington, KY: The University Press of Kentucky.

Torres, C. A., and Schugurensky, D. (2002). The political economy of higher education in the era of neoliberal globalization: Latin America in comparative perspective. Higher Education. 43 (4) 429-455.

Torres, V., and Baxter Magolda, M. B. (2004). Reconstructing Latino identity: The influence of cognitive development on the ethnic identity process of Latino students. Journal of College Student Development. 45 (3) 333-347.

Tung, R. L. (2008). Brain circulation, diaspora, and international competitiveness. European Management Journal. 26 (5) 298-304

Ustubici, A. and Irdam, D. (2012). The impact of remittances on human development: Quantitative analysis and policy implications. Economics \& Sociology, 5 (1) 74-95.

Vallejo, J. (2012). Barrios to burbs: The making of the Mexican American middle class. Stanford, California: Stanford University Press.

Vallejo, J. (2015). How class background affects Mexican Americans' experiences of subtle racism in the white collar workplace. Latino Studies, 13 (1) 69-87 
Van Herk, K. A., Smith, D., and Andrew, C. (2011). Identity matters: Aboriginal mothers' experiences of accessing health care. Contemporary Nurse, 37 (1), 57-68.

Vasconcelos, J., and In Fernández, M. G. G. (1942). Vasconcelos. México DF: Ediciones de la Secretaría de educación pública.

Velasco Ortiz, Laura. (2005). Mixtec transnational identity. Tucson: University of Arizona Press.

Veronis, Luisa. (2006). The Canadian Hispanic day parade, or how Latin American immigrants practice (sub)urban citizenship in Toronto. Environment and Planning, 38 (9) $1653-1671$.

Veronis, Luisa. (2007). Strategic spatial essentialism: Latin Americans' real and imagined geographies of belonging in Toronto. Cultural Geography, 8 (3) 455-473.

Veronis, Luisa. (2010). Immigrant participation in the transnational era: Latin Americans' experiences with collective organizing in Toronto. Journal of International Migration and Integration, 11 (2) 173-192.

Vertovec, Steven. (1999). Conceiving and researching transnationalism. Ethnic \& Racial Studies. 22 (2) 447-462.

Vertovec, S and R, Cohen (2002). Theory, context, and practice. Oxford: Oxford University Press.

Vertovec, Steven. (2006). Is circular migration the way forward in global policy? Around the Globe, 3 (2) 38-44.

Vertovec, Steven (2009). Transnationalism. New York: Routledge.

Villegas, P.E. (2014). I can't even buy a bed because I don't know if I'll have to leave tomorrow: Temporal orientations among Mexican precarious status migrants in Toronto. Citizenship Studies. 18 (3-4). 277-291.

Walker, Louise. (2013). Waking from the dream: Mexico's middle classes after 1968. Stanford, Calif.: Stanford University Press.

Warren, K. B. (1998). Indigenous movements and their critics: Pan-Maya activism in Guatemala. New Jersey: Princeton University Press.

Watt, P, and Zepeda, M. R. (2012). Drug war Mexico: Politics, neoliberalism and violence in the new narcoeconomy. London: Zed Books

Wayman F and P. Diehl (1994). Reconstructing realpolitik. Ann Arbor: University of Michigan Press 
Whittaker, Elvis. (1988). The Mexican presence in Canada: Uncertainty and nostalgia Journal of Ethnic Studies, 16 (2) 29-46.

Woods, N. (2010). Global governance after the financial crisis: A new multilateralism or the last gasp of the great powers?. Global Policy, 1 (1) 51-63.

Wright, Mellisa. (2004) From protests to politics: Sex, work, women's worth, and Ciudad Juarez modernity. Annals of the Association of American Geographers, 94 (2) 369-386.

Yang, D. (2003). Financing constraints, economic shocks, and international labor migration: Understanding the departure and return of Philippine overseas workers. Harvard University, dissertation chapter.

Yeoh, B. S., and Willis, K. (2005). Singaporeans in China: transnational women elites and the negotiation of gendered identities. Geoforum. 36 (2) 211-222.

Yunez-Naude, Antonio. (2002). Lessons from NAFTA: The case of Mexico's agricultural sector final report to the world bank. Unpublished Manuscript.

Zabludovsky, Jaime and Barquera, Odracir. (2011). Mexico-Canada trade relations. Canada Mexico Initiative, Policy Brief April 2011.

Zhu, Yapeng. (2012). Policy entrepreneur, civic engagement and local policy innovation in China: Housing monetarisation reform in Guizhou province. Australian Journal of Public Administration. 71 (2) 191-200.

Willis, P. (2000). The ethnographic imagination. Cambridge, MA: Polity. 
